\title{
EFEITOS DA PROPORÇÃO GRAMÍNEA-LEGUMINOSA E DENSIDADE DE PLANTAS NO ESTABELECIMENTO DE PASTOS MISTOS EM SOLOS DE CERRADO
}

\author{
ADEMIR FLORIO
}

Orientador: HERBERT BARBOSA DE MATTOS

\begin{abstract}
Dissertação apresentada à Escola Superior de Agricultura "Luiz de Queiroz", da Universidade de São Paulo, para obtenção do Título de Mestre em Agronomia. Área de Concentração: Nutrição Animal e Pastagens.
\end{abstract}

P I R A E E E

Estado de São Paulo - Brasil

Setembro, 1983 
Aos meus pais,

Angelina e Antonio, com gratidão e reconhecimento.

A Victoria e Amauri Filho, meus sobrinhos, ofe reço.

A Edna, pelo carinho e incentivo, dedico. 


\section{A G R A D E C I M E N T O S}

A Escola Superior de Agricultura "Luiz de Queiroz", em es pecial ao Departamento de Zootecnia, pela oportunidade de realização do Curso.

Ao Dr. Herbert Barbosa de Mattos, pela orientação competen te e atenção dispensadas no decorrer deste trabalho.

Ao Dr. Irineu Umberto Packer, pelas sugestões oferecidas na anālise estatística e interpretação dos resultados.

Ao Dr. Ricardo Pereira Lima Carvalho, pelas facilidades concedidas, estímulo e amizade.

Ao Eng: Florestal Walter João Diehl, pela elaboração do programa e computação dos dados.

Ao PICD/CAPES/UNESP, pela bolsa de estudos concedida.

Aos funcionārios da Fazenda Experimental da UNESP, "Campus" de Ilha Solteira, que participaram da implantação, cole ta de dados e anālises de laboratório, na pessoa do Sr. Adauto José da Silva.

Aos Eng ${ }^{\circ}$ Agr ${ }^{\circ}$ s Antonio J.B.P. Braz, Carlos Silva Martins, Marco Eustáquio de Sá e Salatier Buzetti e ao Médico Ve terinārio José Luiz Tucci Turco, pelo convívio e amiza de. 
Ao Dr. Zilmar Z. Marcos, pela elaboração do Summary.

A Maria Izaltina Ferreira Alves, pelo trabalho de datilo grafia.

A todos que, direta ou indiretamente, contribuiram para a realização do presente trabalho. 


\section{INDI CE}

Pảgina

RESUMO

$x \mathrm{xi} v$

SUMMARY

xxvi i

1. INTRODUÇAOO $\ldots \ldots \ldots \ldots \ldots \ldots \ldots \ldots \ldots \ldots \ldots \ldots \ldots$

2. REVISÃO BIBLIOGRAFICA $\ldots \ldots \ldots \ldots \ldots \ldots \ldots \ldots$

2.1. Taxa de Semeadura para Espécies For

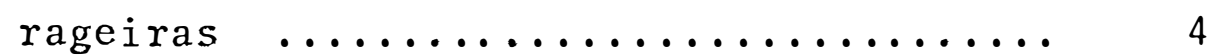

2.2. Espécies de Interesse no Cerrado ....... 6 2.2.1. Viabilidade de consorciação de pastagens no cerrado $\ldots \ldots \ldots$. 7

2.3. Capim Brachiaria ................ 7

2.4. Capim Setāria ...................... 13

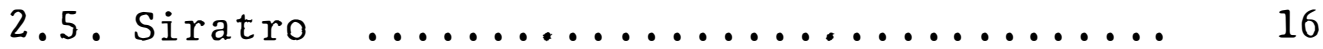

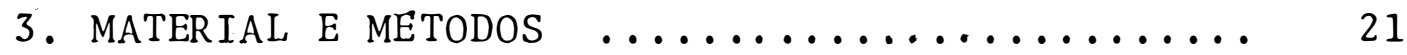

3.1. Local do Ensaio ................. 21

3.2. Característica da Região ............ 21

3.3. Desmatamento e Preparo do Solo ........ 22

3.4. Calagem e Adubação ................. 23

3.5. De1ineamento Experimental .......... 24

3.5.1. Tratamentos $\ldots \ldots \ldots \ldots \ldots \ldots . \ldots . \ldots 25$

3.6. Características das Sementes ......... 26

3.7. Consorciações Estabelecidas .......... 28

3.8. Desbaste e Rebaixamento ............. 28 
3.9. Altura e Intervalo de Corte ........ 29

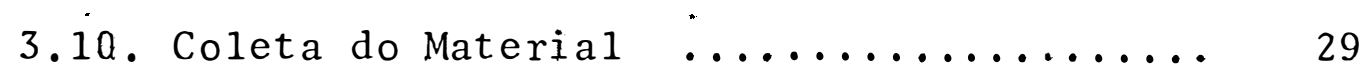

3.11. Avaliação dos Resultados .......... 30

3.11.1. Porcentagem média anual de matêria seca $\ldots \ldots \ldots \ldots \ldots \ldots . \ldots$

3.11.2. Produção anual de matéria se ca $\ldots \ldots \ldots \ldots \ldots \ldots \ldots \ldots \ldots \ldots \ldots \ldots \ldots$

3.11.3. Teor mêdio anual de proteí na bruta $\ldots \ldots \ldots \ldots \ldots \ldots \ldots \ldots \ldots \ldots$

3.11.4. Produção anual de proteína bruta $\ldots \ldots \ldots \ldots \ldots \ldots \ldots \ldots \ldots \ldots$

3.11.5. Número de leguminosas $/ \mathrm{m}^{2}$ ao final do ensaio .......... 31

3.12. Anâlise Estatística $\ldots \ldots \ldots \ldots \ldots \ldots \ldots . \ldots \ldots$

4. RESUltados E DisCUSSAO $\ldots \ldots \ldots \ldots \ldots \ldots \ldots . . \ldots \ldots$

4.1. Consorciação Braquiaria-Siratro ....... 34

4.1.1. Porcentagem de matéria seca ..... 34

4.1.2. Produção anual de matéria se ca $\ldots \ldots \ldots \ldots \ldots \ldots \ldots \ldots \ldots \ldots \ldots \ldots \ldots \ldots \ldots$

4.1.3. Teor de proteína bruta ......... 58

4.1.4. Produção anual de proteínabru ta $\ldots \ldots \ldots \ldots \ldots \ldots \ldots \ldots \ldots \ldots \ldots \ldots \ldots$

4.1.5. Número de plantas de legum nosas ao final do experimento 
Pägina

na consorciação Braquiaria-

Siratro $\ldots \ldots \ldots \ldots \ldots \ldots \ldots \ldots, 81$

4.2. Consorciação Setāria-Siratro ......... 88

4.2.1. Porcentagem de matéria seca $\ldots \ldots 88$

4.2.2. Produção anual de matêria se

ca $\ldots \ldots \ldots \ldots \ldots \ldots \ldots \ldots \ldots \ldots \ldots$

4.2.3. Teor de Proteína Bruta ........ 112

4.2.4. Produção anual de proteína

bruta .................... 115

4.2.5. Número de plantas no final do

experimento $\ldots \ldots \ldots \ldots \ldots \ldots \ldots$

5. CONCLUSOES $\ldots \ldots \ldots \ldots \ldots \ldots \ldots \ldots \ldots \ldots \ldots . \ldots \ldots$

6. BILLIOGRAFIA CITADA $\ldots \ldots \ldots \ldots \ldots \ldots \ldots \ldots$ 


\section{LISTA DE TABELAS}

TABELA

Pägina

1

Principais características quínicas do solo

no local do experimento $\ldots \ldots \ldots \ldots \ldots \ldots$

2

Precipitação pluviométrica mensal (mm) e temperatura média mensais $\left({ }^{\circ} \mathrm{C}\right)$ da região de Selvíria, MS, no período de outubro/80 a fe vereiro/82 $\ldots \ldots \ldots \ldots \ldots \ldots \ldots \ldots \ldots \ldots$

3

Características das sementes das espécies forrageiras utilizadas no experimento ......

Relação entre densidades e taxas de semeadu ra das espécies forrageiras usadas $\ldots . \ldots \ldots$

5 Esquema de anâlise de variância utilizado na avaliação dos resultados $\ldots \ldots \ldots \ldots \ldots \ldots 32$

6 Porcentagem de matéria seca da componente na consorciação braquiaria-siratro. (Média de 4 repetições)

7 Porcentagem de matéria seca da componente 
leguminosa na consorciação braquiaria- sira

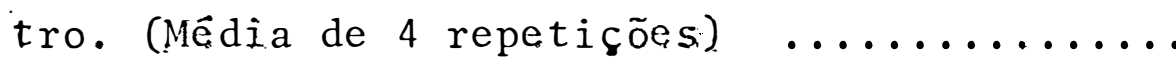

8 Anālise de variância, desdobramento da inte ração $P$ x D, decomposição das $S Q$ dos efe $\underline{i}$ tos e coeficientes de determinação $\left(R^{2}\right)$ pa ra a produção de matéria seca da componente graminea ( $t / h a / a n o)$ na consorciação braquia ria-siratro $\ldots \ldots \ldots \ldots \ldots \ldots \ldots \ldots \ldots \ldots \ldots \ldots \ldots \ldots \ldots$

Dỉferenças mínimas significativas para a comparação de médias, coeficientes de varia ção e equações de regressão usadas na anāli se de variância para a produção de matéria seca da componente gramínea ( $t / h a / a n o) ~ n a$ consorciação braquiaria-siratro (média de 4 repetições)

10 Anālise de variância, desdobramento da inte ração $P x D$, decomposição da $S Q$ dos efeitos coeficientes de determinação $\left(R^{2}\right)$ para a produção de matéria seca da componente legü minosa (t/ha/ano) na consorciação braquia ria-siratro $\ldots \ldots \ldots \ldots \ldots \ldots \ldots \ldots \ldots \ldots \ldots \ldots \ldots \ldots \ldots$ 
11 Diferenças mínimas significativas para a comparação de mẻdias; coeficiente de varia ção e equações de regressão usadas na anảli se de variância da produção de matéria seca da componente leguminosa (t/ha/ano) na con sorciação braquiaria-siratro (média de 4 re petições) $\quad \ldots \ldots \ldots \ldots \ldots \ldots \ldots \ldots \ldots \ldots \ldots \ldots \ldots \ldots \ldots \ldots \ldots$

12 Anālise de variância, desdobramento da inte ração $P x D$, decomposição das $S Q$ dos efei tós, coeficientes de determinação $\left(R^{2}\right)$ para a produção conjunta de matéria seca (t/ha/ ano) na consorciação braquiaria-siratro

Diferenças mínímas significativas para a comparação de médias, coeficientes de varia ção e equações de regressão usadas na anảli se de variância para a produção conjunta de matéria seca ( $t / h a / a n o)$ na consorciação bra quiaria-siratro (média de 4 repetições) .... 57

14 Teor de proteína da componente graminea na consorciação braquiaria-siratro. (Média de 4 repetições) 
Teor de proteína bruta da componente legumi nosa na consorciação braquiaria-siratro. (Mê

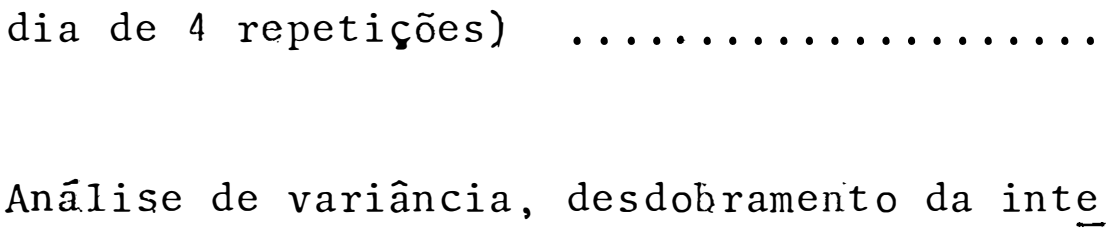
ração $P \times D$, decomposição das $S Q$ dos efei tos, coeficientes de determinação $\left(R^{2}\right)$ para a produção de proteína bruta da componente gramínea (t/ha/ano) na consorciação brachia ria-siratro

Diferenças mínimas significativas para a comparação de médias, coeficientes de varia ção e equações de regressão usadas na anāli se de variância para a produção de proteína bruta da componente gramínea ( $t / h a / a n o) ~ n a$ consorciação brachiaria-siratro (média de 4 repetições) $\quad \ldots \ldots \ldots \ldots \ldots \ldots \ldots \ldots \ldots \ldots$

Análise de variância, desdobramento da inte ração $P \times D$, decomposição da $S Q$ dos efeitos, coeficientes de determinação $\left(R^{2}\right)$ para a produção de proteína biruta da componente le guminosa (t/ha/ano) na consorciação brachia 
TABELA comparação de médias, coeficientes de varia ção e equações de regressão usadas na anảli se de variância, para a produção de proteí na bruta na componente leguminosa ( $t / h a /$ ano) na consorciação brachiaria-siratro (mé dia de 4 repetições) $\ldots \ldots \ldots \ldots \ldots \ldots \ldots \ldots . \ldots \ldots$

20 Anảlise de variância, desdobramento da inte ração $P \times D$, decomposição das $S Q$ dos efei tos, coeficientes de determinação $\left(R^{2}\right)$ para a produção conjunta de proteína bruta na consorciação brachiaria-siratro

21 Diferenças mínimas significativas para a comparação de médias, coeficientes de varia ção e equações de regressão usadas na análi se de variância para a produção conjunta de proteína bruta ( $t / h a / a n o)$ na consorciação brachiaria-siratro (média de 4 repetições) ... 80

22 Análise de variância, desdobramento da inte 
ração $P$ X D, decomposição da SQ dos efeitos, coeficientes de determinação $\left(R^{2}\right)$ para o nú mero de plantas da componente leguminosa ao final do ensaio na consorciação brachiaria-

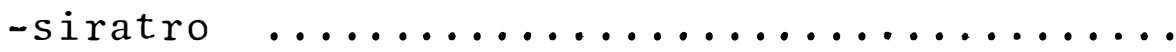

23 Diferenças mínimas significativas para a comparação de médias, coeficientes de varia ção e equações de regressão usadas na anāli se de variância para o nümero de plantas da componente leguminosa na consorciação bra chiaria-siratro (média de 4 repetições) ..... 86

24 Porcentagem de matéria seca da componente gramínea na consorciação setária-siratro (mé

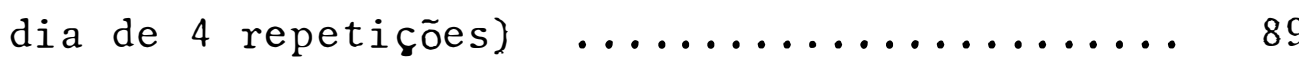

25 Porcentagem de matéria seca da componente leguminosa na consorciação setária- siratro (média de 4 repetições)

26 Anālise de variância, desdobramento da inte ração $P \times D$, decomposição da $S Q$ dos efeitos e coeficientes de determinação $\left(R^{2}\right)$ para a 
produção de matéria seca da componente gra mínea (t/ha/ano) na consorciação setária-si

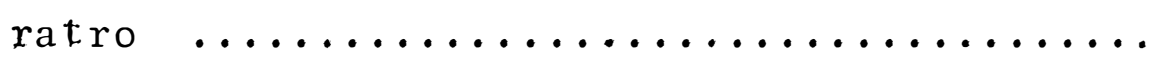

Diferenças mínimas significativas para a comparação de médias, coeficientes de varia ção e equações de regressão usadas na análí se de variância para a produção de matéria seca da componente gramínea (t/ha/ano) na consorciação setária-siratro (média de 4 re

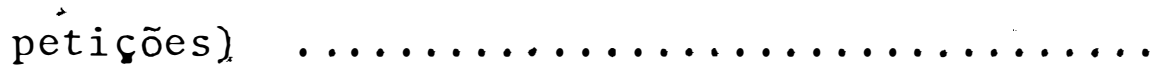

28 Anâlise de variância, desdobramento da inte ração $P \times D$, decomposição da $S Q$ dos efeitos e coeficientes de determinação $\left(R^{2}\right)$ para a produção de matéria seca da componente legu minosa (t/ha/ano) na consorciação setáriasiratro comparação de médias, coeficientes de varia ção e equações de regressão usadas na análí se de variância para a produção de matéria seca da componente leguminosa ( $t / h a / a n o) ~ n a$ 
consorciação setäria-siratro. (Média de 4 re

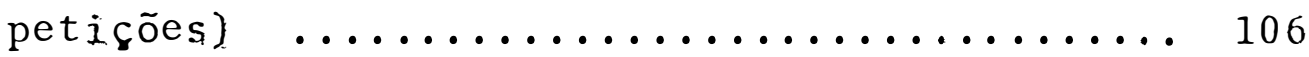

30 Anālise de variância, desdobramento da inte ração $P \times D$, decomposição da $S Q$ dos efeitos e coeficientes de determinação $\left(R^{2}\right)$ para a produção conjunta de matéria seca (t/ha/ ano) na consorciação setária-siratro ....... 107

31 Diferenças mínimas significativas para a comparação de médias, coeficientes de varia ção e equações de regressão usadas na análi se de variância para a produção conjunta de matéria seca (t/ha/ano) da consorciacão se tāria-siratro. (Média de 4 repetições) ..... 111

32 Teor de proteína bruta da componente gramí nea na consorciação setäria-siratro (média de 4 repeticões) $\ldots \ldots \ldots \ldots \ldots . \ldots \ldots \ldots$

33 Teor de proteina bruta da componente legumi nosa na consorciação setária-siratro (média

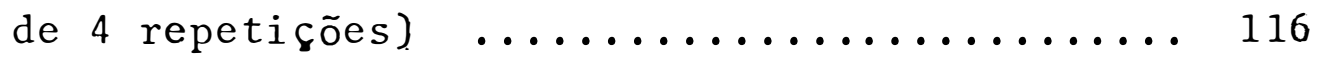


34 Anảlise de variância, desdobramento da inte ração $\mathrm{P} x \mathrm{D}$, decomposição da SQ dos efeitos e coeficientes de determinação $\left(R^{2}\right)$ para a produção de proteína bruta da componente gramínea (t/ha/ano) na consorciação setária

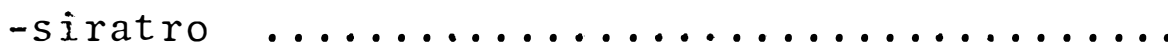

35 Diférenças mínimas significativas para a comparação de médias, coefiçientes de varia ção e equações de regressão usadas na anảli se para a produção de proteína bruta da componente gramínea (t/ha/ano) na consorcia ção setāria-siratro (mẻdia de 4 repetições) ..

36 Anālise de variância, desdobramento da inte ração $P$ X D, decomposição da SQ dos efeitos e coeficientes de determinação $\left(R^{2}\right)$ para a produção de proteína bruta da componente le guminosa (t/ha/ano) na consorciação setária -siratro comparação de médias, coeficientes de varia ção e equações de regressão usadas na análi 
se de variância para a produção de proteína bruta da componente leguminosa ( $t / h a / a n o)$ na consorciação setäria-siratro (média de 4 re petições)

Análise de variância, desdobramento da inte ração $P$ x D, decomposição da SQ dos efeitos e coeficientes de determinação $\left(R^{2}\right)$ para a produção conjunta de proteína bruta (t/ha/ ano) na consorciação setária-siratro ......

Diferenças mínimas significativas para a comparação de mẻdias, coeficientes de varia ção e equações de regressão usadas para a anālise de variância para a produção conjun

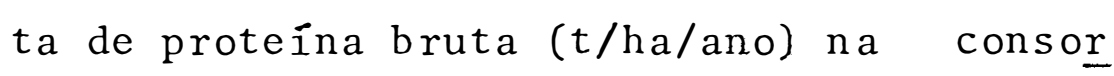
ciação setária-siratro (média de 4 repeti ções)

Anālise de variância, desdobramento da inte ração $P x D$, decomposição da $S Q$ dos efeitos e coeficientes de determinação $\left(R^{2}\right)$ para o número de plantas de leguminosa ao final do experimento na consorciação setāria-siratro 
xviii

TABELA

Página

41

Diferenças mínimas significativas para a comparação de mëdias, coeficiente de varia ção e equações de regressão usadas na análi se de variância para o nümero de plantas de leguminosa para a consorciação setária-sira tro (média de 4 repetições) ............. 142 
1 Variação na porcentagem média anual de maté ria seca da componente gramínea na consor ciação braquiaria-siratro. (Média de 7 cor

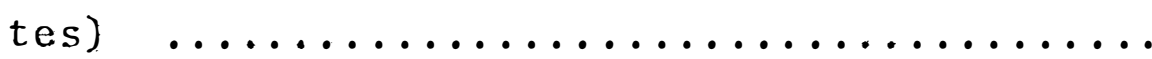

2 Variação na porcentagem média anual de matê ria seca da componente leguminosa na consor ciação braquiaria-siratro. (Média de 7 cor

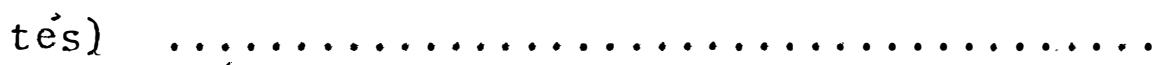

3 Efeito da densidade de plantas (a) e produ ção gramínea-leguminosa estabelecida (b) na produção de matéria seca da componente gra mínea ( $t / h a / a n o)$ na consorciação braquiaria -siratro $\ldots \ldots \ldots \ldots \ldots \ldots \ldots \ldots \ldots \ldots$

4 Efeito da densidade de plantas (a) e propor ção gramínea-leguminosa estabelecida (b) na produção de matéria seca da componente legu minosa ( $t / h a / a n o)$ na consorciação braquia ria-siratro $\ldots \ldots \ldots \ldots \ldots \ldots \ldots \ldots \ldots$ 
Efeito da densidade de plantas (a) e da pro porção gramínea-leguminosa estabelecida (b) na produção conjunta de matéria seca (t/ha /ano) na consorciação braquiaria-siratro .... 56

Variação no teor médio anual de proteína bruta da componente gramínea na consorcia ção braquiaria-siratro. (Média de 7 cortes) .. 60

7 Variação no teor médio anual de proteína bruta da componente leguminosa na consorcia ção braquiaria-siratro. (Média de 7 cortes) ..

8 Efeito da densidade de plantas (a) e da pro porção gramínea-leguminosa estabelecida (b) na produção de proteína bruta da componente gramínea (t/ha/ano) na consorciação braquia ria-siratro

9 Efeito da densidade de plantas (a) e da pro porção gramínea-leguminosa estabelecida (b) na produção de proteína bruta da componente leguminosa (t/ha/ano) na consorciação bra quiaria-siratro $\ldots \ldots \ldots \ldots \ldots \ldots \ldots \ldots \ldots \ldots \ldots \ldots \ldots$ 
FI GURA

Fifeito da densidade de plantas (a) e da pro porção gramínea-leguminosa estabelecida (b) na produção conjunta de proteína bruta (t/ ha/ano) na consorciação braquiaria-siratro ..

11 Efeito da densidade de plantas (a) e da pro proção gramínea-leguminosa estabelecida (b) no nümero de plantas de leguminosa ao final do experimento na consorciação braquiariasiratro

12 Variação na porcentagem média anual de maté ria seca da componente gramínea na consor ciação setária-siratro. (Média de 7 cor tès)

13 Variação na porcentagem média anual de maté ria seca da componente leguminosa na consor ciação setária-siratro. (Média de 6 cortes).. 92

14 Efeito da densidade de plantas (a) e da pro porção gramínea-leguminosa estabelecida (b) na produção de matéria seca da componente gramínea (t/ha/ano) na consorciação setāria

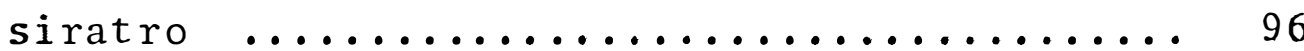


FIGURA

15 Efeito da densidade de plantas (a) e da pro porção gramínea-leguminosa estabelecida (b) na produção de matéria seca da componente leguminosa ( $t / h a / a n o)$ na consorciação setá ria-siratro

16 Efeito da densidade de plantas (a) e da pro porção gramínea-leguminosa estabelecida (b) na produção conjunta de matéria seca (t/ha /ano) na consorciação setária-siratro ...... 110

17 Variação no teor médio anual de proteína bruta da componente gramínea na consorcia ção setāria-siratro (média de 6 cortes) ..... 114

18 Variação no teor médio anual de proteína bruta da componente leguminosa na consorcia ção setária-siratro (média de 6 cortes) ..... 117

19 Efeito da densidade de plantas (a) e da pro porção gramínea-leguminosa estabelecida (b) na produção de proteína bruta da componente gramínea ( $t / h a / a n o)$ na consorciação setāria $-\operatorname{siratro} \ldots \ldots \ldots \ldots \ldots \ldots \ldots \ldots \ldots \ldots \ldots \ldots$ 
Efeito da densidade de plantas (a) e da pro dução gramínea-leguminosa estabelecida (b) na produção bruta da componente leguminosa (t/ha/ano) na consorciação setāria-siratro ... 127

21 Efeito da densidade de plantas (a) e da pro dução gramínea-leguminosa estabelecida (b) na produção conjunta de proteína bruta (t/ ha/ano) na consorciação setária-siratro ..... 134

22 Efeito da densidade de plantas (a) e da pro porção gramínea-leguminosa estabelecida (b) no número de plantas da leguminosa ao final do experimento na consorciação setāria-sí

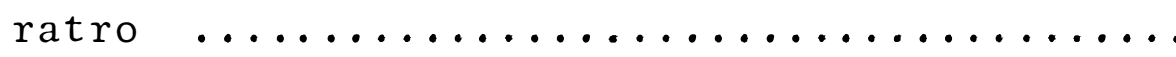


EFEITOS DA PROPORÇAO GRAMTNEA-LEgumJNOSA E DENSIDADE DE PLAN TAS NO ESTABELECIMENTO DE PASTOS MISTOS EM SOLOS SOB VEGETAÇAO

DE CERRADO

Candidato: Ademir Flório

Orientador: Herbert Barbosa de Mattos

R E S U M O

Densidades de 50,100 e $150 \mathrm{plantas} / \mathrm{m}^{2}$ e propor ções entre graminea e leguminosa de 100-0; 80-20; 60-40;40-60; 20-80; 0-100 foram estudadas para a formação de dois tipos de pastagens consorciadas: braquiaria-siratro (Brachiaria decum bens, stapf - Macroptilium atropurpureum cv. siratro DC URB) e setaria-siratro (Setaria anceps cv. Kazungula - Macroptilium atropurpureum cv. siratro DC URb), em solos sob vegetação de cerrado.

O experimento foi conduzido a campo, no Municí pio de Selvíria (MS), durante o período de dezembro/80 a feve reiro/82, em Latossol Vermelho Escuro Alico textura média. A calagem foi aplicada em setembro/80 e constou de 2,0 t/ha de 
calcário dolomítico, enquanto que a adubação básica constou de: $125 \mathrm{~kg} / \mathrm{ha}$ de $\mathrm{P}_{2} \mathrm{O}_{5} ; 0,2 \mathrm{~kg} / \mathrm{ha}$ de mo; $6,0 \mathrm{~kg} / \mathrm{ha}$ de $\mathrm{Zn}$ aplicada antes da semeadura e incorporada por gradagem; e 193,0 kg/ha de $\mathrm{K}_{2} \mathrm{O}$ colocados a lanço em cobertura apỏs o corte de rebaixamen to.

A semeadura foi realizada em dezembro/80 em $1 \underline{i}$ nhas alternadas de gramínea e leguminosa, com sementes sufi cientes para a germinação do número de plantas em estudo. 0 desbaste foi realizado quando as plantas atingiram $10 \mathrm{~cm}$ de a 1 tura.

o corte de rebaixamento foi efetuado aos 60 dias após a semeadura, na altura estipulada $(10 \mathrm{~cm})$; e o intervalo entre os cortes foi de 6 semanas no verão e 9 semanas no in verno. Em cada corte foram separadas as componentes gramínea e leguminosa, que em seguida foram secas, pesadas para a deter minação da produção de matéria seca e moídas em moinhos de 1a boratório tipo Willie com peneira de aço inox Mesh 20, sendo levada em seguida para laboratório, onde foram determinados os teores de proteína bruta.

Os resultados encontrados mostram que na consor ciação braquiária-siratro a produção de matéria seca aumenta com o aumento da densidade usada. A densidade 150 plantas $/ \mathrm{m}^{2}$ a presentou maior produção de proteína bruta conjunta, e a pro porção gramínea-leguminosa indicada foi entre 40 e $60 \%$ de legu minosa no número de plantas.

Para a consorciação setária-siratro, as maiores 
produções de matêria seca e proteína bruta conjunta foram ob tidas com a densidade 100 plantas $/ \mathrm{m}^{2}$ e a proporção indicada de leguminosa no número de plantas varia entre $4 G$ e $60 \%$. 
EFFECTS OF GRASS-LEGUME PROPORTION AND PLANTS DENSITIES ON ES TABLISHED OF MIXTURES PASTURES ON A "CERRADO" TYPE SOIL.

Candidate: Ademir Flório

Adviser: Herbert Barbosa de Mattos

Two kinds pastures combining grass and legume in various proportions were established on a "cerrado" type soil. The combined species utilized were braquiaria-siratro (Brachia ria decumbens stapf - Macroptilium atropurpureum cv. siratro DC URB) and setaria-siratro (Setaria anceps cv. Kazungula - ma croptilium atropurpureum cv. siratro DC URB), for each of the pasture and the proportion for each varied from 0 to $100 \%$ as follows: $100-0 ; 80-20 ; 60-40 ; 40-60 ; 20-80 ; 0-100$. Three plant densities were studied in each case: 50, 100 and 150 plantsper square meter.

This was a field experiment conducted in the Se1 viria municipality in the state of South Mato Grosso from De cember/80 to February/82, on a medium textured Dark-Red Lato 
sol. The experimental site was limed in September/80 with tons/ha of a dolomitic limestone. The plots received a uniform applications of $\mathrm{P}\left(1250 \mathrm{~kg} / \mathrm{ha} \mathrm{P}_{2} \mathrm{O}_{5}\right.$, Mo $(0,2 \mathrm{~kg} / \mathrm{ha}), \mathrm{Zn} \quad(6,0$ $\mathrm{kg} / \mathrm{ha}$ ) prior to sowing. The material was disked in. Potassium $\left(193^{\prime}, 0 \mathrm{~kg} / \mathrm{ha} \mathrm{K} \mathrm{K}_{2} \mathrm{O}\right)$ was bread east after the fish cut.

Sowing was carried out in December/80. The grass and legume were sown in alternate rows. Thinning was done 60 days after sowing at the height of $10 \mathrm{~cm}$. Subsequent cuttings were done at 6 weeks interval in the summer and 9 weeks inter val in the winter. After cutting the grass and legume material was sepparated, dried, weighed, ground and prepared for analy sis to determine raw protein content.

Results obtained indicated that in the brachia ria-siratro combination dry matter yield increases with number of plants per unit area. The highest total raw protein yield was obtained in the $150 \mathrm{plants} / \mathrm{m}^{2}$ treatment and at the propor tion of $40 \%$ to $60 \%$ of legume in the pasture.

In the setaria-siratro combination the highest yields of dry matter and raw protein were obtained for the den sity of $100 \mathrm{plants} / \mathrm{m}^{2}$ and the proportion of $40 \%$ to $60 \%$ of legu me in the pasture. 
1. INTRODUÇAOO

No Brasil, de um modo geral, as pastagens repre sentam a principal, senão a ünica fonte de alimentação dos bo vinos; e os baixos índices zootécnicos da pecuária nacional po dem ser atribuídos à escassa disponibilidade, bem como à baixa qualidade das mesmas, principalmente durante os períodos de seca. Em grande parte do país, a cria e recria de bovinos ain da é feita quase que exclusivamente à base de pastagens nati vas, cujas características são de baixa produtividade e quali dade (EMBRAPA, 1981a).

Essas äreas, em sua grande maioria, são consti tuídas de cerrado, palavra portuguesa que significa denso, es pesso, fechado, e que constitui um dos tipos de vegetação mais comum no Brasil, representando mais de $20 \%$ do território nacio nal, atingindo perto de um milhão e meio de quilômetros quadra dos. Estende-se da fronteira paraguaia ao Equador, e está pre sente na maioria dos Estados brasileiros, com pelo menos um tí po de cerrado, enquanto que os Estados de Minas Gerais, Mato 
Grosso, Mato Grosso do Sul e Goiās possuem praticamente todas as variações que compõem este tipo de vegetação (GOODLAND e FERRI, 1979).

Apesar de ser caracterizado por solos de baixa fertilidade, elevada acidez e baixa troca catiônica, existem diversas maneiras de utilização do cerrado para pastagem, sen do predominante aquela que o utiliza em seu estado natural. En tretanto, o mesmo tem se mostrado favorável ao desenvolvimento de pastagens cultivadas, e trabalhos neste sentido têm sido realizados procurando identificar espëcies mais produtivas e adaptáveis a essas condições.

0 baixo retorno no primeiro ano pode ser devido aos elevados gastos ocasionados pelo controle de plantas inva soras, replantios ou emprego de lotações inadequadas, atribuí dos à falta de conhecimentos básicos sobre técnicas de implan tação de pastagens cultivadas, uma vez que as exigências em temperatura e umidade do solo para germinação das sementes são variảveis com as espēcies forrageiras. Alêm disso, o tipo de preparo do solo, profundidade da semente e taxa de semeadura, são fatores de grande importância no estabelecimento de pasta gens cultivadas (EMBRAPA, 1981a).

A quantidade de sementes utilizadas por unidade de ārea, tem sido um dos fatores limitantes no estabelecimento de pastagens, uma vez que as sementes usadas pelos produtores apresentam "amplas taxas de semeadura", pois se baseiam na se mente comercial, sem levar em consideração o valor cultural da 
mesma. Sabendo-se que as densidades de plantas para se obter uma boa cobertura não é conhecida, faz-se necessārio que a pe quisa determine o número ideal de plantas $/ \mathrm{m}^{2}$, para se obter uma boa formação de pastagens, além de se estabelecer as quan tidades de sementes viáveis a serem semeadas para se obter es te nümero ideal de plantas (ZIMMER, 1981).

o presente trabalho tem por objetivos estabele cer a melhor densidade de plantas e a melhor proporção grami nea-leguminosa, entre duas espécies diferentes de gramíneas, consorciadas com uma leguminosa na formação de pastagens mis tas em solos de cerrado. 
2.1. Taxa de Semeadura para Espécies Forrageiras

$\mathrm{Na}$ formação de cultivares de forrageiras, a taxa de semeadura é variāvel com a espécie forrageira a ser introdu zida e com a qualidade da semente.

RIBEIRO (1979), em trabalho de revisão, encon trou que, para uma densidade de semeadura de 100 sementes por $\mathrm{m}^{2}$, seriam necessários: para a soja perene (Glycine wightii), de 8 a $10 \mathrm{~kg} / \mathrm{ha}$, e para a centrosema (Centrosema pubescens), de 28 a $35 \mathrm{~kg} / \mathrm{ha}$. Para a alfafa (Mendicago sativa) o mesmo au tor encontrou que, onde o solo foi preparado para receber as sementes, $15 \mathrm{~kg} / \mathrm{ha}$ correspondiam a uma densidade de 700 semen tes por $\mathrm{m}^{2}$, o que foi suficiente para garantir boa formação; e para crotalaria (Crotalaria juncea) as densidades variaram de 130 a 260 sementes $/ \mathrm{m}^{2}$, enquanto que para espécies de sementes menores, as densidades raramente estavam ab́aixo de 500 semen tes por $\mathrm{m}^{2}$. No caso de gramíneas, taxas de semeadura de $15 \mathrm{~kg} /$ 
/ha geralmente fornecem mais de 500 sementes $/ \mathrm{m}^{2}$.

Estudando o estabelecimento de capim Buffel cv. Biloela, CORBEA e MARTINES (1980) testaram taxas de semeadura de $2,4,6$ e $8 \mathrm{~kg} / \mathrm{ha}$; encontrando que o estabelecimento da pas tagem foi melhor para a taxa de semeadura mais alta; e que o uso de grade após a semeadura teve efeito positivo no estabele cimento.

Dois cultivares de Cenchrus ciliares foram tam bém testados em densidades de 1,8 e $44,5 \mathrm{plantas} / \mathrm{m}^{2}$, e os re sultados evidenciaram um melhor perfilhamento no primeiro ano na densidade mais alta, embora o completo estabelecimento do stand para a densidade mais baixa tenha se dado no ano seguin te ao da semeadura (RAI et alii, 1981).

WEYERSBERG (1982) testou densidades de 800 , $1.100,1.400$ e 1.700 sementes viāveis por $\mathrm{m}^{2}$, para dois culti vares de azevém, concluindo que o nümero de perfilhos/m² não sofreu influência do número de plantas, enquanto que a produ ção de matéria seca foi mais alta para as densidades de 1.100 e 1.400 sementes viāveis/m².

No Rio Grande do Sul, densidades de 500 sementes üteis $/ m^{2}$ são recomendadas para o azevém (LoZium muZtiflorum), entretanto, Poli e Carmona (1966) citados pela EMBRAPA (1981b), afirmaram que 300 sementes $/ \mathrm{m}^{2}$ proporcionaram boa formação e rendimentos de matéria seca superiores a densidades de 500 plan $\mathrm{tas} / \mathrm{m}^{2}$.

RICKERT e HUMPHREYS (1970), verificando os efe 
tos da variação de densidade de plantas em estilosantes (Stylo santhes humilis), estudaram densidades de 10-50-250-1.250 e $6.240 \mathrm{plantas} / \mathrm{m}^{2}$, e concluiram, com relação à produção de matê ria seca, que a taxa de crescimento aumentou o mäximo nas den sidades 250 e $1.250 \mathrm{plantas} / \mathrm{m}^{2}$ no período inicial de desenvol vimento; e que, com o tempo, esta taxa de crescimento diminuiu nas densidades mais altas. A respeito do número de plantas, es te diminuiu com o decorrer do experimento, sendo mais acentua da a redução nas densidades mais elevadas.

\subsection{Espécies de Interesse no Cerrado}

- Sobre as espécies encontradas no cerrado, FRANCo FILHO (1963) afirmou que estas não têm merecido a devida aten ção, e que o capim gordura (Melinis minutiflora Pal de Beauv) predomina em parte dos cerrados mineiros, onde forma pastagens espontâneas. MARCELINO SOBRINHO et alii (1977) citam os gêne ros Hyparrhenia, Melinis, Panicum e Brachiaria como mais fre quentes no cerrado goiano. GOODLAND (1979) selecionou comomais importantes os gêneros Chloris, Setaria e Melinis, frequentemente usados como pastagens nas regiões quentes.

Dentre as leguminosas, as espëcies pertencentes aos gêneros Centrosema, Macroptilium, Galactia e Stylosanthes, têm demonstrado grande potencial de adaptação ao solo e clima do Brasil Central, conforme relata a EMBRAPA (1981a).

No entanto, é necessário que espécies mais produ 
tivas e adaptâveis às condições de elevada acidez e baixa fẹ tilidade características dos cerrados brasileiros, sejam intro duzidas, e estudos realizados mostraram que as espécies do gê nero Brachiaria têm se apresentado com bom comportamento quan do introduzidas nestas condições (EMGOPA, 1977 e EMGOPA, 1979). LUCK (1979) afirmou que o gênero setaria também tem contribuído para aumentar-se as opcões para pastagens, pois as espécies deste gênero, quando submetidas a condições adver sas, têm se comportado satisfatoriamente.

2.2.1. Viabilidade de consorciação de pastagens no cer - rado

$\mathrm{Na}$ prática, a utilização de pastagens consorcia das leva a problemas sérios, ocasionados quase sempre por for mação e manejo deficientes, entretanto, o estabelecimento da associação gramínea-leguminosa é viāvel apesar da interação de fatores que sugerem a necessidade de novos estudos para as váa rias condições de solo, clima e vegetação onde se pretende in troduzir este tipo de pastagem (Normam, 1961; Lowe, 1972 cita dos por RIBEIRO, 1979).

\subsection{Capim Brachiaria}

LOCH (1977) afirma que as espécies do gênero Bra chiaria são bem adaptadas à utilização intensiva, podendo, a 
través do seu desenvolvimento inicial vigoroso de suas plantas, completar seu crescimento nos três primeiros meses após a se meadura .

o capim braquiaria (Brachiaria decumbens Stapf) é uma das espécies forrageiras de introdução recente mais dí fundidas no cerrado brasileiro e, apesar de sua capacidade de adaptação a solos de baixa fertilidade, sua produção de maté ria seca nestas condições é pequena (SERRÃO e SIMÃO NETO, 1971); entretanto, à medida que se aumenta o nível de fertilidade do solo, aumenta-se o nível de produção (BULLER et alii, 1972 ; WINTER et alii, 1977).

As produções de gramíneas associadas com legumi nosas foram estudadas por NG (1976), que encontrou, para a con sorciação Brachiaria decumbens Stapf - Stylosanthes guianen sis Aub1, produções de matéria seca de 16,0 tha/ano e de pro teína bruta de $1,11 \mathrm{t} / \mathrm{ha} / \mathrm{ano}$, sendo que os componentes gramí. nea-leguminosa contribuiram com respectivamente 10,39 e 4,61 t/ha/ano na matéria seca; o restante correspondendo às plantas invasoras e 0,532 e 0,579 t/ha/ano na proteína bruta. Para a consorciação Brachiaria decumbens Stapf - Centrosema pubescens Benth, as produções anuais foram de 14,41 e 0,944 t/ha/ano pa ra a matéria seca e proteína bruta, e a contribuição das compo nentes gramínea, leguminosa e plantas invasoras foram: 11,42, 2,35 e 0,64 t/ha/ano na produção de matéria seca e 0,521 e $0,423 \mathrm{t} / \mathrm{ha} /$ ano na produção de proteína bruta. O autor concluiu ainda haver pequena tendência de transferência de nitrogênio 
da leguminosa para a gramínea em associação.

Em termos de consorciação, o capim braquiaria (Brachiaria decumbens Stapf) tem apresentado bons resultados quando associado com leguminosas tropicais, notadamente com o siratro (Macroptilium atropurpureum Dc Urb) (FURTADO et alii, 1977; BLASCZYCK e REHFELD, 1973).

Para o capim braquiaria (Brachiaria decumbens) têm sido recomendadas taxas que variam de 2 a $5 \mathrm{~kg} / \mathrm{ha}$ ( $\mathrm{LOCH}$, 1977; VILELA, 1977; AGROCERES, 1977) ou então densidades em torno de 60 sementes viáveis $/ \mathrm{m}^{2}$, conforme citam VIEIRA (1974) e PEDREIRA (1977).

Em estudo sobre o crescimento de Brachiaria de cumbens, AKINOLA (1981), testando densidades de 44.500 e 89.000 plantas/ha, encontrou produções de matéria seca de 6,28 e 6,62 t/ha/ano por intervalos de corte de 6 e 8 semanas, respectiva mente, e concluiu que a idade da planta pouco afetou a produ ção de matéria seca no intervalo de 6 e 8 semanas. Para o efe to densidades não houve diferença significativa nas produções de matéria seca, que foram 6,28 t/ha/ano para a densidade de 44.500 plantas/ha e $6,75 \mathrm{t} / \mathrm{ha} /$ ano para a densidade de 89.000 plantas/ha. O autor associou ainda esta gramínea, embora em "densidades mais baixas", com oito leguminosas cujas taxas de semeadura variaram entre 5,0 e $7,5 \mathrm{~kg} / \mathrm{ha}$, calculadas em função do poder germinativo $(50-80 \%)$, e submeteu-as à semeadura em $1 \underline{i}$ nha e a lanço. As diferenças na produção de matéria seca, oca sionadas pelas espécies, cortes e a interação espécies x cor 
tes foram altamente significativas, e as misturas com Centrose ma pubescens, Desmodium scorpiurus, Stylosanthes humilis e Ma croptilium atropurpureum foram as que apresentaram melhor de sempenho, quando semeadas a lanço. Intervalos de cortes mais longos resultaram em maiores produções de matéria seca, embora esta tenha variado nitidamente ent re as leguminosas, onde a Centrosema pubescens e o Desmodium uncinatum se apresentaram com a maior e a menor produção. Para a associação braquiaria - siratro, com intervalo de corte de 6 semanas, a produção de matéria seca foi de 6,20 e 6,80 t/ha/ano para a semeadura em linha e a lanço, respectivamente, tendo a leguminosa contribuí do com 1,74 e 2,32 t/ha/ano em cada método.

A recuperação de pastagens de braquiaria pela in trodução de leguminosas vem sendo estudada pela EMBRAPA (1981a), atravês da semeadura da leguminosa em faixas de 10,0 metros de largura alternadas por faixas de braquiaria de 20,0 metros de largura. Após o preparo, correção e adubação do solo, as legu minosas foram semeadas em taxas de 3,9-6,7-3,7 e 2,3 $\mathrm{kg}$ de sementes/ha, respectivamente, para Calopogonio, Centrosema, Siratro e Estizosantes, correspondendo a $29-24-31$ e 106 se mentes viâveis $/ \mathrm{m}^{2}$. A contagem das plantas aos 50 e 380 dias após semeadura apresentou os seguintes valores: calopogonio com 24 e 30 plantas $/ \mathrm{m}^{2}$; centrosema com 14 e 24 plantas $/ \mathrm{m}^{2}$; si ratro com 10 e 5 plantas $/ \mathrm{m}^{2}$ e o estilosantes com 18 e 7 plan tas $/ \mathrm{m}^{2}$. Estas duas ũltimas espécies, além de serem mais procu radas pelos animais não apresentaram produção de sementes (re 
semeadura natural).

Trabalhos realizados no Centro de Pesquisas Agro pecuāria do Cerrado (Brasília, DF) sobre forrageiras, tem se direcionado para a obtenção de gramíneas e leguminosas passí veis de consorciação e que sejam persistentes sob condições de pastejo. Entre as espécies avaliadas notaram-se diferenças a centuadas na produção de matéria seca da gramínea exclusiva, sendo a Brachiaria humidicola a de menor produção, com 2.955 $\mathrm{kg} / \mathrm{ha}$; enquanto que a Brachiaria decumbens cv. Basilisk, tam bém chamada de Australiana, teve uma produção de matéria seca de $4.435^{\circ} \mathrm{kg} / \mathrm{ha}$ e a Brachiaria ruziziensis teve uma produção de matéria seca de $3.616 \mathrm{~kg} / \mathrm{ha}$. Quando introduziu-se styzosanthes guianensis civ. Cook, em consorciação, as produções de matéria seca elevaram-se para $4.323,5.820$ e $6.552 \mathrm{~kg} / \mathrm{ha}$, respectiva mente, para as três espécies; e a participação da leguminosana mistura, em termos de porcentagem na matéria seca variou entre $81 \%$ na $B$. humidicola, 39\% na $B$. decumbens e 58\% na $B$. ruzizien sis; sendo que com a $B$. humidicola a alta quantidade de legumi nosa na consorciação reflete a baixa produção desta gramínea (EMBRAPA, 1981c).

FURTADO et alii (1977), estudando o efeito da consorciação de leguminosas com o capim braquiaria (Brachiaria decumbens) citam que, em termos de composição botânica, os tra tamentos com siratro e centrosema contribuiram com $15,5^{\circ}$ e $14,0 \%$ no primeiro ano, 31,4 e $19,5 \%$ no segundo ano respectiva mente, na cobertura do solo. 
A porcentagem de leguminosa em pastagens de ruzi

- ziensis (Brachiaria ruziziensis) consorciadas com soja perene (Glycine wightii) e siratro (Macroptilium atropurpureum) evi dencia uma relação direta com a taxa de lotação usada, princi palmente no período chuvoso. Para taxa de lotação de 0,8 U.A.l ha, o conteúdó de leguminosa na matéria seca total variou en tre 10,0 e $20,0 \%$, para o início e final do período chuvoso, enquanto que para taxa de lotação 1,4 U.A./ha variou entre 10,0 e 13,05\%; o que significa um maior consumo de leguminosa no período seco, e pequeno consumo no período chuvoso, pois o animal passa a consumir mais o capim. O estudo da composição botânica durante a estação chuvosa foi realizado em pastagem de Brachiaria humidicola - Calopogonium mucunoides, onde observa-se uma elevação na porcentagem de leguminosa de $10,0 \%$ no in cio para 65,0\% no final do período das chuvas (EMBRAPA, 1981c).

A avaliação sob pastejo do capim Andropogon cv. Planaltina (Andropogon gayanus var. Bisquamulatus) e o capim braquiaria cv. Basilisk (Brachiaria decumbens) consorciados com leguminosas foi realizado em parcelas de $100 \mathrm{~m}^{2}$ pela EMBRAPA (1982). As espécies mais persistentes e produtivas nesse tipo de avaliação foram o Stylosanthes capitata cv. CPAC-706 e CPAC -704, e Stylosanthes macroephala cv. CPAC-139, sendo que as produções de matéria seca destas consorciações maiores, embora não quantificadas, às obtidas nas parcelas com gramíneas puras. No ano agrícola 1980/81, a participação destes três ecotipos nas consorciações com o capim Andropogon e o capim Brachiaria 
variaram entre 27,0 e $38,0 \%$ da matêria seca.

\subsection{Capim Setāria}

LUCK (1979) afirma que o capim setária (Setária anceps Stapf) é uma das gramíneas mais importantes em áreas de pastagens na Austrália, e que o potencial de produção de todos os cultivares é alto, sendo que a produção de matéria seca po de atingir 10 t/ha/ano e que a produção da cultivar Nandi po de ser de 10 a $20 \%$ menor que a das cultivares Kazungula e Na rok. Com relação à consorciação, Desmodium intortum, Desmodium uncinatum e Macroptilium atropurpureum são as leguminosas mais indicadas para a associação.

Para Setaria anceps as taxas de semeadura reco mendadas por LUCK (1979) dependem da qualidade da semente; no entanto, com sementes de boa qualidade estas variam entre 1 e $2 \mathrm{~kg} / \mathrm{ha}$, e que para a cultivar Kazungula pode-se usar taxas mais baixas do que para as cultivares Nandi ou Narok.

THAIRU (1972), utilizando $1,5 \mathrm{~kg} / \mathrm{ha}$ de sementes puras de Setaria sphacelata com $2,0 \mathrm{~kg} / \mathrm{ha}$ de sementes de Des modium uncinatum encontrou, no ano do estabelecimento, produ ções de matéria seca de $12,77 \mathrm{t} / \mathrm{ha}$ e $14,71 \mathrm{t} / \mathrm{ha}$, respectivamen te, para os tratamentos gramínea sem adubação nitrogenada e gramínea + leguminosa, sendo que neste ủltimo a produção de ma têria seca da componente leguminosa foi da ordem de 2,38 t/ha. A produção de nitrogênio foi de 0,250 th ha para o tratamento 
gramínea sem adubo e de 0,311 t/ha para o tratamento gramínea + leguminosa, sendo de 0,067 t/ha a contribuição da componente leguminosa.

Para MIDDLENTON (1973), que testou taxas de se meadura de $3,3-9,9$ e $29,7 \mathrm{~kg} / \mathrm{ha}$ para o siratro (M. atropurpu reum), com 2,2 e $6,6 \mathrm{~kg} / \mathrm{ha}$ de taxa de setaria anceps cv. Nan di; aumentos na taxa de semeadura do siratro resultou em aumen tos na produção de matêria seca da leguminosa e conteūdo de ni trogênio da gramínea associada; e que as respostas aos aumen tos de densidades na leguminosa eram maiores nas densidades mais baixas da gramínea. Verificou ainda que o efeito da densi dade na leguminosa diminuia com o tempo, e que no terceiro ano este efeito tinha cessado completamente.

A forma mais econômica de pastagens nas terras secas ao sul de Burnett (Austrália) è aquela que apresenta as componentes gramínea-leguminosa associadas. Taxas de semeadura de 0,5 a $2,0 \mathrm{~kg} / \mathrm{ha}$ para o siratro podem ser associadas com ta xas de semeadura de 1 a $4 \mathrm{~kg} / \mathrm{ha}$ para o capim setária cv. Kazun gula, desde que observada uma porcentagem de pureza de $97,0 \%$ para a leguminosa e de $60,0 \%$ para a gramínea, enquanto que a porcentagem de germinação deve ser de $70,0 \%$ pảra a leguminosa e de $20,0 \%$ na gramínea. E usado ainda com certa frequência a mistura de sementes de outras gramíneas com taxas de semeadu ras variảveis entre 10 e $20 \mathrm{~kg} / \mathrm{ha}$; entretanto, essa mistura le va a um selecionamento das espécies menos palatáveis, indican do ser pouco recomendável a associação entre espécies de gra 
mineas (HODGE, 1979).

JONES (1971), relacionando taxa de lotação $(1,3$ e 2,6 Cab/ha/ano) com doses de fösforo $(24,48,96$ e $144 \mathrm{~kg}$ de $\mathrm{P} / \mathrm{ha}$ ) com diferentes quantidades de sementes de siratro ( $M$. atropurpureum) $1,1-4,5-9,0 \mathrm{~kg} / \mathrm{ha}$ em pastagens de capim se tária (Setária anceps cv. Nandi); concluiu que a produção da leguminosa aumentou com a taxa de semeadura, além de reduzir o número de plantas invasoras; e que a resposta do siratro aumen tou com o nível de $\mathrm{P}$, apesar de ter diminuido sua resposta à taxa de semeadura. O autor relatou ainda que houve uma redução progressiva na produção do siratro com alta taxa de lotação.

Para proporção nada se encontrou na literatura com respeitó a espécie em discussão. Entretanto, espécies com hábito de crescimento semelhantes e consorciadas em solos de cerrado.também foram estudadas por ROLÓN e COSTA (1979), que utilizando taxas de semeaduras de $20 \mathrm{~kg} / \mathrm{ha}$ para o capim guiné (Panicum maximum) com uma mistura de $3 \mathrm{~kg} / \mathrm{ha}$ de sementes de centrosema (Centrosema pubescens), com $1,5 \mathrm{~kg} / \mathrm{ha}$ de sementes de calopogonio (Calopogonium mucunoides), encontraram, no pri meiro ano, relação gramínea-leguminosa de $65 \%$ a $35 \%$ respectiva mente, ao passo que no segundo ano a relação apresentou o ca pim guinê com $21,47 \%$, centrosema $9,82 \%$, calopogonio $51,53 \%$ e plantas invasoras e outros resíduos $17,18^{\circ}$. 
2.5. Siratro

Com respeito às leguminosas, o siratro (Macropti lium atropurpureum) apresenta-se como forrageira de crescimen to contínuo em áreas tropicais e sub-tropicais, segundo JONES (1979).

CARVALHO et alii (1975), comparando as produçoes de leguminosas forrageiras em pastagens de capim pangola e pas tagens naturais de capim gordura e capim jaraguá, verificaram que o siratrofoi a leguminosa que melhor se consorciou, segui da da centrosema, enquanto que a soja perene não apresentou es tabelecimento satisfatório.

- A produção de matéria seca do siratro, citada por MATTos (1977) é variável entre 5 e 6 t/ha/ano, enquanto que RAYMENT et alii (1977) citam produções de matéria seca de $3,54 \mathrm{t} / \mathrm{ha}$ como produção média encontrada quando a forrageira foi submetida a diferentes doses de adubo potássico.

Em estudos sobre a nutricão mineral do siratro, MONTEIRO et alii (1980) encontraram aumentos na produção de ma téria seca e proteína bruta com uso de $100 \mathrm{~kg} / \mathrm{ha} / \mathrm{ano}$ de $\mathrm{K}_{2} \mathrm{O}$. Para o tratamento sem potássio, a produção de matéria seca foi de $996 \mathrm{~kg} / \mathrm{ha} / \mathrm{ano}$ e a produção de proteína bruta foi de $201 \mathrm{~kg} /$ ha/ano, enquanto que para o tratamento $100 \mathrm{~kg} / \mathrm{ha}$ de $\mathrm{K}_{2} \mathrm{O}$ a pro dução de matéria seca foi de $1.876 \mathrm{~kg} / \mathrm{ha} /$ ano e a produção de proteina bruta de $389 \mathrm{~kg} / \mathrm{ha} / \mathrm{ano}$.

Efetuando-se cortes com intervalos de 40-60 dias 
no verão e 80 - 120 dias no inverno, TOSI et alii (1979), tes

- tando diferentes doses de fósforo em leguminosas encontraram, para o siratro (Macroptilium atropurpureum DC) produções de ma têria seca de $4.401,5$ e $1.945,2 \mathrm{~kg} / \mathrm{ha} / a n o$ como média das pro duções em diferentes doses de adubo, em duas regiões do Estado de São Paulo.

Segundo RIBEIRO (1979), para obter-se densidades de 100 sementes $/ \mathrm{m}^{2}$ para o siratro (Macroptilium atropurpureum DC Urb) seriam necessārios de 11 a $15 \mathrm{~kg}$ de sementes/ha.

$\mathrm{Na}$ Austrália, as densidades de semeadura recomen dadas para o siratro variam entre 1,12 e $3,0 \mathrm{~kg} / \mathrm{ha}$ (HUMPHREYS, 1965) e 1,56 e $9,0 \mathrm{~kg} / \mathrm{ha}$ (Jones, 1967 citado por GONSALVES e BARRETO, 1979), sendo que este último encontrou aumentos na produção de matéria seca quando aumentaram-se as quantidades de sementes utilizadas.

O siratro (M. atropurpureum) é comumente semeado em taxas que variam de 2 a $3 \mathrm{~kg}$ de sementes viāveis/ha, segun do JONES (1975). Entretanto, experimentos realizados em cante ros têm demonstrado que, com variações nas condições de solo e clima, é desejável, a curto prazo, ter-se taxas de semeadura superiores a $2 \mathrm{~kg} / \mathrm{ha}$ (MIDDLETON, 1970), apesar de baixas taxas de semeadura, como $0,6 \mathrm{~kg} / \mathrm{ha}$ ter promovido "stands satisfató rios" (T'Mannetje, 1967 citado por COOK e LOWE, 1977). A eme $\underline{r}$ gência de plantas é proporcional à taxa de semeadura, contudo, não há diferença na produção da leguminosa no segundo ano, mesmo variando-se as taxas de semeadura de 2 a $18 \mathrm{~kg} / \mathrm{ha}$. Entre 
tanto, quando se usam baixas taxas de semeadura, o tempo para a pastagem se formar é maior, o que prolonga a fase de estabe lecimento para um ou dois anos (COOK e LOWE, 1977).

No Brasil, GONÇALVES e BARRETo (1979), estudando três densidades de capim de Rhodes (ChZoris gayana Kunth) $(6,15$ e $30,0 \mathrm{~kg} / \mathrm{ha}$ de sementes com $60 \%$ de poder germinativo), com duas densidades de siratro (M. atropurpureum) cv. Siratro (3 e $10 \mathrm{~kg} / \mathrm{ha}$ de sementes com $50 \%$ de poder germinativo) concluiram que as produções de matéria seca da gramínea no ano do estabe lecimento aumentaram com as densidades, muito embora as produ ções correspondentes às duas ưltimas não tenham diferido estạ tisticamente entre si. No $2^{\circ}$ ano as produções referentes às três densidảdes nãọ apresentaram diferenças significativas. Pa ra o siratro não houve diferenças significativas para densida des; e também interação densidade de graminea $x$ densidade legu minosa, no primeiro e segundo ano do ensaio.

RIBEIRO (1979), introduzindo uma associação de leguminosas em pastagens estabelecidas de capim Napier, usou densidades de 10 sementes viäveis $/ \mathrm{m}^{2}$ por espécie. A densidade de plantas 35 dias após a semeadura, obtidas pela média dos dí ferentes mëtodos, foi de 5,59 e 9,86 plantas $/ \mathrm{m}^{2}$, respectivamen te, para o início e final do período chuvoso, enquanto que no final do primeiro ano as densidades médias dos diferentes méto dos foram de 2,12 e 4,75 plantas $/ \mathrm{m}^{2}$ para as duas ëpocas de se meadura. A distribuição das espécies em relação à época de semeadura apresentou o siratro com densidade média de 1,01 e 1,9 
plantas $/ \mathrm{m}^{2}$ na contagem realizada 35 dias após a semeadura; en quanto que, em relação a sistemas de semeadura, a densidade mêdia foi de $1,45 \mathrm{plantas} / \mathrm{m}^{2}$. Sobre sistemas de semeadura o au tor concluiu que preparo do solo com semeadura tardia foi a melhor maneira de introdução de leguminosas, embora a produção de matêria seca e o número de plantas, após o primeiro ano, te rem apresentado diferenças altamente significativas para se avaliar o estabelecimento de plantas. O autor concluiu ainda que, para se conseguir $10 \%$ de aumento na produção anual de ma téria seca, atravês da produção da componente leguminosa, foi necessärio uma densidade maior que 3 a 5 plantas de legumino $\mathrm{sa} / \mathrm{m}^{2}$.

A avạliação da composição botânica em pastagem de capim Napier (Pennisetum purpureum) consorciado com legumi nosas foi realizado por LOURENÇO et alii (1979). A porcentagem de siratro (Macroptilium atropurpureum cv. Siratro) na quant $\underline{i}$ dade de matêria seca disponível não foi significativa nas ava liações feitas: após pastejo, entre períodos de pastejo, e pa ra a interação desses fatores. Com relação ao número de plan tas, a centrosema e o siratro apresentaram maior facilidade em aumentar o número de $\mathrm{plantas} / \mathrm{m}^{2}$ de ano para ano, apesar do au mento no primeiro ano ter sido de 1,4 para $1,7 \mathrm{plantas} / \mathrm{m}^{2}$. JONES et alii (1967), em ensaio sobre a contri buição da leguminosa na produção de matéria seca de pastagens, concluiram que após 5 anos de experimento, o siratro se mos trou a leguminosa mais persistente quando consorciada com Pas 
palum plicatulum, com produções de 10,4 t/ha de matéria seca e - 0,190 t/ha de nitrogênio, sendo que a leguminosa contribuiu com 30 e $45 \%$ respectivamente na produção de matéria seca e ni trogênio; e relaciona os meses de junho e julho como os menos produtivos, e que a variação estacional na produção de nitrogê nio foi semelhante à da matêria seca.

0 aumento no ganho de peso vivo tem estreita re lação com o conteûdo de leguminosa na pastagem, conforme mos tra Bryan (1970) citado por JONES (1972), que aumentou nitida mente o ganho de peso vivo quando aumentou a porcentagem de le guminosa na pastagem de 13 para $20 \%$ e de $20 \%$ para $30 \%$, sendo que esta ûltima obteve ganhos de peso ligeiramente inferiores a adubações nitrogenadas de $0,4 \mathrm{t}$ de $\mathrm{N} / \mathrm{ha}$. 
3. MATERIAL E METODOS

3.1. Local do Ensaio

O ensaio foi instalado no setor de Bovinocultura da Fazenda Experimental da UNESP - "Campus". de Ilha Solteira, localizada no Município de Selvíria, MS; à latitude $20^{\circ} 22^{\prime}$ s, longitude $51^{\circ} 22^{\prime} W$ com altitude de $335 \mathrm{~m}$.

3.2. Característica da Região

A área utilizada na instalação do experimento apresenta topografia plana, e anteriormente ao ensaio era reco berta por vegetação de cerrado. O solo foi classificado, segun do DEMATtE (1980), como Latossol Vermelho Escuro Alico, textü ra média (20 - 35\% argila), e suas características químicas, de terminadas no Laboratório de Adubação e Fertilidade do Solo, do "Campus" de Ilha Solteira, estão representadas na Tabela 1. 
TABELA 1 - Principais características químicas do solo no 10 cal do experimento.

\begin{tabular}{ccccccc}
\hline Profundidade & $\mathrm{pH}$ & $\mathrm{e} . \mathrm{mg} / 100 \mathrm{ml} \mathrm{TFSA}$ & & \multicolumn{2}{c}{$\mathrm{ppm}$} \\
\cline { 3 - 4 } \cline { 5 - 6 } & & $\mathrm{Al} \mathrm{Ca}+\mathrm{Mg}$ & & $\mathrm{P}$ & $\mathrm{K}$ \\
\hline $0-20 \mathrm{~cm}$ & 5,9 & 0,0 & 1,9 & & 3,0 & 52,0 \\
\hline
\end{tabular}

A precipitação pluvial no ano agrícola 1980/81 foi de 1.271,0 mm, distribuídos em dois períodos: outubro a março (período chuvoso) com 82,5\%; e de abril a setembro (período seco) 'com $17,5 \%$ da precipitação total. As temperaturas mé dias anuais foram mäximas de $37,2^{\circ} \mathrm{C}$ e minimas de $14,5^{\circ} \mathrm{C}$ (Dados mensais de precipitação e temperatura encontram-se na Tabela 2).

\subsection{Desmatamento e Preparo do Solo}

o desmatamento foi realizado no mês de Junho/ 1980, através de quebra e enleiramento de toda a cobertura ve getal por máquinas de esteiras, providas de lâminas dentadas para evitar o acúmulo da camada superficial do solo nas leiras. 0 preparo do solo constou de duas operações de gradagem pesa da tipo Home. 
TABElA 2 - Precipitação pluviomêtrica mensal (mm) e temperatü ra mêdia mensais $\left({ }^{\circ} \mathrm{C}\right)$ da região de Selvíria, MS, no período de outubro/80 a fevereiro/82.

\begin{tabular}{lcc}
\hline Mês/Aro & $\begin{array}{c}\text { Precipitação } \\
(\mathrm{mm})\end{array}$ & $\begin{array}{c}\text { Temperatura Média } \\
\left({ }^{\circ} \mathrm{C}\right)\end{array}$ \\
\hline outubro/80 & 70,0 & 26,4 \\
novembro & 138,0 & 27,5 \\
dezembro & 339,0 & 31,0 \\
janeiro/81 & 282,0 & 29,0 \\
fevereiro & 99,0 & 28,8 \\
março & 121,0 & 26,4 \\
abri1 & 112,0 & 26,2 \\
maio & 19,0 & 25,0 \\
junho & 79,0 & 21,8 \\
julho & - & 18,5 \\
agosto & 9,0 & 22,9 \\
setembro & 3,0 & 24,9 \\
outubro & 130,0 & 25,7 \\
novembro & 220,0 & 25,8 \\
dezembro & 219,0 & 28,6 \\
janeiro/82 & 8,0 & 27,8 \\
fevereiro & 65,0 & 25,1 \\
& &
\end{tabular}

3.4. Calagem e Adubação

A calagem foi realizada em setembro/80 e constou de 2,0 t/ha de calcäreo dolomítico com PRNT de 60\%, distribuí dos a lanço e incorporados pela segunda operação de gradagem pesada. 
A adubação bāsica realizada a lanço e seguida de incorporação após a semeadura constou de $125 \mathrm{~kg} / \mathrm{ha}$ de $\mathrm{P}_{2} \mathrm{O}_{5}$ na forma de superfosfato simples; $0,2 \mathrm{~kg} / \mathrm{ha}$ de Mo na forma de mo libdato de sódio; $6,0 \mathrm{~kg} / \mathrm{ha}$ de $\mathrm{Zn}$ na forma de sulfato de $z$ inco e $193 \mathrm{~kg} / \mathrm{ha}$ de $\mathrm{K}_{2} \mathrm{O}$ na forma de cloreto de potássio. A adubação foi colocada em cobertura após o rebaixamento.

\subsection{Delineamento Experimenta1}

o delineamento experimental estabelecido foi o de blocos ao acaso em parcelas subdivididas, com quatro repe tições, com as densidades $\left(\mathrm{D}_{50}, \mathrm{D}_{100}, \mathrm{D}_{150}\right)$, designadas às par celas; e as proporções $\left(\mathrm{P}_{0}, \mathrm{P}_{20}, \mathrm{P}_{40}, \mathrm{P}_{60}, \mathrm{P}_{80}, \mathrm{P}_{100}\right)$, sendo designadas às subparcelas. Cada subparcela mediu 4,0 m $(2,0 \mathrm{x}$ $2,0 \mathrm{~m})$, e o material para estudo foi coletado em $1,0 \mathrm{~m}^{2}$ cen tral em cada subparcela, enquanto que o restante constituiu-se em bordadura.

As densidades em estudo constituiram-se de $D_{50}$, $\mathrm{D}_{100}$ e $\mathrm{D}_{150}\left(50,100\right.$ e $\left.150 \mathrm{plantas} / \mathrm{m}^{2}\right)$, enquanto que as pro porções, estahelecidas em termos de: crescente de leguminosa dentro de cada densidade foram denominadas de: $\mathrm{P}_{0}(100 \%$ gramí nea - $0 \%$ leguminosa); $\mathrm{P}_{20}\left(80 \%\right.$ gramínea - $20 \%$ leguminosa); $\mathrm{P}_{40}$ $\left(60 \%\right.$ gramínea - 40\% leguminosa); $\mathrm{P}_{60}$ (40\% gramínea - 60\% legu minosa); $\mathrm{P}_{80}\left(20 \%\right.$ gramínea - 80\% leguminosa); $\mathrm{P}_{100}(0 \%$ gramí nea - 100\% leguminosa). 


\subsubsection{Tratamentos}

Os tratamentos estabelecidos, suas relações gra mínea-leguminosa, em termos de porcentagem e nümero de plan tas, foram:

1) $\mathrm{D}_{50} \mathrm{P}_{0} \quad-50 \mathrm{plantas} / \mathrm{m}^{2} ; 100 \%$ gramínea - $0 \%$ leguminosa; 50 - $0 \mathrm{plantas} / \mathrm{m}^{2}$;

2) $\mathrm{D}_{50} \mathrm{P}_{20}-50 \mathrm{plantas} / \mathrm{m}^{2} ; 80 \%$ graminea - $20 \%$ leguminosa; $40-10 \mathrm{plant}$ as $/ \mathrm{m}^{2}$;

3) $\mathrm{D}_{50} \mathrm{P}_{40}-50 \mathrm{plantas} / \mathrm{m}^{2} ; 60 \%$ gramínea - $40 \%$ leguminosa; $30-30 \mathrm{plantas} / \mathrm{m}^{2}$;

4) $\mathrm{D}_{50} \mathrm{P}_{60}-50 \mathrm{plantas} / \mathrm{m}^{2} ; 40 \%$ graminea - $60 \%$ leguminosa; $20-30 \mathrm{plantas} / \mathrm{m}^{2}$;

5) $\mathrm{D}_{50} \mathrm{P}_{80}-50 \mathrm{plantas} / \mathrm{m}^{2} ; 20 \%$ graminea - $80 \%$ leguminosa; $10-40 \mathrm{plantas} / \mathrm{m}^{2}$;

6) $\mathrm{D}_{50} \mathrm{p}_{100}-50 \mathrm{plantas} / \mathrm{m}^{2} ; 0 \%$ gramínea - $100 \%$ leguminosa; 0 - $50 \mathrm{plantas} / \mathrm{m}^{2}$;

7) $\mathrm{D}_{100} \mathrm{P}_{0}-100 \mathrm{plantas} / \mathrm{m}^{2} ; 100 \%$ gramínea - $0 \%$ leguminosa; $100-0 \mathrm{plantas} / \mathrm{m}^{2}$;

8) $\mathrm{D}_{100} \mathrm{P}_{20}-100 \mathrm{plantas} / \mathrm{m}^{2}, 80 \%$ gramínea - $20 \%$ leguminosa; $80-20 \mathrm{plantas} / \mathrm{m}^{2}$;

9) $\mathrm{D}_{100} \mathrm{P}_{40}-100 \mathrm{plantas} / \mathrm{m}^{2} ; 60 \%$ gramínea - 40\% leguminosa; $60-40 \mathrm{plantas} / \mathrm{m}^{2}$;

10) $\mathrm{D}_{100} \mathrm{P}_{60}-100 \mathrm{plantas} / \mathrm{m}^{2} ; 40 \%$ gramínea - $60 \%$ leguminosa; $40-60 \mathrm{plantas} / \mathrm{m}^{2}$;

11) $\mathrm{D}_{100} \mathrm{P}_{80}-100 \mathrm{plantas} / \mathrm{m}^{2} ; 20 \%$ gramínea - $80 \%$ 
leguminosa; $20-80 \mathrm{plantas} / \mathrm{m}^{2}$;

12) $\mathrm{D}_{100} \mathrm{P}_{100}-100 \mathrm{plantas} / \mathrm{m}^{2} ; 0 \%$ gramínea - $100 \%$ leguminosa; 0 - $100 \mathrm{plantas} / \mathrm{m}^{2}$;

13) $\mathrm{D}_{150} \mathrm{P}_{0}-150 \mathrm{p} 1$ antas $/ \mathrm{m}^{2} ; 100 \%$ gramínea - $0 \%$ leguminosa; 150 - 0 plantas $/ \mathrm{m}^{2}$;

14). $\mathrm{D}_{150} \mathrm{P}_{20}-150 \mathrm{plantas} / \mathrm{m}^{2} ; 80 \%$ gramínea - $20 \%$ leguminosa; 120 - $30 \mathrm{plantas} / \mathrm{m}^{2}$;

15) $\mathrm{D}_{150} \mathrm{P}_{40}-150 \mathrm{plantas} / \mathrm{m}^{2} ; 60 \%$ gramínea - $40 \%$ leguminosa; $90-60 \mathrm{plantas} / \mathrm{m}^{2}$;

16) $\mathrm{D}_{150} \mathrm{P}_{60}-150 \mathrm{plantas} / \mathrm{m}^{2} ; 40 \%$ gramínea - $60 \%$ leguminosa; $60-90 \mathrm{p} 1$ antas $/ \mathrm{m}^{2}$;

17) $\mathrm{D}_{150} \mathrm{P}_{80}-150 \mathrm{plantas} / \mathrm{m}^{2} ; 20 \%$ gramínea $-80 \%$ leguminosa; $30-120 \mathrm{plantas} / \mathrm{m}^{2}$;

18) $\mathrm{D}_{150} \mathrm{P}_{100}-150 \mathrm{p} 1 \mathrm{antas} / \mathrm{m}^{2} ; 0 \%$ gramínea - $100 \%$ leguminosa; $0-150 \mathrm{plantas} / \mathrm{m}^{2}$.

3.6. Características das Sementes

As sementes das espécies forrageiras em estudo eram sementes comerciais adquiridas na região.

As sementes, analisadas pelo Laboratörio de Anâa lise de Sementes de Campinas, revelaram as seguintes caracte rísticas, expressas na Tabela 3 . 
TABELA 3 - Características das sementes das espécies forrage ras utilizadas no experimento.

\begin{tabular}{lccc}
\hline Espécie & Pureza & : Germinação & Valor Cultural \\
\hline Brachiaria & 47,4 & 9,0 & 4,3 \\
Setäria & 60,0 & 29,0 & 17,4 \\
Siratro & 97,6 & 83,0 & 80,6 \\
\hline
\end{tabular}

A relação entre densidades em estudo e taxas de semeadura equivalente, foram calculadas com base nos dados da AGROCERES (1974) citados por ZIMMER (1981) e DE LOCH (1977) e nas características das sementes contidas na Tabela 3 estão ex pressas na Tabela 4 .

TABELA 4 - Relação entre densidades e taxas de semeadura das espêcies forrageiras usadas.

\begin{tabular}{lcc}
\hline Espécies & $\begin{array}{c}\text { Densidade } \\
\text { plantas } / \mathrm{m}^{2}\end{array}$ & $\begin{array}{c}\text { Taxa de semeadura } \\
\text { equivalente }(\mathrm{kg} / \mathrm{ha})\end{array}$ \\
\hline Brachiaria & 50 & 10,71 \\
& 100 & 21,42 \\
& 150 & 32,13 \\
Setäria & 50 & 0,57 \\
& 100 & 1,14 \\
& 150 & 1,71 \\
Siratro & 50 & 7,32 \\
& 100 & 14,64 \\
& 150 & 21,96 \\
\hline
\end{tabular}




\subsection{Consorciações Estabelecidas}

As densidades de plantas e proporções gramínea - leguminosa, foram testadas em duas consorciações: brachiaria-siratro (Brachiaria decumbens Stapf - Macroptilium atropurpu reum cv. Siratro DC Urb) e setāria-siratro (Setaria anceps cv. Kazungula - Macroptilium atropurpureum cv. Siratro DC Urb).

Para os dois tipos de consorciação, a semeadura foi realizada em linhas espaçadas de 0,20 m entre si, introdu zindo-se alternativamente a graminea e a leguminosa; em quantí dades suficientes para garantir, com segurança, a emergência do número de plantas em estudo. Para a consorciação brachiaria -siratro, a semeadura foi realizada em 10 de dezembro de 1980, e para a consorciação setária-siratro a semeadura foi realiza da em 17 de dezembro de 1980 .

\subsection{Desbaste e Rebaixamento}

O desbaste nas densidades e proporções em estudo foi realizado quando as plantas atingiram entre 0,05 e $0,10 \mathrm{~m}$ de altura levando-se em consideração o número de plantas em es tudo sem considerar o número de linhas semeadas em 09 e 16 de janeiro de 1981, e o corte de uniformização do "stand" foi rea lizado na consorciação brachiaria-siratro em 14 de fevereirode 1981 e para a consorciação setária-siratro em 27 de fevereiro de 1981. 


\subsection{Altura e Intervalo de Corte}

A altura de corte estipulada foi entre 0,10 $0,12 \mathrm{~m}$ de altura do solo, enquanto que o intervalo entre cor tes foi de 6 semanas no crescimento de verão (outubro - março) e de 9 semenas no crescimento de inverno (abril-setembro).

\subsection{Coleta do Material}

A avaliação foi realizada através de 7 cortes na consorciação braquiaria-siratro, efetuados em 27/03, 29/05, $31 / 07,11 / 09,23 / 10,04 / 12 / 82$; e de 6 cortes na consorciação setária-sirátro, efetuados em 10/04,12/06,14/08,06/11, 18/ /12/81 e 05/02/82 (corte de 25/09/81 não foi realizado, pois as plantas não atingiram altura de corte).

Os cortes foram feitos manualmente com cutelos, separando-se as componentes gramínea e leguminosa, onde foi de terminado o peso verde de cada componente; retirada uma amos tra representativa de $0,4-0,5 \mathrm{~kg}$ de cada uma, que foram colo cadas em estufa com circulação forçada de ar a $65-70^{\circ} \mathrm{C}$ até peso constante. Posteriormente foi determinado o peso seco das amostras, que em seguida passaram por moinho de laboratório tipo Willey, com peneira de aço inox malna Mesh 20, e acondi cionadas em frascos de vidro etiquetados. 
3.11. Avaliação dos Resultados

A avaliação dos resultados foi feita através das seguintes determinações:

3.11.1. Porcentagem Média Anual de Matéria Seca

Determinada em estufa seca a $105^{\circ} \mathrm{C}$ por um perío do mínimo de 4 horas; sendo que cada amostra das componentes re presenta a média de 4 repetições; enquanto que a porcentagem de matéria seca por corte representa a média de 4 blocos enquanto que a porcentagem média anual foi obtida pela média aritmética de cada componente nos diversos cortes realizados.

\subsubsection{Produção Anual de Matéria Seca}

Foi determinada em cada componente, com base na matéria seca a $105^{\circ} \mathrm{C}$, e produção conjunta obtida pela soma da produção das componentes.

3.11.3. Teor Médio Anual de Proteína Bruta

o teor de proteina bruta foi determinado nas duas componentes em todos os cortes realizados, pelo método de Kjeldahl modificado segundo AOAC (1965) e os dados obtidos re presentam a média de duas repetições por amostra. o teor médio 
anual em cada componente foi obtido pela média aritmética dos teores encontrados nos diversos cortes realizados.

\subsubsection{Produção Anual de Proteína Bruta}

Determinada para cada componente, pela somatória da produção de cada corte, enquanto que a produção conjunta foi obtida pela soma da produção anual das duas componentes.

3.11.5. Nümero de Leguminosas $/ \mathrm{m}^{2}$ ao Final do Ensaio

o número de plantas foi determinado após o $7{ }^{\circ}$ corte, em 22 de janeiro de 1982, para a consorciação braquia ria-siratro; e após o 6: corte, em 05 de fevereiro de, 1982, para a consorciação setâria-siratro.

\subsection{Anālise Estatística}

Os dados coletados foram analisados para as com ponentes gramínea e leguminosa separadamente quanto à porcenta gem média de matéria seca e teor médio de proteína bruta, en quanto que a produção de matêria seca no rebaixamento, produ ção anual de matéria seca e produção anual de proteína bruta foram analisados também através da produção conjunta das com ponentes.

o número de plantas foi analisado apenas na com 
ponente leguminosa, através do número de plantas desta compo nente obtido ao final do ensaio.

A anālise de variância foi determinada de acordo com esquema "split-plot", tendo como parcelas o fator densida de, e como subparcelas o fator proporções. A análise de variân cia preliminar foi realizada nos efeitos $D, P$ e na interaça entre eles, segundo o esquema abaixo.

TABELA 5 - Esquema de anālise de variância utilizado na avalia ção dos resultados.

\begin{tabular}{|c|c|c|}
\hline Causas de Variação & G.L. & \\
\hline Blocos & 3 & \\
\hline Densidades (D) & 2 & \\
\hline 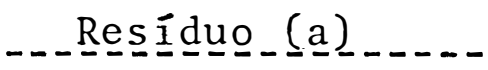 & 6 & \\
\hline Parcelas & 11 & \\
\hline 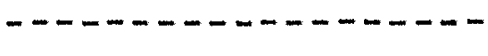 & $---n$ & ------ \\
\hline Proporcões (P) & 4 & (5) a \\
\hline $\mathrm{D} \times \mathrm{P}$ & 8 & $(10) \mathrm{b}$ \\
\hline Resíduo (b) & 36 & $(45) \mathrm{c}$ \\
\hline Subparcelas & 59 & \\
\hline
\end{tabular}

$\mathrm{a}, \mathrm{b}, \mathrm{c}=$ número de graus de liberdade para a produção conjun ta.

Como no caso de tratamentos quantitativos, pode haver uma dependência entre eles e procurando ver se justifica a existência de uma correspondência funcional entre eles (equa ção de regressão) que ligue os valores dos tratamentos (x) aos 
dados analisados $(Y)$, a soma de quadrados de $D$ e $P$ foi decom - posta em componente linear, quadrático e desvios, de acordocom os polinômios ortogonais.

A interação $D \times P$ desdobrada para se verificar os efeitos D dentro de P e P dentro de D. A soma de quadrados deste desdobramento também foi decomposta de acordo com os po linômios ortogonais em componente linear, quadrätico, cúbico e de $4:$ grau.

As comparações das médias dos tratamentos foram realizadas pelo teste de Tukey. 
4. RESULTADOS E DISCUSSAO

4.1. Consorciação Braquiaria-Siratro

4.1.1. Porcentagem de Matéria Seca

As pórcentagens de matéria seca por corte estão expressas nas Tabelas e representam a média de quatro blocos, enquanto que a variação na porcentagem média anual estão reprẹ sentadas pelas Figuras.

4.1.1.1. Porcentagem de matéria seca da compo nente graminea

A porcentagem de matéria seça por cortes da com ponente gramínea está expressa na Tabela 6 e representa a mé dia de 4 repetições.

A Figura 1 representa a variação anual da maté ria da componente gramínea, nas três densidades em estudo e re 
presenta a média de todos os cortes realizados.

$$
\begin{aligned}
& \text { 4.1.1.2. Porcentagem de matéria seca da compo } \\
& \text { nente leguminosa }
\end{aligned}
$$

A Tabela 7 mostra a porcentagem de matéria seca da componente leguminosa nos diferentes cortes realizados; en quanto que a Figura 2 mostra a variação na porcentagem média anual de matéria seca desta componente.

4.1.2. Produção Anual de Matéria Seca

4.1.2.1. Produção de matéria seca da componen te gramínea

A análise de variância dos dados obtidos para a produção anual de matéria seca da componente gramínea está con tida na Tabela 8. 0 valor de F obtido mostrou-se significativo para o efeito de blocos comprovando novamente a heterogeneida de da área. Embora a interação $P$ x $D$ não tenha se mostrado sig nificativa, os valores de F obtidos do desdobramento da intera ção mostrou-se significativo apenas para $\mathrm{D}$ dentro de $\mathrm{P}_{0}$, indi cando que, nesta proporção, a densidade de plantas usadas au mentou a produção anual de matéria seca da componente gramí nea.

A decomposição das $S Q$ dos efeitos mostrou (Tabe 
36.

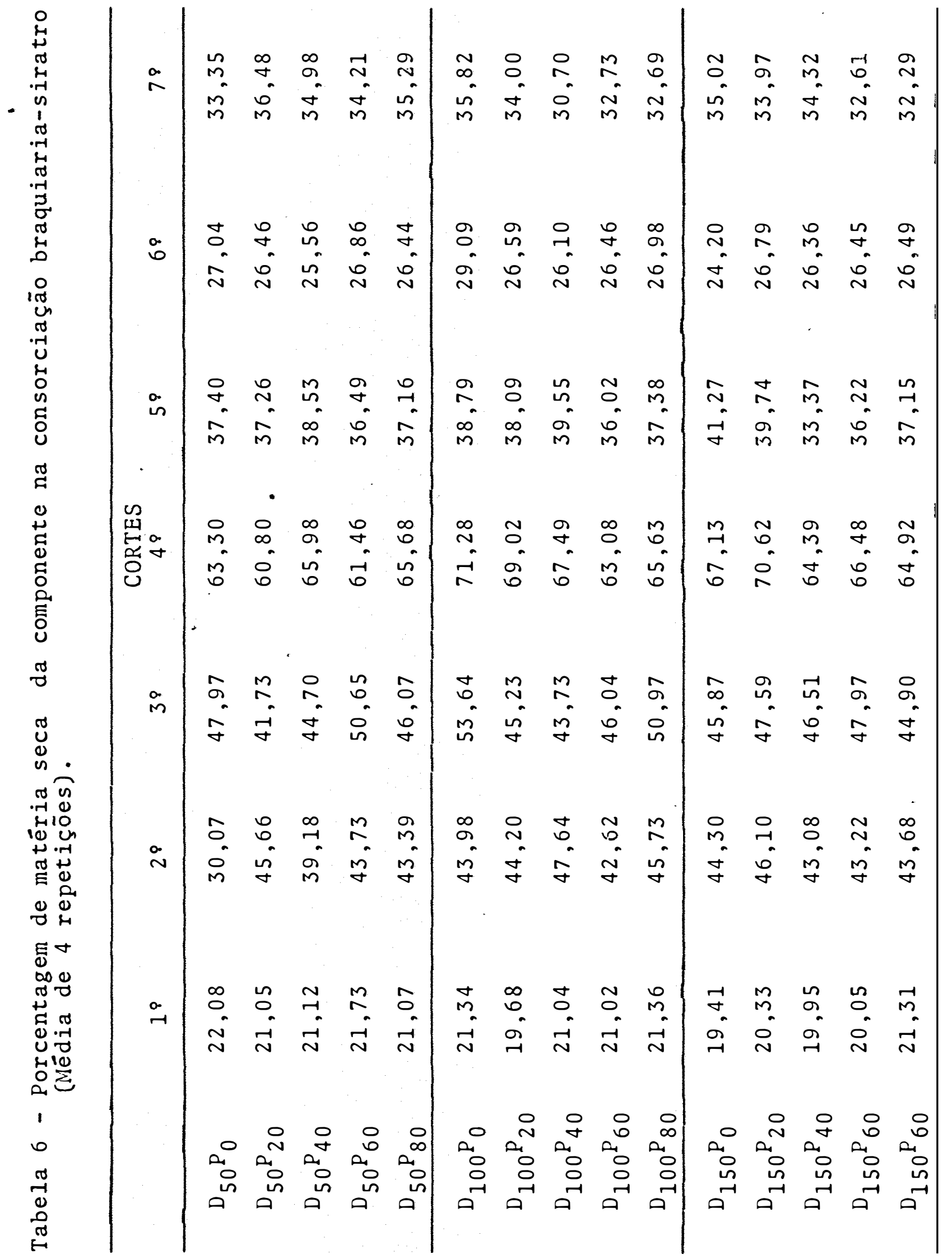




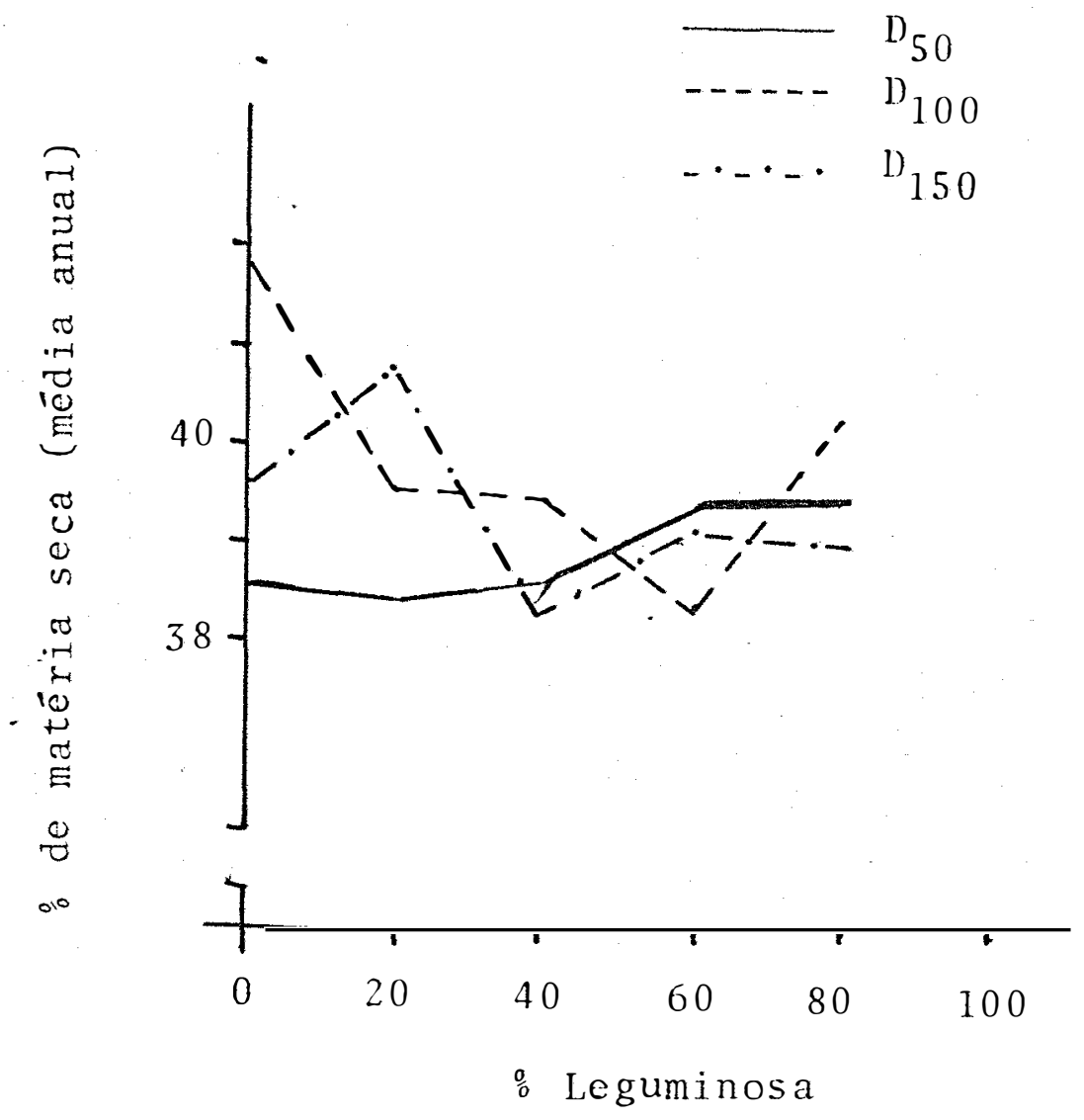

FIGURA 1 - Variação na porcentagem média anual de matêria seca da componente gramínea; na consorciação braquiariasiratro. (Média de 7 cortes). 
38.

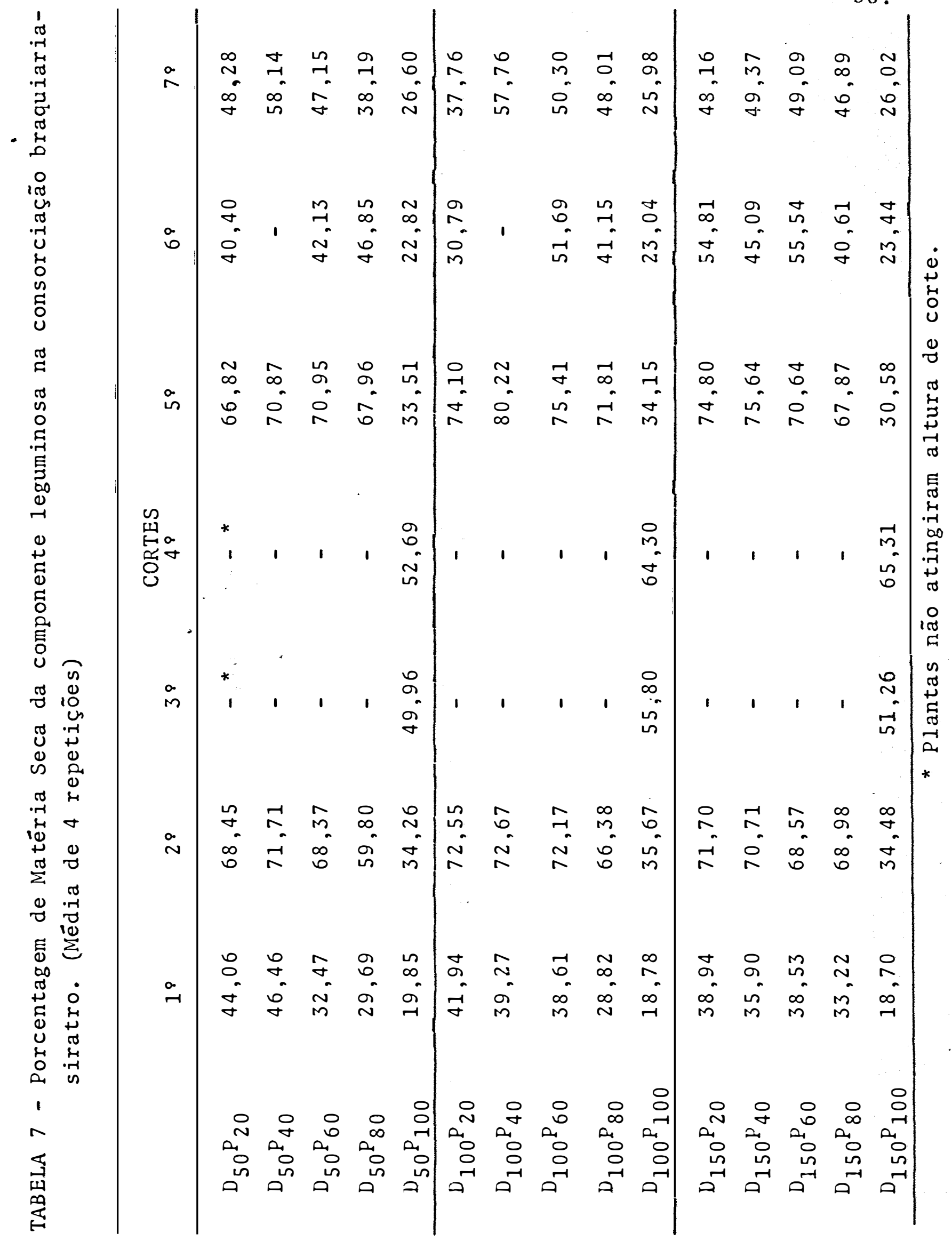




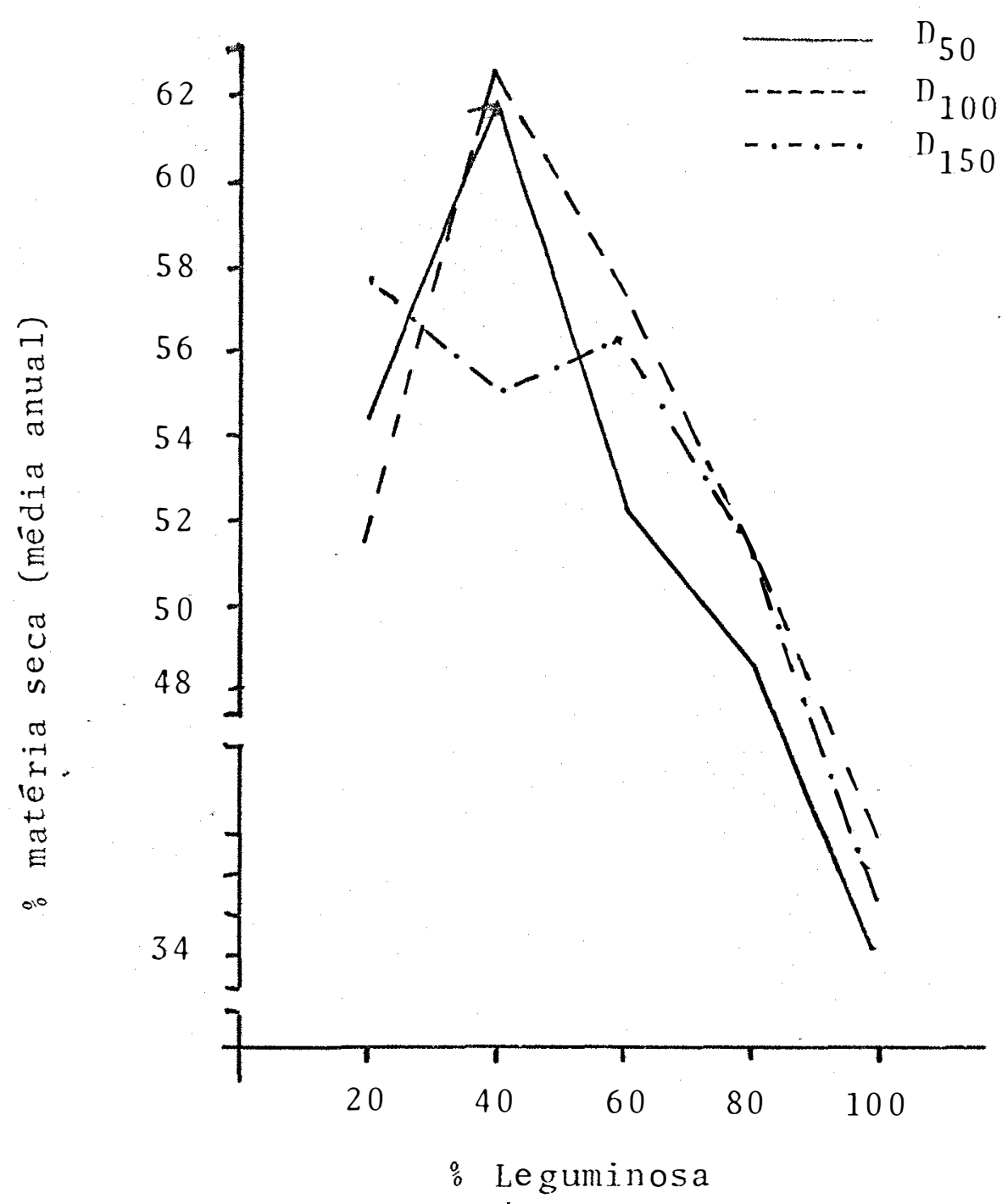

FIGURA 2 - Variação na porcentagem média anual de matéria seca da componente leguminosa na consorciação braquiaria -siratro. (Média de 7 cortes). 
la 8) que, para $\mathrm{P}$ dentro de $\mathrm{D}_{50}$, a curva de produção de maté ria seca da componente se ajusta à equação linear, com $\mathrm{R}^{2}$ de $95,32 \%$, enquanto que para $\mathrm{P}$ dentro $\mathrm{D}_{100}$ a componente quadrátí ca foi a que melhor se ajustou à produção anual de matéria se ca da componente graminea, sendo que $\circ \mathrm{R}^{2}$ equivalente foi de $90,52 \%$. Para D dentro $\mathrm{P}_{0}$ a equação da componente quadrática é a que melhor explica os dados obtidos, sendo que $O R^{2}$ foi de $93,59 \%$.

Pela Figura 3(a) observa-se que, para o efeito densidade, a produção de matéria seca da componente gramínea aumentou com o número de plantas, em concordância com AKINOLA (1981). Para D dentro de $\mathrm{P}_{0}$ observa-se uma queda no parâmetro em anälise, quando.elevou-se a densidade de 50 para 100 plan tas $/ \mathrm{m}^{2}$, entretanto, quando elevou-se a densidade para $150 \mathrm{plan}$ $\mathrm{tas} / \mathrm{m}^{2}$, a componente em estudo elevou sua produção anual de ma téria seca.

Para $\mathrm{P}, \mathrm{P}$ dentro $\mathrm{D}_{150}$ (Figura $3 . \mathrm{b}$ ), observa - se que, elevando-se a participação da leguminosa na mistura, obte ve-se uma queda linear na produção de matéria seca da componen te, e para $\mathrm{P}$ dentro $\mathrm{D}_{150}$ a produção de matéria seca aumentou até $\mathrm{P}_{40}$, passando, a partir desta, a declinar com aumentos na proporção gramínea-leguminosa.

As médias de densidades não se mostraram signifi cativas quando comparadas pelo teste de Tukey, sendo que com portamento semelhante foi observado para as médias de propor ções (Tabela 9). 
TABELA 8 - Anâlise de variância, desdobramento da interação $P \times D$, decomposição das $S Q$ dos efeitos e coeficien tes de determinação $\left(R^{2}\right)$ para a produção de matériá seca da componente gramínea ( $t / h a / a n o)$ na consorcia ção braquiaria-siratro.

\begin{tabular}{|c|c|c|c|}
\hline Causas de Variação & G.L. & Q.M. & $\mathrm{R}^{2}$ \\
\hline B1ocos & 3 & 140,420247 ** & \\
\hline Densidades (D) & 2 & 2,960838 & \\
\hline$L$ & 1 & 3,041 & 51,36 \\
\hline Q & 1 & 2,879 & 48,63 \\
\hline Residuo (a) & 6 & 9,935412 & \\
\hline Proporções (P) & 4 & 11,296428 & . \\
\hline$L$ & 1 & 36,223 & 80,16 \\
\hline Q & 1 & 6,517 & 14,42 \\
\hline$P \times D$ & 8 & 13,165887 & \\
\hline$P$ dentro $D_{50}$ & 4 & 21,332220 & \\
\hline $\mathrm{L}$ & 1 & 81,396 ** & 95,39 \\
\hline$Q$ & 1 & 1,524 & 1,28 \\
\hline$P$ dentro $D_{100}$ & 4 & 13,607442 & \\
\hline$L$ & 1 & 2,093 & 3,84 \\
\hline Q & 1 & $49,275^{*}$ & 90,52 \\
\hline$P$ dentro $D_{150}$ & 4 & 2,688531 & \\
\hline$L$ & 1 & 8,118 & 75,48 \\
\hline Q & 1 & 1,857 & 17,27 \\
\hline Resíduo & 36 & 9,893359 & \\
\hline
\end{tabular}


- Tabela 8 - continuação

\begin{tabular}{|c|c|c|c|}
\hline Causas de Variação & G.L. & Q.M. & $\mathrm{R}^{2}$ \\
\hline D dentro $\mathrm{P}_{0}$ & 2 & $33,029325^{*}$ & ${ }^{\prime}$ \\
\hline $\mathrm{L}$ & 1 & 4,234 & 6,40 \\
\hline Q & 1 & $61,824^{*}$ & 93,59 \\
\hline D dentro $P_{20}$ & 2 & 1,134698 & \\
\hline $\mathrm{L}$ & 1 & 0,00004 & 0,002 \\
\hline Q & 1 & 2,269 & 99,99 \\
\hline D dentro $\mathrm{P}_{40}$ & 2 & 4,028635 & \\
\hline $\mathrm{L}$ & 1 & 0,168 & 2,08 \\
\hline$\cdot$ & 1 & 7,889 & 97,91 \\
\hline D dentro $\mathrm{P}_{60}$ & 2 & 11,435010 & \\
\hline $\mathrm{L}$ & 1 & 9,159 & 40,04 \\
\hline$Q$ & 1 & 13,710 & 59,95 \\
\hline $\mathrm{D}$ dentro $\mathrm{P}_{80}$ & 2 & 5,996724 & \\
\hline $\mathrm{L}$ & 1 & 11,115 & 92,68 \\
\hline Q & 1 & 0,877 & 7,31 \\
\hline Resíduo & 31 & 9,901770 & \\
\hline
\end{tabular}


(a)
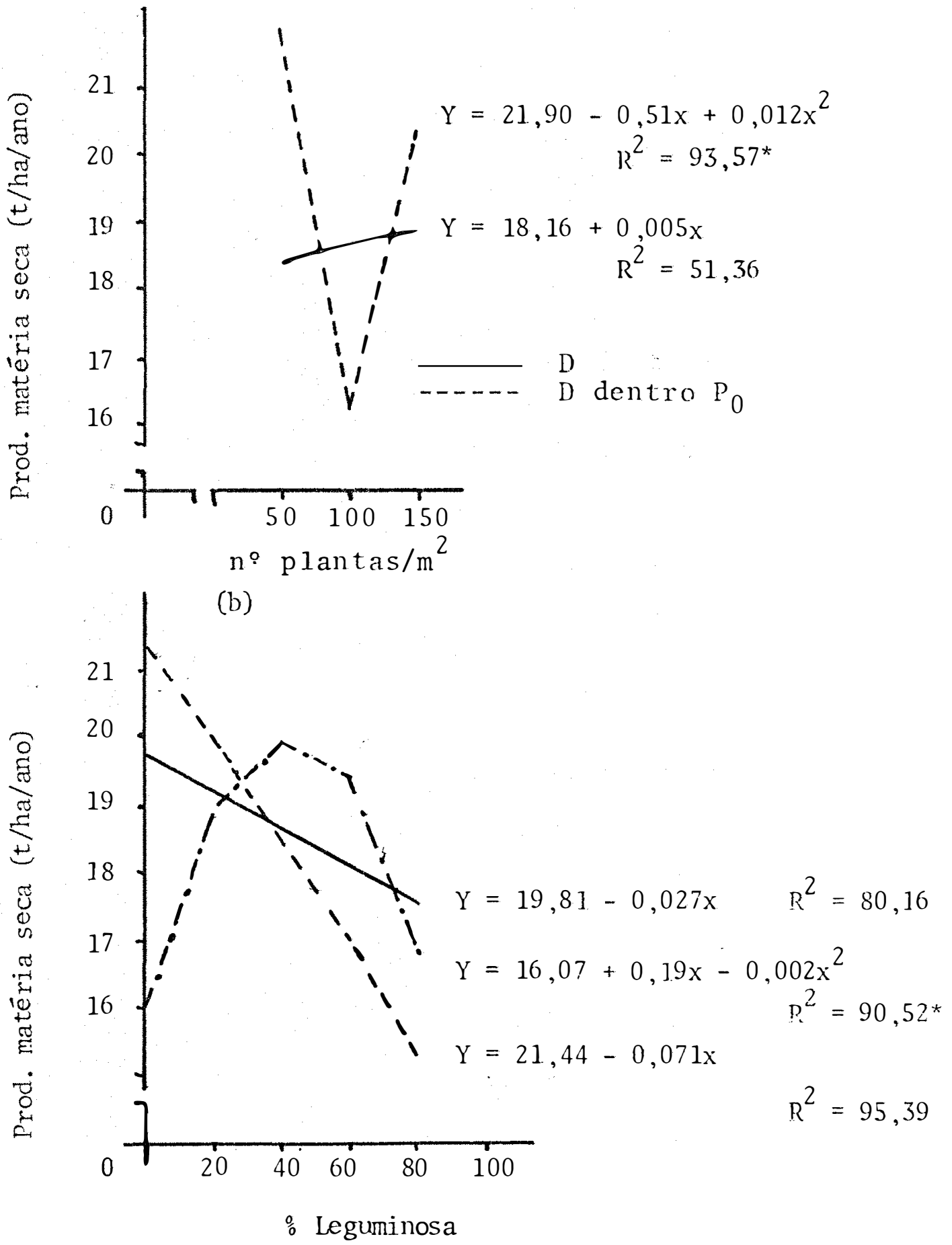

FIGURA 3 - Efeito da densidade de plantas (a) e produção gramí nea-leguminosa estabelecida (b) na produção de maté ria seca da componente graminea ( $t / h a / a n o)$ na coñ sorciaça braquiaria-siratro. 
TABELA 9 - Diferenças mínimas significativas para a comparação de médias, coeficientes de variação e equações de regressão usadas na análise de variância para a pro dução de matéria seca da componente graminea ( $t / h a /$ ano) na consorciação braquiaria-siratro (média de 4 repetições).

\begin{tabular}{|c|c|c|c|c|c|c|}
\hline \multirow[t]{2}{*}{ DENSIDADES } & & $\mathrm{D}_{50}$ & & $\mathrm{D}_{100}$ & & $\mathrm{D}_{150}$ \\
\hline & & $18,59 a$ & & $18,40 \mathrm{a}$ & & $19,14 a$ \\
\hline \multirow[t]{2}{*}{ PROPORC,OES } & & $\mathrm{P}_{0}$ & $\mathrm{P}_{20}$ & $\mathrm{P}_{40}$ & $\mathrm{P}_{60}$ & $\mathrm{P}_{80}$ \\
\hline & & $19,57 \mathrm{a}$ & $19,11 a$ & $19,24 a$ & $18,53 \mathrm{a}$ & $17,11 a$ \\
\hline \multirow[t]{3}{*}{ D.M.S. $(5 \%)$} & & & D & & $\mathrm{P}$ & \\
\hline & & & 3,05 & & 3,69 & \\
\hline & & & (a) & & (b) & \\
\hline \multirow[t]{2}{*}{ C.V. $\left(\begin{array}{l}0 \\
0\end{array}\right)^{*}$} & & & 16,84 & & 16,80 & \\
\hline & & \multicolumn{4}{|c|}{ EQUACOES DE REGRESSÃO } & $\mathrm{R}^{2}\left(\begin{array}{l}0 \\
0\end{array}\right)$ \\
\hline Densidades & $\mathrm{L}$ & \multicolumn{4}{|c|}{$Y=18,1+0,0055 x$} & 51,36 \\
\hline D dentro $\mathrm{P}_{0}$ & Q & \multicolumn{4}{|c|}{$Y=21,9-5,17 x+0,012 x^{2}$} & $93,59^{*}$ \\
\hline Proporções & $\mathrm{L}$ & \multicolumn{4}{|c|}{$Y=19,8-0,0119 x$} & 80,16 \\
\hline$P$ dentro $D_{50}$ & $\mathrm{~L}$ & \multicolumn{4}{|c|}{$Y=21,4-0,071 x$} & $95,39^{*}$ \\
\hline$P$ dentro $D_{100}$ & Q & \multicolumn{4}{|c|}{$Y=16,07+0,19 x-0,0023 x^{2}$} & $90,52^{*}$ \\
\hline
\end{tabular}


As produções mëdias encontradas variaram de 18,59 t/ha/ano em $D_{50}$, a 19,14 t/ha/ano em $D_{150}$, enquanto que para proporções as produções variaram de $19,57 \mathrm{t} / \mathrm{ha} / \mathrm{ano}$ en $\mathrm{P}_{0}$ a $17,11 \mathrm{t} / \mathrm{ha} /$ ano em $\mathrm{P}_{80}$. As produções encontradas foram superio res às citadas pela EMBRAPA (1981c) para a Brachiaria humidico Ia (2,955 t/ha/ano), para a Brachiaria decumbens australiana (4,435 t/ha/ano) e para Brachiaria ruziziensis (3,61 t/ha/ano), e as citadas por SERRÃO e SIMAOO NETO (1971) (1-2 t/ha/ano); e BULLER et alii (1972) (6-7 t/ha/ano); mas mostraram-se seme lhantes às produções de matéria seca encontradas por WINTER et alii (1977) (18-20 t/ha/ano).

\subsubsection{Produção de matéria seca da componente leguminosa}

A anālise de variância dos dados obtidos para a produção anual de matéria seca da componente leguminosa está contida na Tabela 10. O valor F encontrado mostrou-se signifi cativo para proporções, indicando que a produção da matéria se ca da componente em estudo foi afetada pela proporção gramínea -leguminosa estabelecida.

No desdobramento da interação $\mathrm{P} \times \mathrm{D}$, os valores de $F$ mostraram-se significativos para $\mathrm{P}$ dentro $\mathrm{D}_{50}$, $\mathrm{P}$ dentro $\mathrm{D}_{100}$ e $\mathrm{P}$ dentro $\mathrm{D}_{150}$, mostrando que nas três densidades em es tudo a proporção gramínea-leguminosa estabelecida afetou a pro dução anual de matéria seca da componente leguminosa. 
TABELA 10 - Anâlise de variância, desdobramento da interação $P \times D$, decomposição da SQ dos efeitos, coeficientes de determinação $\left(R^{2}\right)$ para a produção de matê ria seca da componente leguminosa ( $t / h a / a n o$ ) na consorciação braquiaria-siratro.

\begin{tabular}{|c|c|c|c|}
\hline Causas de Variação & G.L. & Q.M. & $\mathrm{R}^{2}$ \\
\hline Blocos & 3 & 0,663616 & \\
\hline Densidades (D) & 2 & 0,813331 & \\
\hline $\mathrm{L}$ & 1 & 0,0079 & 0,44 \\
\hline Q & 1 & 1,6193 & 99,44 \\
\hline Resíduo (a) & 6 & 0,697405 & \\
\hline Proporções (P) & 4 & $358,381218^{* *}$ & \\
\hline $\mathrm{L}$ & 1 & $771,5500 * *$ & 53,82 \\
\hline$Q$ & 1 & $488,2400 * *$ & 34,05 \\
\hline $\mathrm{P} \times \mathrm{D}$ & 8 & 0,528443 & \\
\hline$P$ dentro $D_{50}$ & 4 & $116,211492^{\star *}$ & \\
\hline $\mathrm{L}$ & 1 & $266,5100 * *$ & 57,33 \\
\hline Q & 1 & 150,9700 * & 32,47 \\
\hline P dentro $D_{100}$ & 4 & $108,924412^{* *}$ & \\
\hline $\mathrm{L}$ & 1 & $233,040 * *$ & 53,48 \\
\hline Q & 1 & 149,600 * & 34,33 \\
\hline$P$ dentro $D_{150}$ & 4 & $134,302199^{*}$ & \\
\hline $\mathrm{L}$ & 1 & $272,900 * *$ & 50,79 \\
\hline Q & 1 & $189,150^{* *}$ & 35,21 \\
\hline Resíduo & 36 & 1,175644 & \\
\hline
\end{tabular}


Tabela 10 - continuação.

\begin{tabular}{|c|c|c|c|}
\hline Causas de Variação & G.L. & $Q \cdot M$ & $\mathrm{R}^{2}$ \\
\hline D dentro $P_{20}$ & 2 & 0,032025 & \\
\hline $\mathrm{L}$ & 1 & 0,0040 & 6,32 \\
\hline Q & 1 & 0,0600 & 93,67 \\
\hline D dentro $\mathrm{P}_{40}$ & 2 & 0,063074 & \\
\hline $\mathrm{L}$ & 1 & 0,0946 & 75,00 \\
\hline Q & 1 & 0,0315 & 25,00 \\
\hline D dentro $\mathrm{P}_{60}$ & 2 & 0,165658 & \\
\hline $\mathrm{L}$ & 1 & 0,1596 & 48,17 \\
\hline Q & 1 & 0,1717 & 51,82 \\
\hline D dentro $\mathrm{P}_{80}$ & 2 & 0,780033 & \\
\hline $\mathrm{L}$ & 1 & 1,4280 & 91,53 \\
\hline Q & 1 & 0,1320 & 8,46 \\
\hline D dentro $\mathrm{P}_{100}$ & 2 & 1,886310 & . \\
\hline $\mathrm{L}$ & 1 & 1,0657 & 28,25 \\
\hline Q & 1 & 2,7088 & 71,74 \\
\hline Resíduo & 42 & 1,079996 & \\
\hline
\end{tabular}


A decomposição da SQ de proporções mostra que a componente linear e quadrática foram significativas, com $\mathrm{R}^{2}$ de $53,82 \%$ (linear) e $34,05^{\circ}$ (quadrätica), enquanto que na decompo sição da $S Q$ do desdobramento da interação observa-se que para $\mathrm{P}$ dentro $\mathrm{D}_{50}$ mostraram-se significativas as componentes linear e quadrática, com $\mathrm{R}^{2}$ de $57,33 \%$ e $33,47 \%$, respectivamente.

Para P dentro $D_{100}$ as componentes linear $\left(R^{2}\right.$ de $53,48 \%$ ) e quadrática $\left(R^{2}\right.$ de $\left.34,33 \%\right)$, se mostraram significatí vas, enquanto que para $P$ dentro $D_{150}$ também as componentes $1 \underline{i}$ near e quadrätica foram significativas, sendo que os $\mathrm{R}^{2}$ foram, respectivamente, de 50,79\% (1inear) e 35,21\% (quadrática).

Na Figura 4(a) tem-se o efeito da densidade de plantas na produção de matéria seca da componente leguminosa, onde observa-se que, à medida que aumenta-se a densidade de 50 para $100 \mathrm{plantas} / \mathrm{m}^{2}$, diminui-se a produção de matéria seca da componente leguminosa, entretanto, esta produção aumenta na densidade $150 \mathrm{plantas} / \mathrm{m}^{2}$. Na Figura $4(\mathrm{~b})$ tem-se o efeito da proporção gramínea-leguminosa na produção de matéria seca da componente leguminosa, onde observa-se que $\mathrm{P}$ dentro $\mathrm{D}_{50}, \mathrm{P}$ den tro $\mathrm{D}_{100}$ e $\mathrm{P}$ dentro $\mathrm{D}_{150}$ apresentam uma tendência de mesmo com portamento, ou seja, a produção de matéria seca da componente leguminosa não variou estatisticamente nas proporções estabele cidas, exceção à $\mathrm{P}_{100}$ onde estes valores foram elevados.

A comparação das médias de densidades pelo teste de Tukey mostrou-se não significativa, enquanto que para as mé dias de proporções apenas $\mathrm{P}_{100}(13,52 \mathrm{t} / \mathrm{ha} / \mathrm{ano})$ diferiu signi 


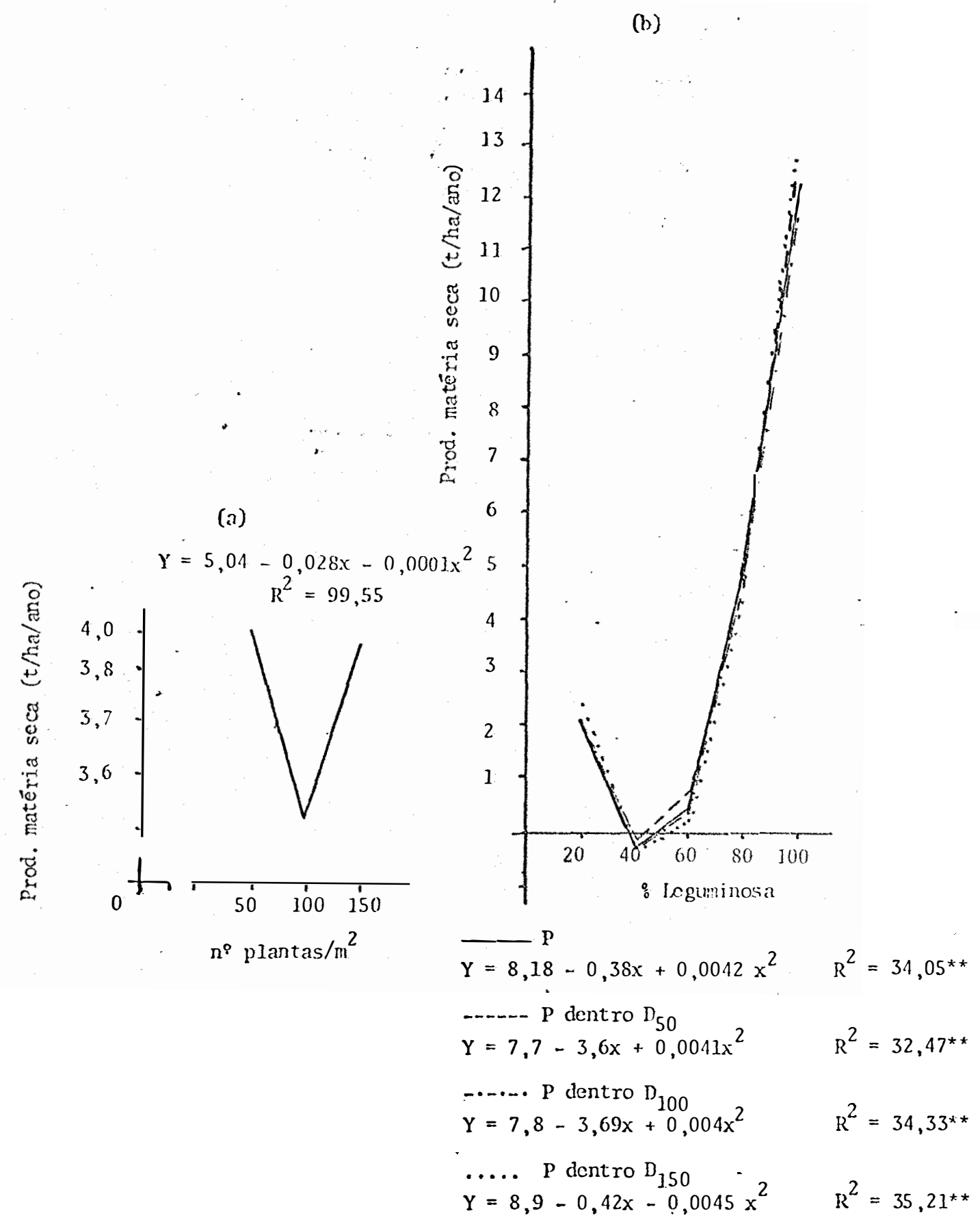

FIGURA 4 - Efeito da densidade de plantas (a) e da proporção graminea-leguminosa estabelecida (b) na produção de matéria seca da componente leguminosa ( $t / h a / a n o) ~ n a$ consorciação braquiaria-siratro. 
ficativamente $(P<0,05)$ das demais médias, sendo que as de mais comparações entre as médias mostraram-se não significatí vas (Tabela 11).

Para o efeito densidade, a variação na produção de matéria seca da componente leguminosa foi de 3,98 t/ha/ano $\left(D_{50}\right)$ a 3,95 t/ha/ano $\left(D_{150}\right)$, enquanto que para o efeito pro porção a variação foi de 1,24 t/ha/ano para $\mathrm{P}_{20}$ e 13,62 t/ha/ ano para $\mathrm{P}_{100}$. As produções médias das densidades foram supe riores à encontrada por NG (1976) na consorciação braquiariacentrosema com 2,35 t/ha/ano e a encontrada por AKINOLA (1981) na consorciação braquiaria-siratro com 2,01 t/ha/ano para a produção de matéria seca da componente leguminosa e inferior à encotnrada pelo mesmo autor com a consorciação braquiaria- sty losanthes $(4,6$ t/ha/ano $)$.

As produções médias das proporções foram máximas em $\mathrm{P}_{100}$, sendo que nesta proporção as produções de matéria se ca da componente leguminosa $(13,62 \mathrm{t} / \mathrm{ha} / \mathrm{ano})$ foram superiores às encontradas por MATTOS (1977) com 5,0 - 6,0 t/ha/ano; RAY MENT et alii (1977), com 3,54 t/ha/ano; TOSI et alii (1979), com 4,4 e 1,9 t/ha/ano; MONTEIRO et alii (1980) com 0,99 e $1,876 \mathrm{t} / \mathrm{ha} / \mathrm{ano}$. 
TABELA 11 - Diferenças mínimas significativas para a compara ção de médias; coeficiente de variação e equações de regressão usadas na análise de variância da pro dução de matêria seca da componente leguminosa ( $t /$ /ha/ano) na consorciação braquiaria-siratro (mêdia de 4 repetições).

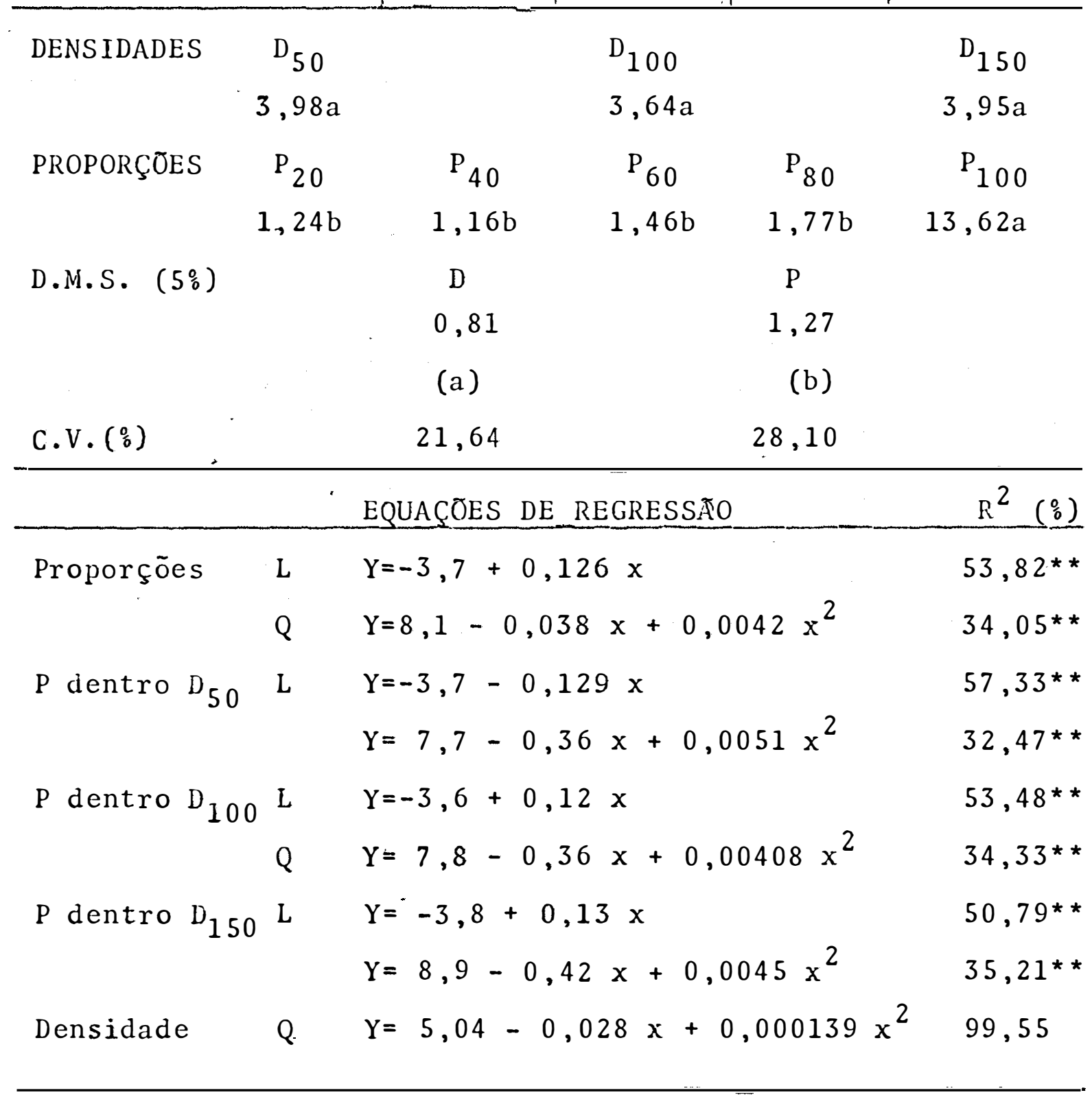


4.1.2.3. Produção conjunta de matéria seca na consorciação braquiaria-siratro

A Tabela 12 contem a análise de variância dos da dos obtidos para a produção conjunta de matéria seca na consor ciação braquiaria-siratro. Os valores de F mostraram-se signi ficativos para blocos, o que indica heterogeneidade na ärea experimental, e para proporções, que indica que o parâmetro em análise foi afetado pela proporção gramínea-leguminosa estabe lecida .

0 desdobramento da interação $\mathrm{P} \times \mathrm{D}$ revelou, at ra vês dos valores de $\mathrm{F}$, significância para $\mathrm{P}$ dentro $\mathrm{D}_{50}, \mathrm{P}$ den tro $\mathrm{D}_{100}$, $\mathrm{P}$ dentro, $\mathrm{D}_{150}$ e para $\mathrm{D}$ dentro $\mathrm{P}_{0}$, evidenciando que nas três densidades o parâmetro em análise foi afetado pelapro porção gramínea-leguminosa, e que em $\mathrm{P}_{0} \circ$ parâmetro em añálise foi afetado pela densidade de plantas em estudo.

A decomposição de $S Q$ de proporções mostra que a componente linear e quadrática se mostram significativas, com $\mathrm{R}^{2}$ de 50,69\% (1inear) e 42,79\% (quadrática), enquanto que para densidades a decomposição de SQ foi não significativa. Para o desdobramento da interação, a decomposição da SQ de $P$ dentro D a componente linear se mostrou significativa para $\mathrm{P}$ dentro $\mathrm{D}_{50}$ e $\mathrm{P}$ dentro $\mathrm{D}_{150}$, sendo que os $\mathrm{R}^{2}$ foram, respectivamente, $85,11 \%$ e $50,39 \%$; e para $\mathrm{P}$ dentro $\mathrm{D}_{100}$ a componente quadrática é que se mostrou significante, com $\mathrm{R}^{2}$ de $86,65^{\circ}$.

$\mathrm{Na}$ Figura 5(a) tem-se o efeito da densidade de 
QUADRO 12 - Anālise de variância, desdobramento da interação $P \times D$, decomposição das $S Q$ dos efeitos, coeficien tes de determinação $\left(R^{2}\right)$ para a produção conjunta de matéria seca ( $t /$ ha/ano) na consorciação bra quiaria-siratro.

\begin{tabular}{|c|c|c|c|}
\hline Causas de Variação & G.L. & Q.M. & $\mathrm{R}^{2}$ \\
\hline Blocos & 3 & $131,384500^{* *}$ & \\
\hline Densidades (D) & 2 & 5,373596 & \\
\hline $\mathrm{L}$ & 1 & 2,5576 & 23,79 \\
\hline Q & 1 & 8,1891 & 76,20 \\
\hline Resíduo (a) & 6 & 10,382130 & \\
\hline Proporções (P) & 5 & 81,517636 * * & \\
\hline $\mathrm{L}$ & 1 & $206,6300 * *$ & 50,69 \\
\hline Q & 1 & 174,41100 ** & 42,79 \\
\hline$P \times D$ & 10 & 9,291352 & \\
\hline$P$ dentro $D_{50}$ & 5 & 33,509707 * * & \\
\hline $\mathrm{L}$ & 1 & $142,6100 * *$ & 85,11 \\
\hline Q & 1 & 10,5220 & 6,28 \\
\hline $\mathrm{P}$ dentro $\mathrm{D}_{100}$ & 5 & $42,551655^{* *}$ & \\
\hline$-\mathrm{L}$ & 1 & 26,7590 & 12,57 \\
\hline Q & 1. & $184,3600 * *$ & 86,65 \\
\hline$P$ dentro $D_{150}$ & 5 & $24,038955^{*}$ & \\
\hline $\mathrm{L}$ & 1 & $60,5700^{*}$ & 50,39 \\
\hline Q & 1 & 36,6360 & 30,48 \\
\hline Resíduo & 45 & 9,099307 & \\
\hline D dentro $\mathrm{P}_{0}$ & 2 & $32,168699^{*}$ & \\
\hline $\mathrm{L}$ & 1 & 4,2340 & 6,58 \\
\hline Q & 1 & $60,1030^{*}$ & 93,41 \\
\hline
\end{tabular}


Tabela 12 - Continuação.

\begin{tabular}{|c|c|c|c|}
\hline Causas de Variação & G.L. & Q.M. & $\mathrm{R}^{2}$ \\
\hline D dentro $\mathrm{P}_{0}$ & 2 & $32,168699 *$ & \\
\hline $\mathrm{L}$ & 1 & 4,2340 & 6,38 \\
\hline Q & 1 & $60,1030^{*}$ & 93,41 \\
\hline D dentro $\mathrm{P}_{20}$ & 2 & 1,754610 & \\
\hline $\mathrm{L}$ & 1 & 0,0055 & 0,15 \\
\hline Q & 1 & 3,5037 & 99,84 \\
\hline D dentro $\mathrm{P}_{40}$ & 2 & 3,471778 & \\
\hline $\mathrm{L}$ & 1 & 0,0097 & 0,14 \\
\hline Q & 1 & 6,9337 & 99,85 \\
\hline D dentro $\mathrm{P}_{60}$ & 2 & 9,013656 & \\
\hline $\mathrm{L}$ & 1 & 7,9003 & 43,82 \\
\hline Q & 1 & 10,1270 & 56,17 \\
\hline D dentro $\mathrm{P}_{80}$ & 2 & 3,535301 & \\
\hline $\mathrm{L}$ & 1 & 4,6512 & 65,78 \\
\hline Q & 1 & 2,4193 & 34,21 \\
\hline D dentro $\mathrm{P}_{100}$ & 2 & 1,886310 & $\cdot$ \\
\hline $\mathrm{L}$ & 1 & 1,0657 & 28,25 \\
\hline Q & 1 & 2,7068 & 71,74 \\
\hline Resíduo & 49 & 9,313111 & \\
\hline
\end{tabular}


plantas na produção conjunta de matéria seca da consorciação braquiaria-siratro, onde observa-se uma queda na produção com o aumento na densidade de 50 para 100 plantas $/ \mathrm{m}^{2}$, elevou-se pa ra valores superiores aos obtidos com a densidade 50 plantas/ $\mathrm{m}^{2}$.

$\mathrm{Na}$ Figura 5 (b) tem-se o efeito das proporções na produção conjunta de matéria seca. Para a média das proporções e para $\mathrm{P}$ dentro $\mathrm{D}_{100}$ a produção de matéria seca aumenta até $\mathrm{P}_{40}$ passando a declinar a partir desta proporção, em concordân cia com CORBEA e MARTINES (1980) e RICKERT e HUMPHREYS (1970), que aumentaram a produção de matéria seca com aumentos na den sidade de plantas atê determinado ponto, sendo que, a partir deste, à medida que aumentou-se a densidade, diminuiu-se a pro dução de matéria seca. Para as densidades de 50 e 100 plantas/ $\mathrm{m}^{2}$, a queda de produção de matéria seca com o aumento na dens $\underline{i}$ dade de plantas foi linear.

A comparação das médias pelo teste de Tukey reve la que as médias de densidades não diferiram significativamente $(P<0,05)$, quando comparadas entre si, e que para as mé dias de proporções, enquanto que as demais médias não diferi ram quando comparadas entre si (Tabela 13).

As proporções encontradas para as densidades va riaram entre $18,81 \mathrm{t} / \mathrm{ha} /$ ano $\left(\mathrm{D}_{50}\right)$ e $19,28 \mathrm{t} / \mathrm{ha} / \mathrm{ano}\left(\mathrm{D}_{150}\right)$ e foram superiores às citadas pela EMBRAPA (1981c), que foi de 4,32 t/ha/ano na consorciação brachiaria humidicola- stylosan thes, 5,32 t/ha/ano na brachiaria decumbens australiana-stylo santhes, e de 6,55 t/ha/ano na consorciação brachiaria ruzi 

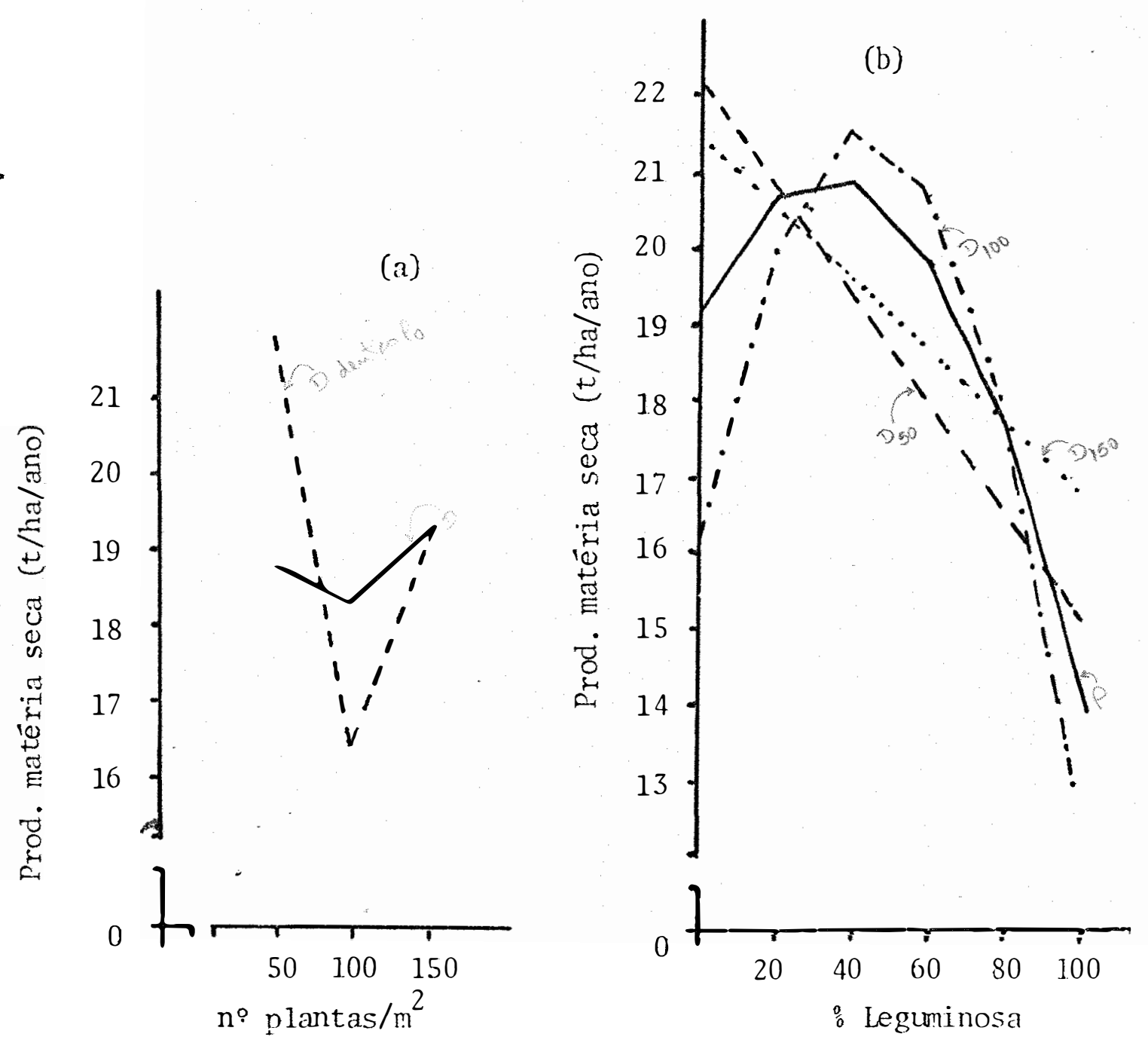

$$
\begin{aligned}
& \begin{array}{l}
\mathrm{D}=20,33-0,052 x+0,0002 x^{2} \quad P \quad P \\
Y=19,21+0,106 x-0,0015 x^{2} \quad P^{2}=42,79 * *
\end{array} \\
& \mathrm{R}^{2}=76,20 \quad \mathrm{Y}=22,3-0,071 \mathrm{x} \quad \mathrm{R}^{2}=85,11^{* *} \\
& Y=2,19-0,51 x+0,011 x^{2} \\
& \mathrm{R}^{2}=93,41^{*} \\
& Y=16,17+0,24 x-0,0027 x^{2} \quad R^{2}=86,65^{* *} \\
& Y=21,6-0,046 x \quad R^{2}=50,39 *
\end{aligned}
$$

FIGURA 5 - Efeito da densidade de plantas (a) e da proporção gramínea-leguminosa estabelecida (b) na produção conjunta de matéria seca ( $t / h a / a n o)$ na consorcia ção brachiaria-siratro. 
TABELA 13 - Diferenças minimas significativas para a comparação de médias, coeficientes de variação e equa ções de regressão usadas na anälise de variância para a produção conjunta de matêria seca ( $t / h a /$ ano) na consorciação brachiaria-siratro (mêdia de 4 repetiçães).

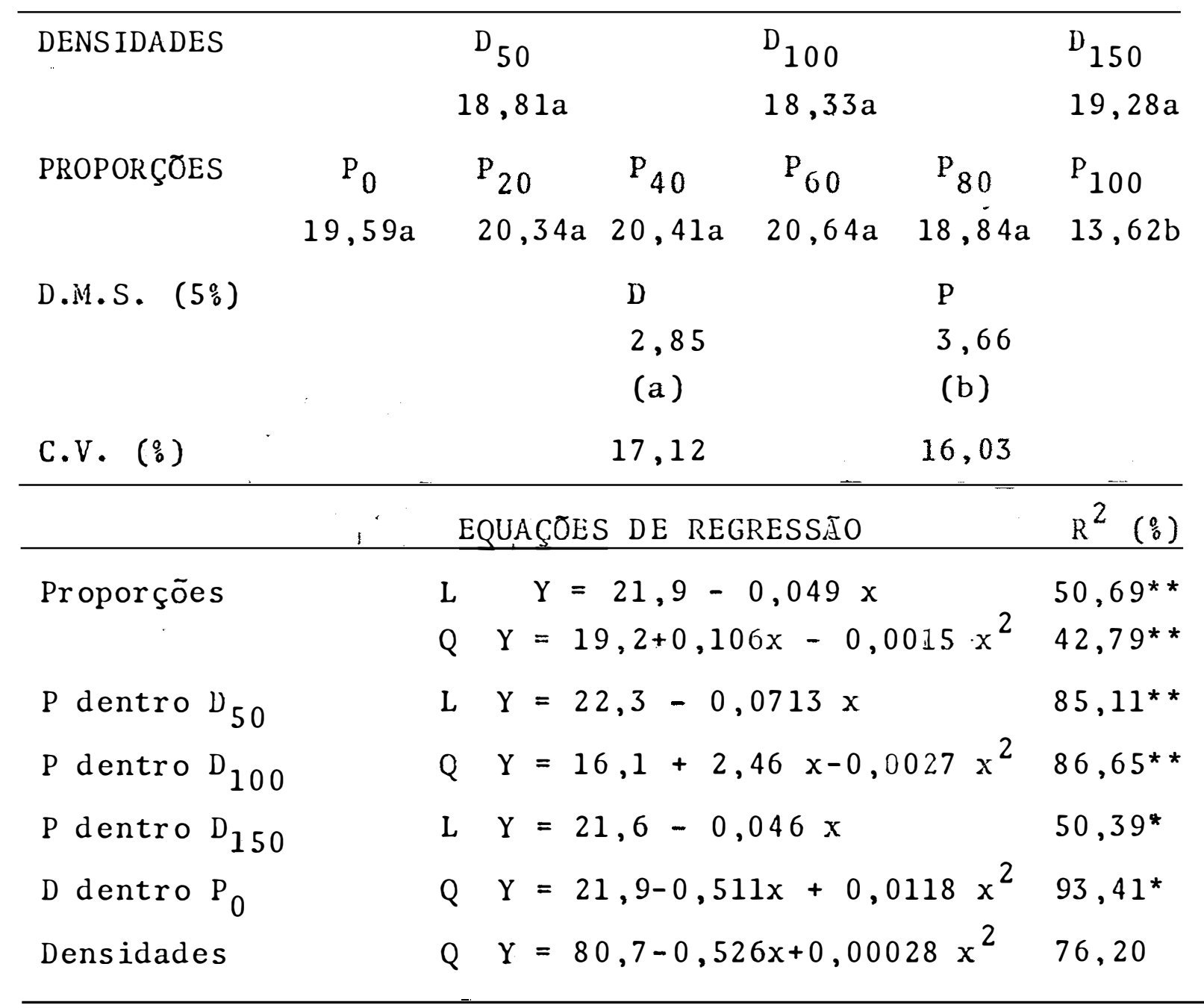


ziensis-stylosanthes, e ainda se mostraram superiores à produ ção de matéria seca encontrada por AKINOLA (1981), com produ ções de 6,5 t/ha/ano para a consorciação brachiaria-siratro.

As produções encontradas ainda superaram as en contradas por NG (1976) na consorciação brachiaria-centrosema, com 14,41 t/ha/ano, e na consorciação brachiaria-styloșanthes, com 16,0 t/ha/ano.

\subsubsection{Teor de Proteína Bruta}

4.1.3.1. Teor de proteína bruta da componente graminea

Os teores de proteína bruta da componente gramí nea (média de 4 repetições) nos 7 cortes realizados, estão con tidos na Tabela 14.

A Figura 6 representa a variação média anual de proteína bruta da componente gramínea (média de todos os cor tes realizados) para as três densidades em estudo.

4.1.3.2. Teor de proteína bruta da componente leguminos a

A Tabela 15 contem os teores de proteína bruta da componente leguminosa nos diferentes cortes realizados, en quanto que a Figura 7 representa a variação média anual do 


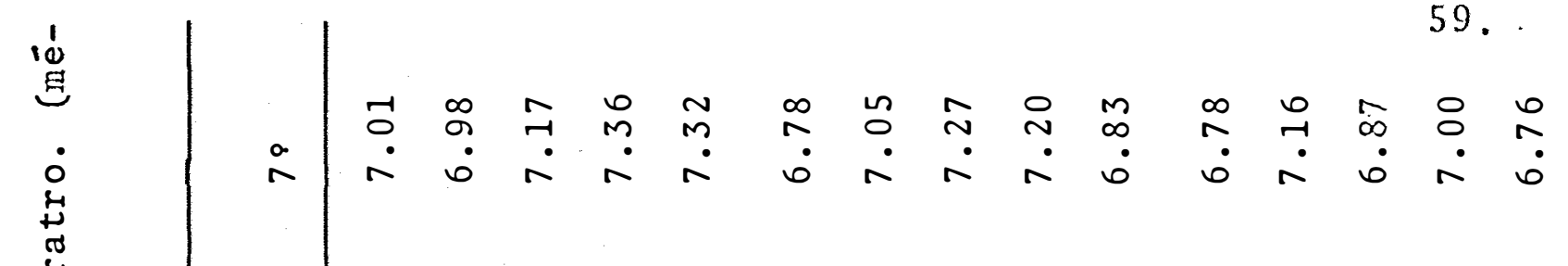

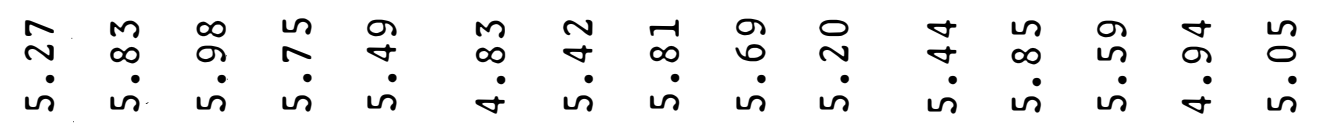

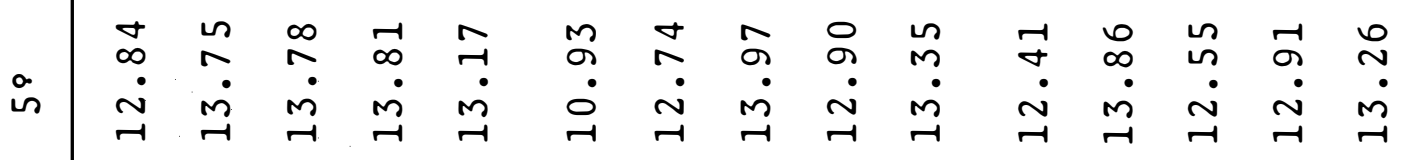

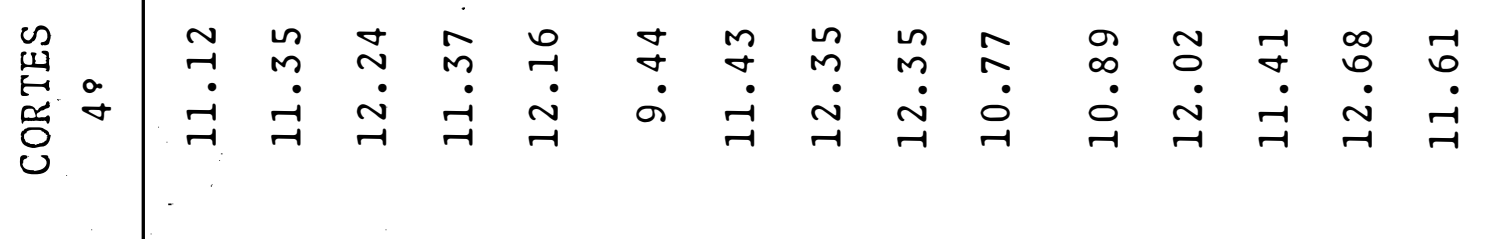

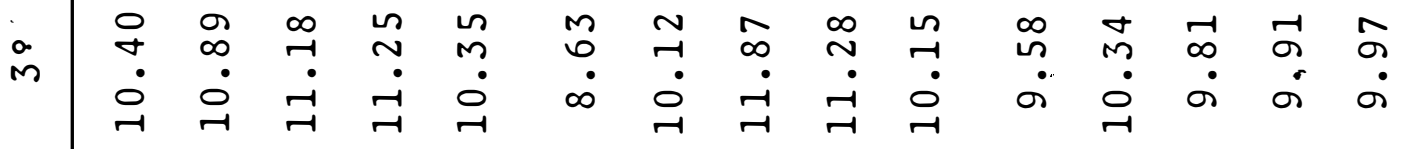

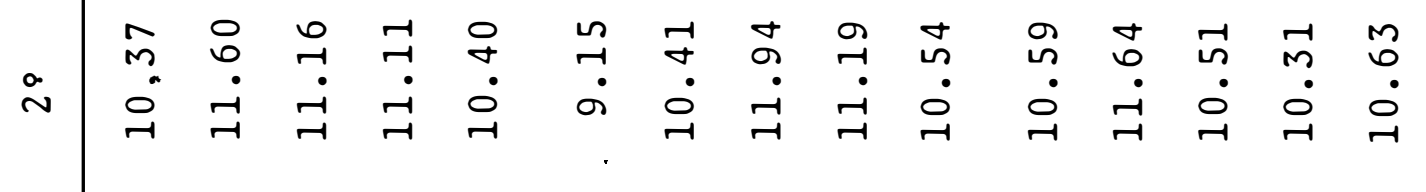

$$
\begin{aligned}
& \text { in }
\end{aligned}
$$

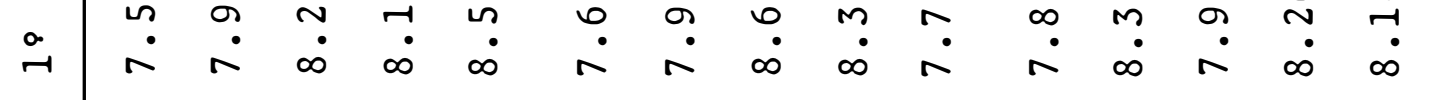

$$
\begin{aligned}
& \stackrel{\leftrightarrow}{\circ} \stackrel{0}{\infty} \\
& \text { 崖 }
\end{aligned}
$$

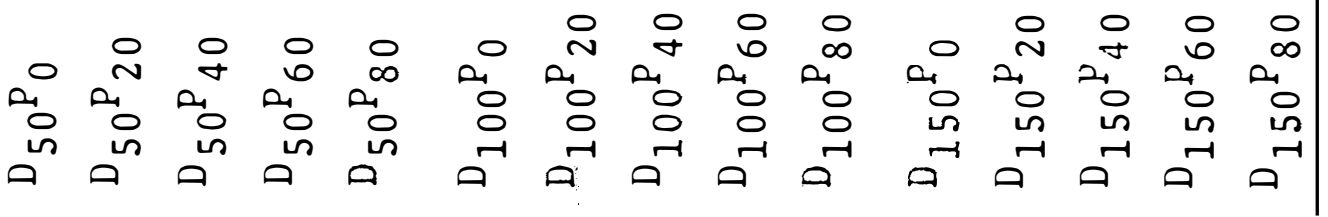




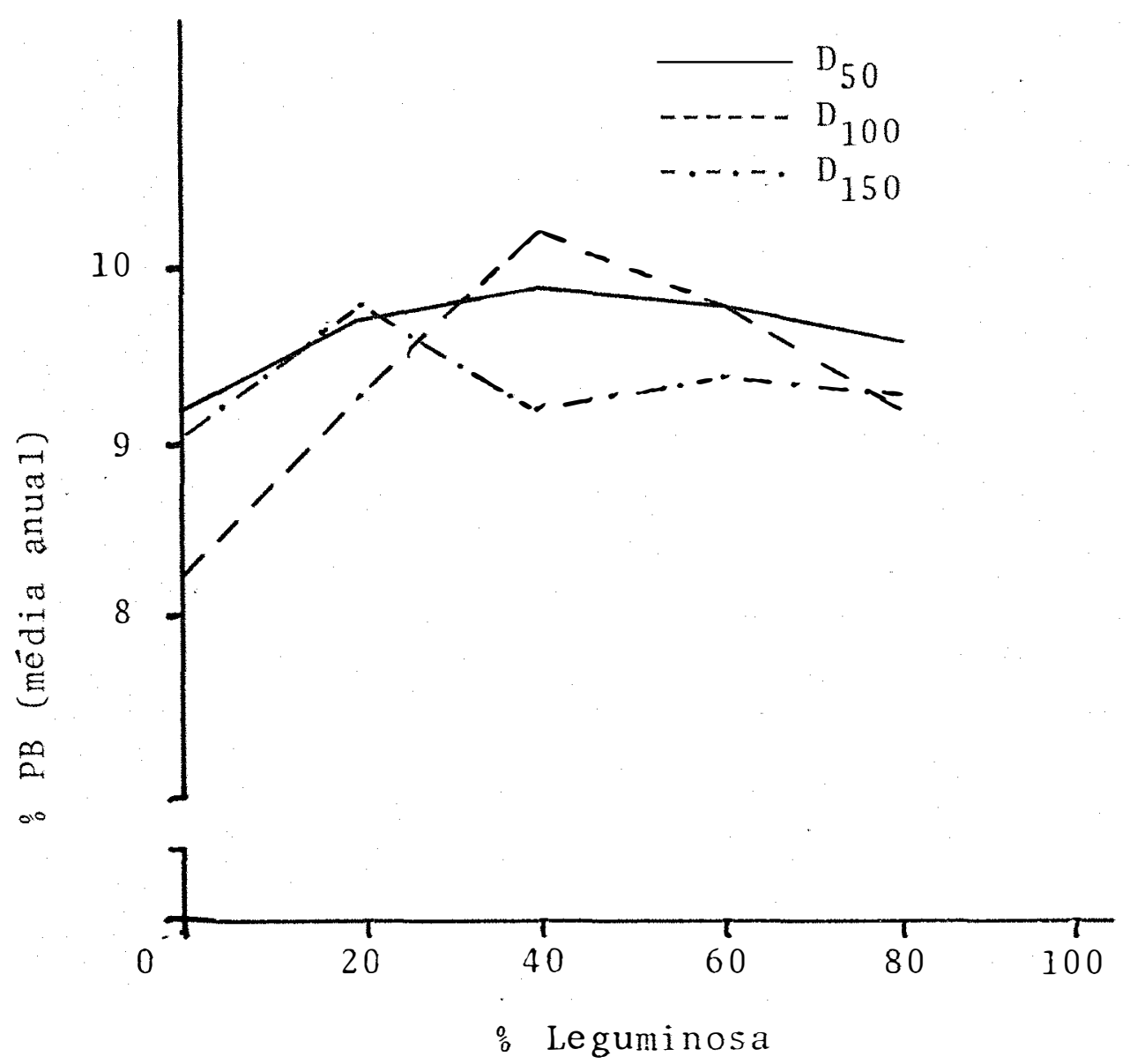

FIGURA 6 - Variação no teor médio anual de proteína bruta da componente gramínea na consorciação braquiaria-sira tro (média de 7 cortes). 


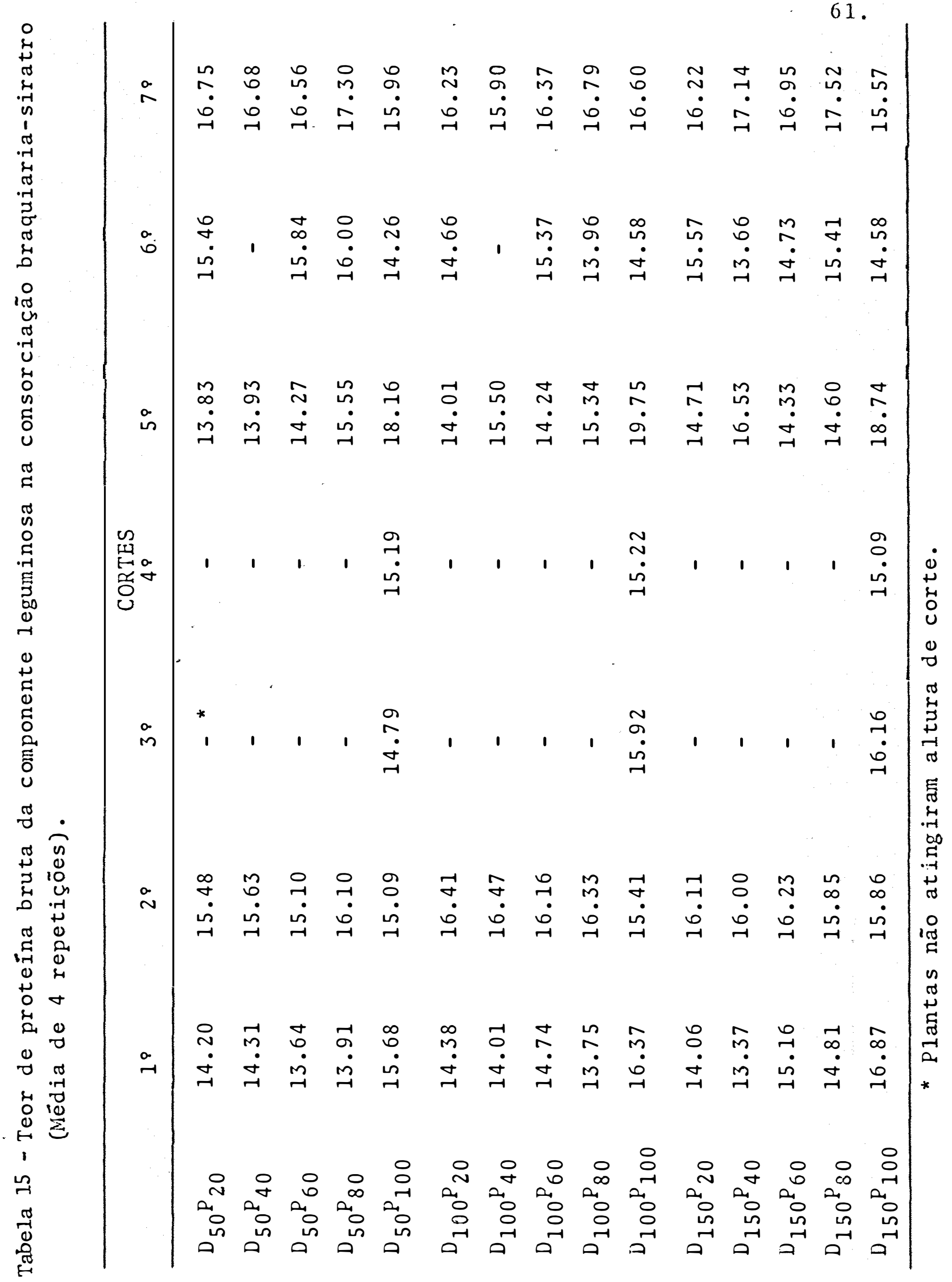




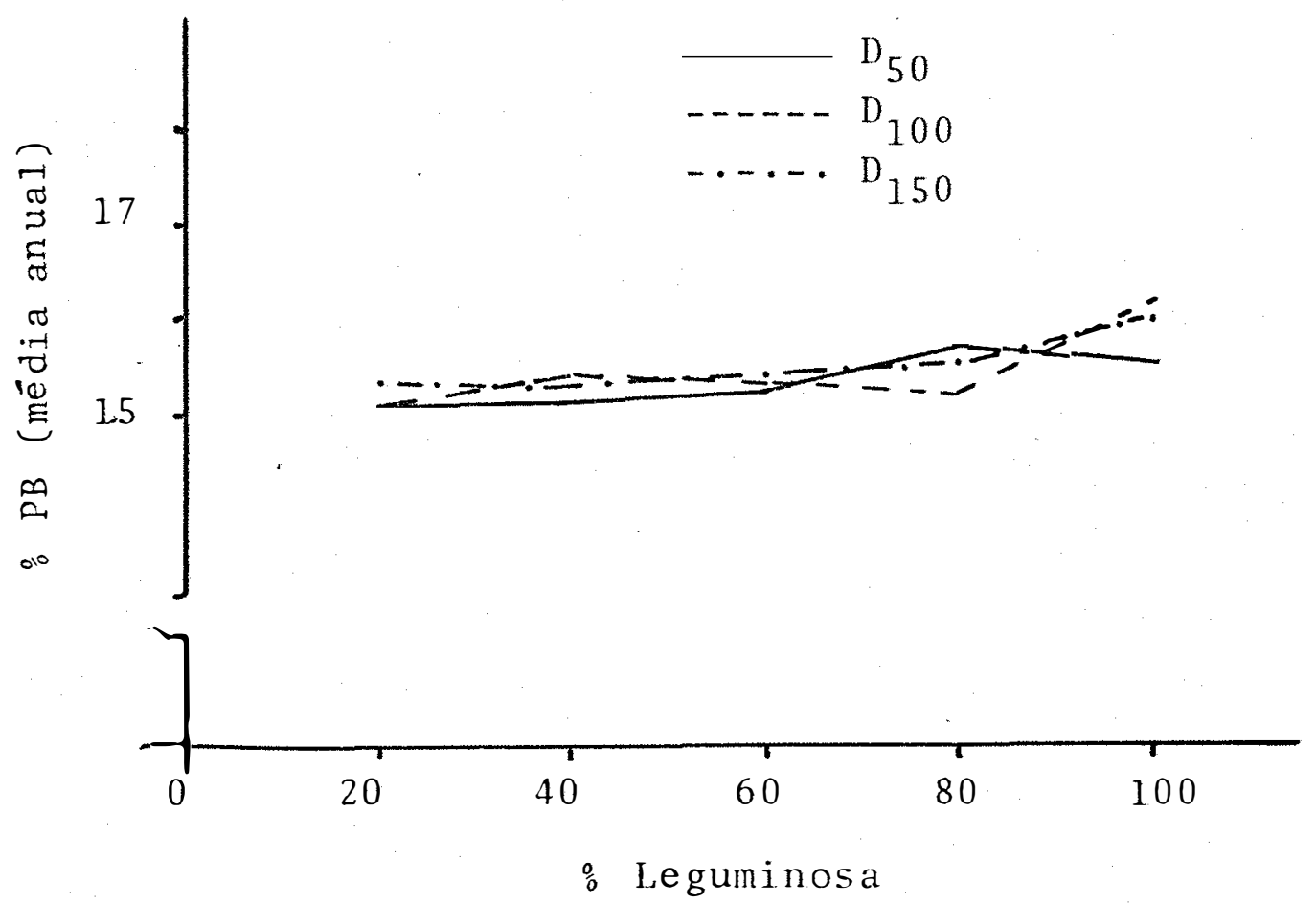

FIGURA 7 - Variação no teor médio anual de proteína bruta da componente leguminosa na consorciação braquiariasiratro (média de 7 cortes). 
do teor de proteína bruta desta componente.

4.1.4. Produção Anual de Proteína Bruta

4.1.4.1. Produção de proteína bruta da componen te graminea

A anālise de variância dos dados obtidos para a produção anual de proteína bruta da componente gramínea está contida na Tabela 16. Dos valores de F obtidos apenas o de blo $\cos$ é que se mostrou significativo, o que permite dizer que o parâmetro em discussão não foi afetado pela densidade de plan tas, nem pelia proporção gramínea-leguminosa estabelecida.

A decomposição da SQ do desdobramento da intera ção $P$ X D mostra que em $P$ dentro $D_{50}$ a componente linear foi significativa, com $R^{2}$ igual a $93,49 \%$, e que em $P$ dentro $\mathrm{D}_{100}$ foi significativa a componente quadrática, com $\mathrm{R}^{2}$ igual a $47,77^{\circ}$. Observando-se a Figura $8(a)$, nota-se que a queda na produção de proteína bruta da componente gramínea foi bas tante pequena, quando elevou-se a densidade de 50 para 100 plantas $/ \mathrm{m}^{2}$, e pequeno $t$ ambém foi o aumento de produção quando elevou-se a densidade de 100 para 150 plantas $/ \mathrm{m}^{2}$, que à medida que eleva-se a proporcão gramínea-leguminosa diminui linearmen te a produção anual de proteína bruta da componente gramínea, enquanto que para a densidade 100 plantas $/ \mathrm{m}^{2}$, à medida que ele va-se a participação da leguminosa até 40\% na mistura, eleva- 
TABELA 16 - Anālise de variância, desdobramento da interação P $\times$ D, decomposição das SQ dos efeitos, coeficien tes de determinação $\left(R^{2}\right)$ para a produção de proteí na bruta da composição gramínea (t/ha/ano) na con sorciação brachiaria-siratro.

\begin{tabular}{|c|c|c|c|}
\hline Causas de Variação & G.L. & Q.M. & $\mathrm{R}^{2}$ \\
\hline Blocos & 3 & $1,439.019$ & \\
\hline Densidades (d) & 2 & 0,003222 & \\
\hline $\mathrm{L}$ & 1 & 0,0004 & 6,55 \\
\hline Q & 1 & 0,0060 & 93,44 \\
\hline Resíduo (a) & 6 & 0,049405 & \\
\hline Propor ções (P) & 4 & 0,0889437 & \\
\hline $\mathrm{L}$ & 1 & 0,1092 & 30,69 \\
\hline Q & 1 & 0,1621 & 45,58 \\
\hline$P \times D$ & 8 & 0,103881 & \\
\hline$P$ dentro $D_{50}$ & 4 & 0,100632 & \\
\hline $\mathrm{L}$ & 1 & $0,3763^{*}$ & 93,49 \\
\hline Q & 1 & 0,0001 & 0,04 \\
\hline$P$ dentro $D_{100}$ & 4 & 0,186695 & \\
\hline $\mathrm{L}$ & 1 & 0,0189 & 2,53 \\
\hline Q & 1 & $0,3568^{*}$ & 47,77 \\
\hline$P$ dentro $D_{150}$ & 4 & 0,009380 & \\
\hline $\mathrm{L}$ & 1 & 0,0093 & 24,79 \\
\hline Q & 1 & 0,0075 & 20,10 \\
\hline Resíduo & 36 & 0,077636 & \\
\hline
\end{tabular}


Tabela 16 - continuação.

\begin{tabular}{llll}
\hline Causas de Variação & G.L. & Q.M. & $\mathrm{R}^{2}$ \\
\hline D dentro $P_{0}$ & 2 & 0,102900 & \\
L & 1 & 0,0882 & 42,85 \\
Q & 1 & 0,1176 & 57,14 \\
D dentro $P_{20}$ & 2 & 0,109308 & \\
L & 1 & 0,0001 & 0,05 \\
Q & 1 & 0,2185 & 99,94 \\
D dentro $P_{40}$ & 2 & 0,074258 & \\
L & 1 & 0,0120 & 8,08 \\
Q & 1 & 0,1365 & 91,91 \\
D dentro P 60 & 2 & 0,104925 & 17,36 \\
L & 1 & 0,0364 & 82,63 \\
Q & $I$ & 0,1734 & \\
D dentro P80 & 2 & 0,027358 & 59,41 \\
L & 1 & 0,0325 & 40,58 \\
Q & 1 & 0,0222 & \\
Resíduo & 42 & 0,077636 & \\
\hline
\end{tabular}



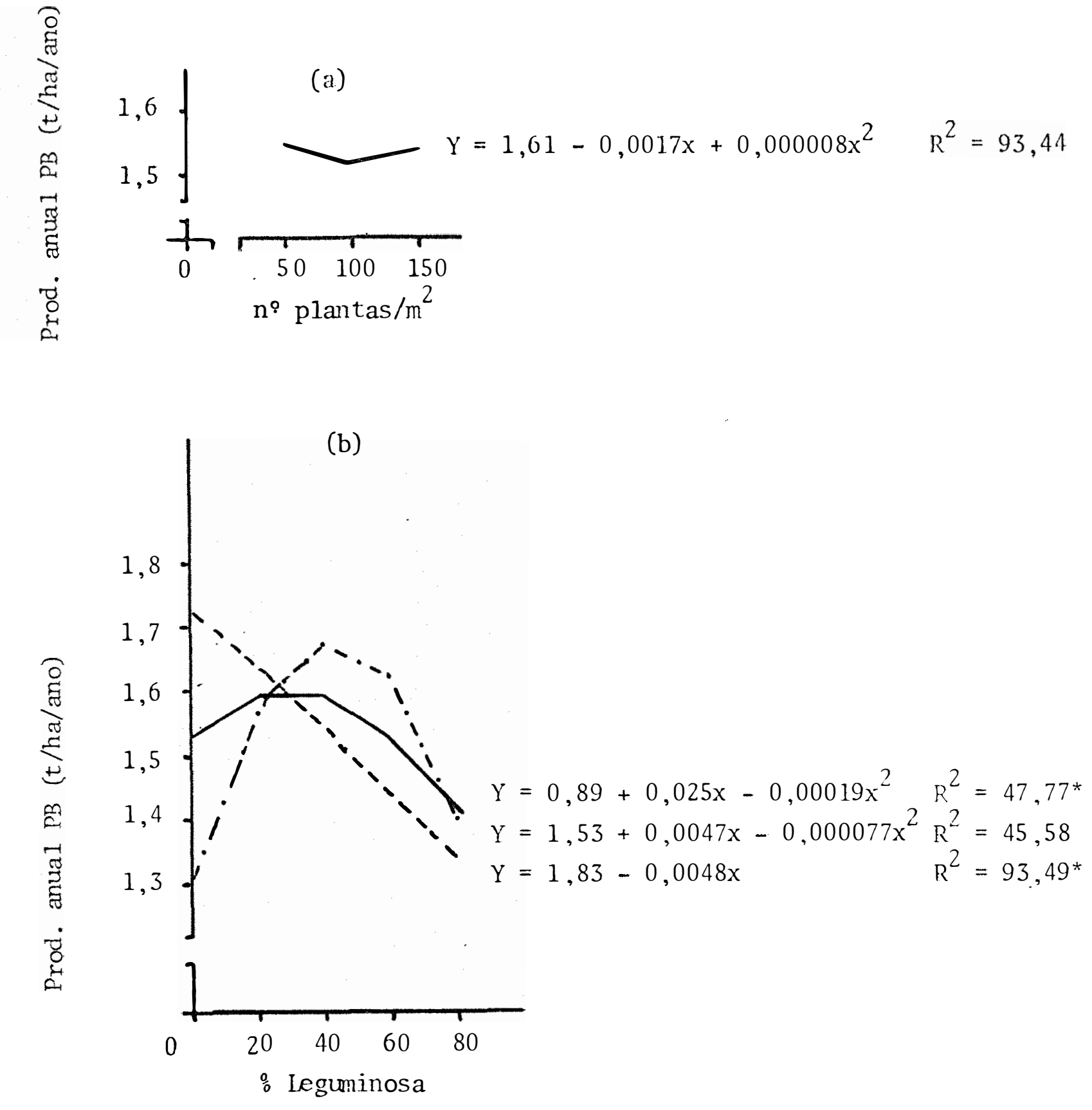

FIGURA 8 - Efeito da densidade de plantas (a) e da proporção gramínea-leguminosa estabelecida (b) na produção de proteína bruta da componente gramínea ( $t / h a / a n o) ~ n a$ consorciação brachiaria-siratro. 
-se a produção anual de proteína bruta da componente gramínea, pela maior introdução de nitrogênio no sistema, mas a partir desta proporção a produção tende a declinar, o que está rela cionado com a queda de produção de matéria seca da gramínea (pela redução no número de plantas).

A comparação pelo teste de Tukey não revelou sig nificância para as médias de densidades, nem para as médias de proporções (Tabela 17).

As produções anuais de proteína bruta encontra das variaram de $1,54 \mathrm{t} / \mathrm{ha} / a n o$ (na densidade de $50 \mathrm{plantas} / \mathrm{m}^{2}$ ), $1,51 \mathrm{t} / \mathrm{ha} / \mathrm{ano}$ (na densidade de $100 \mathrm{plantas} / \mathrm{m}^{2}$ ), e $1,53 \mathrm{t} / \mathrm{ha} /$ ano (na densidade de $150 \mathrm{plantas} / \mathrm{m}^{2}$ ). Para as proporções as variações fóram de, $1,55 \mathrm{t} / \mathrm{ha} /$ ano $\left(\mathrm{P}_{0}\right)$ a $1,39 \mathrm{t} / \mathrm{ha} / \mathrm{ano}\left(\mathrm{P}_{100}\right)$, e foram superiores às encontradas por THAIRU (1976) na consor ciação brachiaria-cent rosema, com 0,42 t/ha/ano e na consorcia ção brachiaria-stylonsanthes, com 0,57 t/ha/ano.

4.1.4.2. Produção anual de proteína bruta da componente leguminosa

Os dados relativos à análise de variância para a produção anual de proteína bruta estão contidos na Tabela 18 . Os valores de F encontrados mostraram-se significativos para os efeitos D e P, bem como para a interação destes dois fato res, o que significa que a densidade de plantas usada, a pro porção gramínea-leguminosa estabelecida, assim como a intera 
TABELA 17 - Diferenças mínimas significativas para a compara ção de mêdias, coeficientes de variação e eqquações de regressão usadas na anâlise de variância para a produção de proteína bruta da componente gramínea ( $t / h a / a n o)$ na consorciação brachiaria-si ratro (média de 4 repetições).

\begin{tabular}{|c|c|c|c|c|c|}
\hline DENS IDADES & $\mathrm{D}_{50}$ & \multicolumn{3}{|c|}{$\mathrm{D}_{100}$} & $\begin{array}{l}\mathrm{D}_{150} \\
1,53 \mathrm{a}\end{array}$ \\
\hline \multirow[t]{2}{*}{ PROPORÇOES } & $\mathrm{P}_{0}$ & $\mathrm{P}_{20}$ & $\mathrm{P}_{40}$ & $P_{60}$ & $\mathrm{P}_{80}$ \\
\hline & $1,55 \mathrm{a}$ & $1,52 \mathrm{a}$ & $1,63 \mathrm{a}$ & $1,54 \mathrm{a}$ & $1,39 \mathrm{a}$ \\
\hline \multirow[t]{3}{*}{ D.M.S. $(5 \%)$} & & $\mathrm{D}$ & & $\mathrm{P}$ & \\
\hline & & 0,21 & & 0,32 & \\
\hline & & (a) & & (b) & \\
\hline \multirow[t]{2}{*}{ C.V. $\left(\begin{array}{l}0 \\
0\end{array}\right)$} & . & 14,49 & & 18,17 & \\
\hline & \multicolumn{4}{|c|}{ EQUAÇŌES DE REGRESSÃO } & $\mathrm{R}^{2}\left(\frac{\mathrm{o}}{0}\right)$ \\
\hline Proporções & Q & $Y=1,5+$ & $0,0047 x-$ & $0,0000776 x^{2}$ & 45,58 \\
\hline$P$ dentro $\mathrm{D}_{50}$ & Q & $Y=1,8-($ & $0,0048 \times$ & & $93,49 *$ \\
\hline$P$ dentro $D_{150}$ & Q & $Y=0,8+$ & $0,025 \times-$ & $0,00019 x^{2}$ & 47,77 * \\
\hline Densidades & $Q$ & $Y=1,6-$ & $0,00176 x+$ & $+0,00000849 x^{2}$ & 293,44 \\
\hline
\end{tabular}


TABELA 18 - Anälise de variância, desdobramento da interação P X D, decomposição da SQ dos efeitos, coeficien tes de determinação $\left(R^{2}\right)$ para a produção de prote $\bar{i}$ na bruta da componente leguminosa (t/ha/ano) na consorciação brachiaria-siratro.

\begin{tabular}{|c|c|c|c|}
\hline Causas de Variação & G. L. & Q.M. & $R^{2}$ \\
\hline B1ocos & 3 & 0,012488 & \\
\hline Densidades (D) & 2 & $0,233031^{*}$ & \\
\hline $\mathrm{L}$ & 1 & $0,3010^{*}$ & 64,59 \\
\hline Q & 1 & 0,1650 & 35,40 \\
\hline Resíduo (a) & 6 & 0,041530 & \\
\hline Proporções (P) & 4 & $7,630969 * *$ & \\
\hline $\mathrm{L}$ & 1 & 14,9530 * * & 48,98 \\
\hline Q & 1 & $9,0535^{* *}$ & 29,66 \\
\hline$P \times D$ & 8 & 0,264127 ** & \\
\hline$P$ dentro $\mathrm{D}_{50}$ & 4 & $2,233195^{* *}$ & \\
\hline $\mathrm{L}$ & 1 & $2,8783 * *$ & 32,22 \\
\hline Q & 1 & 1,4304 ** & 16,01 \\
\hline P dentro $\mathrm{D}_{100}$ & 4 & $2,833605^{*}$ * & \\
\hline $\mathrm{L}$ & 1 & $6,0606 * *$ & 53,47 \\
\hline Q & 1 & $3,8745^{*} *$ & 34,47 \\
\hline$P$ dentro $D_{150}$ & 4 & 3,092424 ** & $\cdot$ \\
\hline $\mathrm{L}$ & 1 & $6,4480 * *$ & 52,12 \\
\hline Q & 1 & $4,1911^{*}$ * & 33,88 \\
\hline Resíduo (b) & 36 & 0,049280 & \\
\hline
\end{tabular}


Tabela 18 - continuação.

\begin{tabular}{llll}
\hline Causas de Variação & G.L. & Q.M. & $\mathrm{R}^{2}$ \\
\hline D dentro $\mathrm{P}_{20}$ & 2 & 0,000474 & \\
$\mathrm{~L}$ & 1 & 0,0006 & 64,47 \\
Q & 1 & 0,0003 & 35,52 \\
D dentro $\mathrm{P}_{40}$ & 2 & $1,204558^{\star *}$ & \\
$\mathrm{~L}$ & 1 & $1,7391^{\star *}$ & 72,18 \\
Q & 1 & $0,6700^{*}$ & 27,81 \\
D dentro $\mathrm{P}_{60}$ & 2 & 0,002633 & \\
L & 1 & 0,0024 & 46,51 \\
Q & 1 & 0,0028 & 53,48 \\
D dentro P80 & 2 & 0,019308 & \\
L & 1 & 0,0338 & 87,52 \\
Q & 1 & 0,0048 & 12,47 \\
D dentro $P_{100}$ & 2 & 0,062558 & \\
L & 1 & 0,1225 & 97,91 \\
Q & 1 & 0,0026 & 2,08 \\
Residuo & 42 & 0,047730 & \\
\hline
\end{tabular}


ção de densidades $x$ proporções afetaram a anual de proteína bruta da componente leguminosa.

No desdobramento da interaça $\mathrm{P} \times \mathrm{D}$, os valores de F também foram significativos para $P$ dentro $D_{50}$, $P$ dentro $\mathrm{D}_{100}$, P dentro $\mathrm{D}_{150}$, e para $\mathrm{D}$ dentro $\mathrm{P}_{40}$, que implica dizer que nas três densidades em estudo, a proporção gramínea-legumi nosa estabelecida afetou a produção anual de proteína bruta na componente leguminosa, e que na proporção $60 \%$ graminea - 40\% le guminosa, este parâmetro foi afetado pela densidade de plantas usadas .

A decomposição da SQ dos efeitos, também contida na Tabela 18; mostra que, para D a componente linear foi signi ficativa, com $R^{2}$ igual a $64,59 \%$, enquanto que, para proporções foram significativas as componentes linear ( $R^{2}$ igual a $\left.48,98 \%\right)$, quadrática $\left(R^{2}\right.$ de $\left.29,66^{\circ}\right)$. Para o desdobramento da interação $P \times D$, a decomposição da $S Q$ mostra que, em $P$ dentro $D_{50}$, foram significativas as componentes linear e quadrática, sendo que os $\mathrm{R}^{2}$ equivalentes foram de $32,22 \%$ ( 1 inear) e $16,01 \%$ (quadrát ca); em $P$ dentro $D_{100}$ foram significativas as componentes $1 \underline{i}$ near, quadrática, enquanto que para $P$ dentro $D_{150}$ foram signi ficativas as componentes linear $\left(R^{2}\right.$ igual a $\left.52,12 \%\right)$, quadráti ca $\left(R^{2}\right.$ igual a $\left.33,88 \%\right)$. Para $D$ dentro $P_{40}$ foram significativas as componentes linear e quadrática, sendo que os $\mathrm{R}^{2}$ foram de $72,18 \%$ e $27,81 \%$, respectivamente.

Pela Figura 9(a) nota-se que para o efeito $D$ a produção de proteína bruta da componente leguminosa diminui $1 \underline{i}$ 

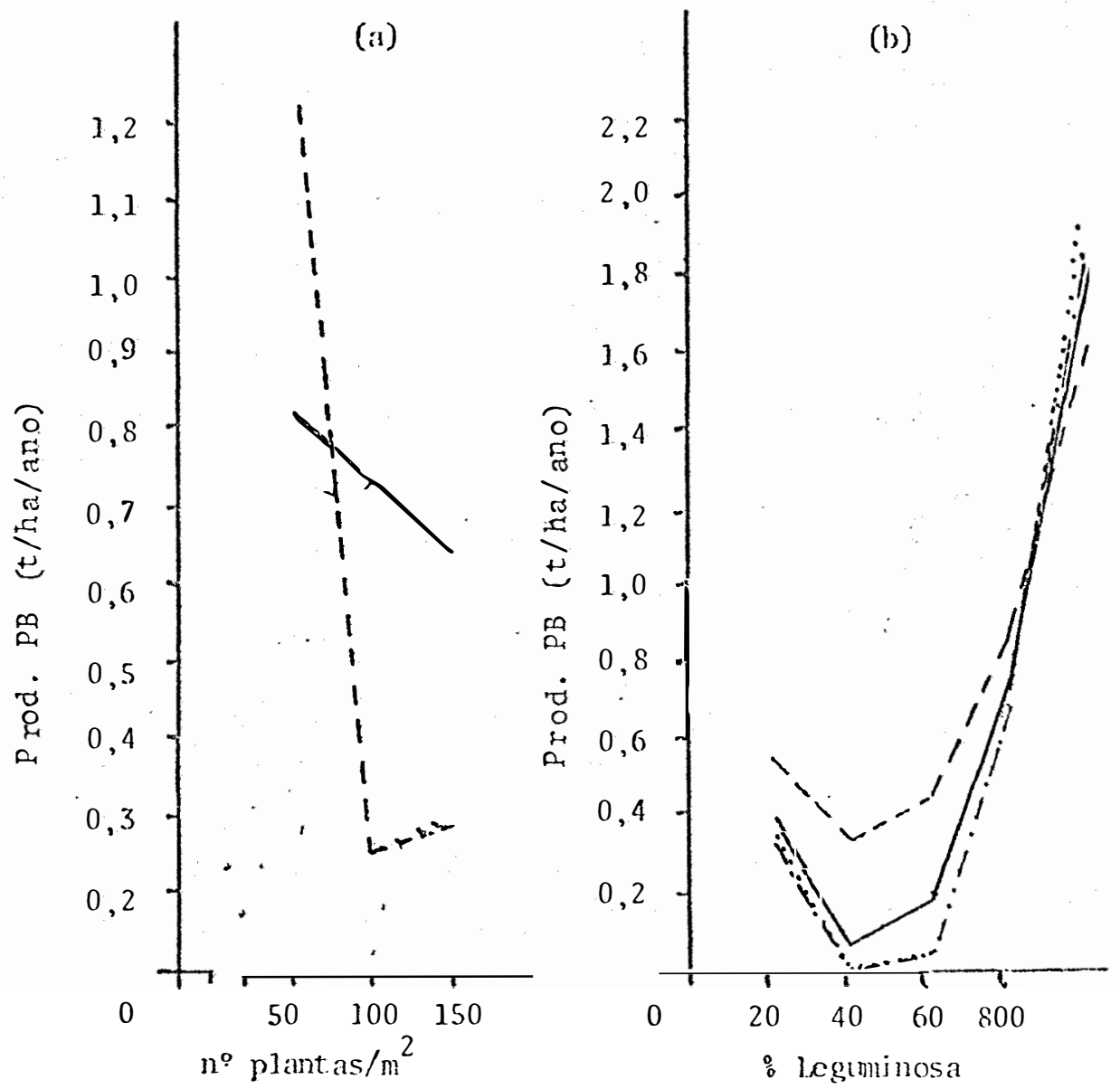

$$
\begin{aligned}
& Y=1,21-0,051 x+0,00058 x^{2} \quad R^{2}=29,60 * * \\
& \text {-.... P dentro }{ }^{2}{ }_{50} \\
& Y=1,08-0,034 x^{5}+0,00039 x^{2} \quad R^{2}=16,01^{* *} \\
& \text {..... P dent ro } D_{100} \\
& Y=1,24-0,059 x+0,00065 x^{2} \quad R^{2}=34,18^{* *} \\
& \text {...... P dentro } \mathrm{D}_{150} \\
& Y=1,30-0,061 x+0,00068 x^{2} \quad R^{2}=33,88^{* *}
\end{aligned}
$$

FIGURA 9 - Efeito da densidade de plantas(a) e da proporção gra mínea-leguminosa estabelecida (b) na produção de pro teína bruta da componente leguminosa ( $t / h a / a n o)$ na consorciação brachiaria-siratro. 
nearmente com a densidade de plantas. Todavia, em $\mathrm{P}_{40} \mathrm{o}$ parâ - metro diminui com o aumento no número de plantas; entretanto, quando eleva-se $D_{100}$ aumenta-se a produção de matéria seca da componente leguminosa. Para proporcões (Figura 9.b), nota-se que em $\mathrm{P}$ a produção de matéria seca da componente leguminosa diminuiuquando esta passou de $\mathrm{P}_{20}$ para $\mathrm{P}_{40}$, entretanto, a par tir desta elevou-se rapidamente. Tal comportamento foi seme lhante também para $\mathrm{P}$ dentro $\mathrm{D}_{50}$, $\mathrm{P}$ dentro $\mathrm{D}_{100}$ e $\mathrm{P}$ dentro $\mathrm{D}_{150}$, isto é, nas três densidades houve uma mesma tendência de com portamento que foi caracteristico por uma queda inicial e gran de aumento na produção de matéria seca na produção $100 \%$ de le guminosa.

- Na comparação das médias pelos teste de Tukey (Tabela 19), observa-se que as médias de densidades, quando comparadas, mostraram que $\mathrm{D}_{50}$ diferiu significativamente ( $\mathrm{P}<$ $0,05)$ quando comparada com $\mathrm{D}_{100}$, embora não tenha definido quando comparada com $D_{150}$ e que estas duas ültimas, quando com paradas entre si, também não revelaram diferença significativa. A comparação das médias de $\mathrm{P}$ mostra que $\mathrm{P}_{100}$ diferiu signifi cativamente $(P<0,05)$ quando comparada com as demais médias de proporções e que $\mathrm{P}_{40}$ também diferiu significativamente ( $\mathrm{P}<$ $0,05)$ quando comparada com $\mathrm{P}_{20}$; e ainda que $\mathrm{P}_{60}$ também diferiu significativamente $(\mathrm{P}<0,05)$ quando comparada com $\mathrm{P}_{40}$. As de mais comparações entre as médias foram não significativas.

Para a comparação de $\mathrm{P}$ dentro $\mathrm{D}_{50}$, o teste de $\underline{\mathrm{u}}$ key revelou que $P_{100}$ diferiu significativamente $(P<0,05)$ quan 
TABELA 19 - Diferenças mínimas significativas para a comparação de médias, coeficientes de variação e equações de regressão usadas na anālise de variância, para a produção de proteína bruta na componente

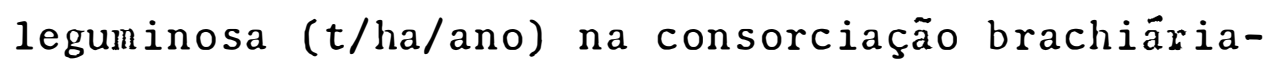
siratro (média de 4 repetições).

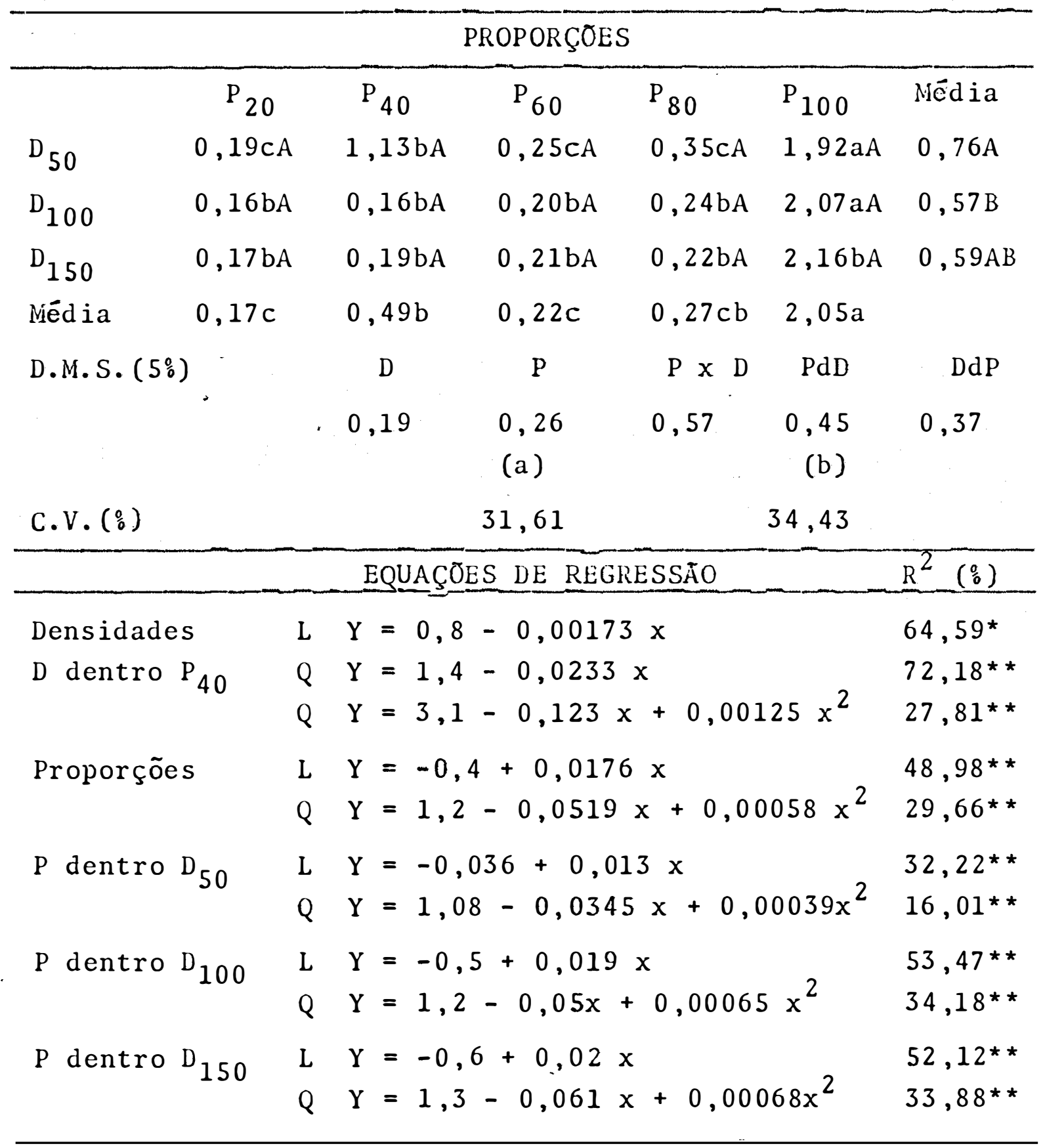


do comparada com as demais proporcões; que $\mathrm{P}_{80}, \mathrm{P}_{60}$ e $\mathrm{P}_{40}$ tam bẻm diferiram significativamente $(P<0,05)$ quando comparada com $\mathrm{P}_{60}, \mathrm{P}_{40}$ e $\mathrm{P}_{20}$, respectivamente. $\mathrm{P}_{100}$ também diferiu signi ficativamente $(P<0,05)$, quando comparada às demais densida des 100 e 150 plantas $/ \mathrm{m}^{2}$, sendo que tambëm em ambas as demais comparações de mẻdias revelaram-se não significativas.

A produção anual de proteína bruta da componente leguminosa na consorciação brachiaria-siratro variou entre 0,76 t/ha/ano $\left(D_{50}\right)$ a $0,59 \mathrm{t} / \mathrm{ha} /$ ano $\left(D_{150}\right)$, enquanto que para pro porções as variações estiveram entre $0,17 \mathrm{t} / \mathrm{ha} / \mathrm{ano}\left(\mathrm{P}_{20}\right)$ e $2,05 \mathrm{t} / \mathrm{ha} /$ ano $\left(\mathrm{P}_{100}\right)$. Neste caso os resultados encontrados fo ram ligeiramente superiores aos citados por NG (1976), com $0,42 \mathrm{t} / \mathrm{ha} /$ ano na consorciação brachiaria-centrosema, e 0,57 t/ ha/ano na consorciação brachiaria-stylonsanthes.

4.1.4.3. Produção conjunta de proteína bruta

A Tabela 20 contem a anâlise de variância dos da dos obtidos para a produção conjunta de proteína bruta para a consorciação brachiaria-siratro. Os valores de F encontrados. se mostram significativos para blocos e P, indicando que no ca so de proporção, a produção anual conjunta de proteína bruta da consorciação brachiaria-siratro foi afetada pela proporção gramínea-leguminosa estabelecida. No desdobramento da intera ção $\mathrm{P} \times \mathrm{D}$ os valores de $\mathrm{F}$ foram significativos para $\mathrm{P}$ dentro $\mathrm{D}_{100} \cdot$ 
TABELA 20 - Anâlise de variância, desdobramento da interação $P \times D$, decomposição das $S Q$ dos efeitos, coeficien tes de determinação $\left(R^{2}\right)$ para a produção conjunta de proteína bruta na consorciação brachiaria- sira tro.

\begin{tabular}{|c|c|c|c|}
\hline Causas de Variação & G.L. & Q.M. & $\mathrm{R}^{2}$ \\
\hline B1ocos & 3 & $1,356183^{* *}$ & \\
\hline Densidades (D) & 2 & 0,009405 & \\
\hline $\mathrm{L}$ & 1 & 0,0025 & 13,56 \\
\hline$Q$ & 1 & 0,0162 & 86,43 \\
\hline Resíduo (a) & 6 & 0,066546 & \\
\hline Proporções (P) & 5 & $0,331649 * *$ & \\
\hline $\mathrm{L}$ & 1. & $0,9062^{* *}$ & 54,64 \\
\hline Q & 1 & 0,0137 & 0,82 \\
\hline$P \times D$ & 10 & 0,088720 & \\
\hline$P$ dentro $D_{50}$ & 5 & 0,035664 & \\
\hline $\mathrm{L}$ & 1 & 0,0150 & 8,41 \\
\hline Q & 1 & 0,0527 & 29,58 \\
\hline$P$ dentro $\mathrm{D}_{100}$ & 5 & $0,293710^{* *}$ & \\
\hline $\mathrm{L}$ & 1 & $0,6880 * *$ & 46,85 \\
\hline $\mathrm{Q}$ & 1 & 0,0610 & 4,15 \\
\hline$P$ dentro $D_{150}$ & 5 & 0,179716 & \\
\hline $\mathrm{L}$ & 1 & $0,4855^{\star}$ & 54,03 \\
\hline Q & 1 & 0,0485 & 5,40 \\
\hline Resíduo & 45 & 0,075346 & \\
\hline $\mathrm{D}$ dentro $\mathrm{P}_{0}$ & 2 & 0,102900 & \\
\hline $\mathrm{L}$ & 1 & 0,0882 & 42,85 \\
\hline Q & 1 & 0,1176 & 57,14 \\
\hline
\end{tabular}


Tabela 20 - continuação.

\begin{tabular}{lclc}
\hline Causas de Variação & G.L. & \multicolumn{1}{c}{$\mathrm{Q} \cdot \mathrm{M}}$. & $\mathrm{R}^{2}$ \\
\hline D dentro $\mathrm{P}_{20}$ & 2 & 0,129175 & \\
$\mathrm{~L}$ & 1 & 0,0000 & 0,004 \\
$\mathrm{Q}$ & 1 & 0,2583 & 99,99 \\
D dentro $\mathrm{P}_{40}$ & 2 & 0,061758 & \\
L & 1 & 0,0045 & 3,65 \\
Q & 1 & 0,1190 & 96,34 \\
D dentro $\mathrm{P}_{60}$ & 2 & 0,074308 & \\
L & 1 & 0,0210 & 14,13 \\
Q & 1 & 0,1276 & 85,86 \\
D dentro P 80 & 2 & 0,023433 & \\
L & 1 & 0,0000 & 0,10 \\
Q & 1 & 0,0468 & 99,89 \\
D dentro $P_{100}$ & 2 & 0,061433 & \\
L & 1 & 0,1200 & 97,70 \\
Q & 1 & 0,0028 & 2,29 \\
Residuo & 50 & 0,073879 & \\
\hline
\end{tabular}


A Tabela 20 contem ainda a decomposição das SQ dos efeitos. Para o efeito P observa-se que a componente li near se mostrou significativa, com $R^{2}$ de $54,64^{\circ}$. Para a decom posição da SQ no desdobramento da interação observa-se que pa ra $P$ dentro $D_{100}$ a componente linear foi significativa, sendo que $\circ \mathrm{R}^{2}$ correspondente foi de $46,85^{\circ}$ e para $\mathrm{P}$ dentro $\mathrm{D}_{150}$ tam bém foi significativa a componente linear, com $\mathrm{R}^{2}$ igual a $54,03 \%$.

Na anālise de Figura $10(a)$, observa-se que ofe $\underline{i}$ to da densidade de plantas na produção conjunta de proteína bruta fö̈ praticamente nulo, causando pequena variação neste teor. O efeito da proporção gramínea-leguminosa estabelecida na produção conjunța de proteína bruta da consorciação brachia ria-siratro pode ser vista na Figura $10(b)$, onde nota-se que, para $\mathrm{P}, \mathrm{P}$ dentro $\mathrm{D}_{50}$, $\mathrm{P}$ dentro $\mathrm{D}_{100}$ e $\mathrm{P}$ dentro $\mathrm{D}_{150}$, o parâme tro aumenta linearmente com a participação da leguminosa na proporção estabelecida, o que era esperado, pois uma vez que aumenta-se o número de plantas de leguminosa, aumenta-se a in trodução de nitrogênio no sistema de pastagens.

A comparação das médias pelo teste de Tukey (Tâ bela 21) revela que as médias de densidades não diferem quando comparadas entre si; e que para as proporções as comparações mostram $\mathrm{P}_{100}(2,05 \mathrm{t} / \mathrm{ha} / \mathrm{ano})$, diferindo significativamente ( $\mathrm{P}<$ $0,05)$, quando comparada com $P_{0}(1,55$ t/ha/ano $), P_{20}(1,72$ t/ha /ano), $\mathrm{P}_{80}(1,67 \mathrm{t} / \mathrm{ha} / \mathrm{ano})$, enquanto que as demais comparações revelaram-se não significativas. 


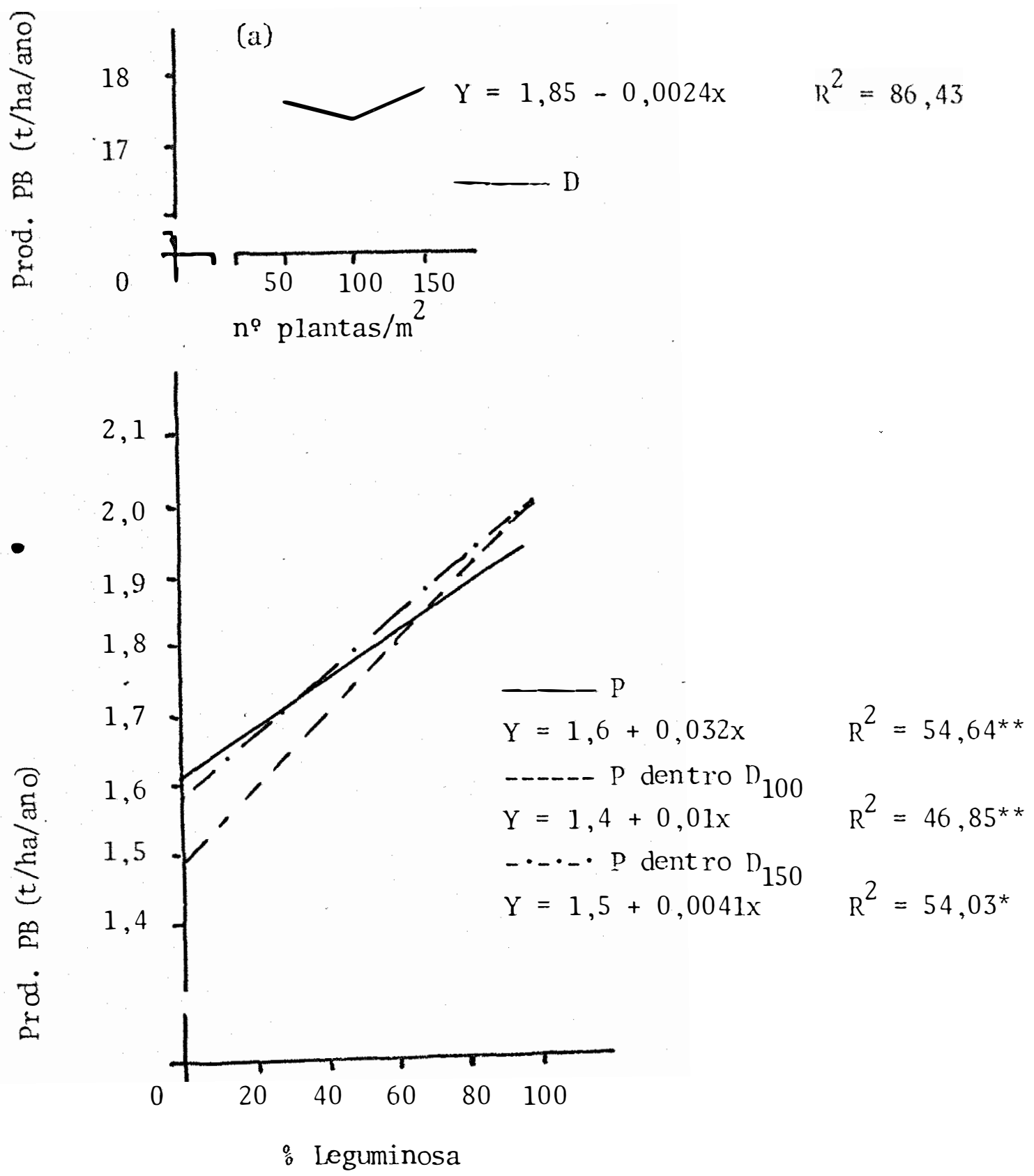

FIGURA 10 - Efeito da densidade de plantas (a) e da proporção gramínea-leguminosa estabelecida (b) na produção conjunta de proteína bruta ( $t / h a / a n o)$ na consorcia ção brachiaria-siratro. 
TABELA 21 - Diferenças mínimas significativas para a comparação de mêdias, coeficientes de variação e equa ções de regressão usadas na análise de variância para a produção conjunta de proteína bruta ( $t / h a /$ ano) na consorciação brachiāria-siratro (média de 4 repetições).

\begin{tabular}{|c|c|c|c|c|c|c|}
\hline \multirow{2}{*}{$\begin{array}{l}\text { DENSIDADES } \\
\text { PROPORÇOES }\end{array}$} & \multicolumn{2}{|r|}{$\begin{array}{c}\mathrm{D}_{50} \\
1,76 \mathrm{a}\end{array}$} & \multicolumn{2}{|r|}{$\begin{array}{r}D_{100} \\
1,74 a\end{array}$} & \multicolumn{2}{|r|}{$\begin{array}{l}\mathrm{D}_{150} \\
1,78 \mathrm{a}\end{array}$} \\
\hline & $\mathrm{P}_{0}$ & $\mathrm{P}_{20}$ & $\mathrm{P}_{40}$ & $P_{60}$ & $\mathrm{P}_{80}$ & $P_{100}$ \\
\hline & $1,55 \mathrm{~b}$ & $1,72 b$ & $1,81 \mathrm{ab}$ & $1,76 \mathrm{ab}$ & $1,67 \mathrm{~b}$ & $2,05 a$ \\
\hline \multirow[t]{3}{*}{ D.M.S. $(5 \%)$} & & & $\mathrm{D}$ & & $\mathrm{P}$ & \\
\hline & & & 0,22 & & 0,33 & \\
\hline & & & (a) & & (b) & \\
\hline \multirow[t]{2}{*}{ C.V. $\left(\frac{0}{0}\right)$} & & & 14,60 & & 15,54 & \\
\hline & \multicolumn{4}{|c|}{ EQUAÇŌES DE REGRESSÃO } & & $\mathrm{R}^{2}\left(\frac{0}{0}\right)$ \\
\hline \multirow[t]{2}{*}{ Proporçōes } & $\mathrm{L}$ & $Y=1,6$ & $+0,0032$ & & & $54,64 * *$ \\
\hline & $Q$ & $Y=1,6$ & $+0,0019$ & \multicolumn{2}{|c|}{$+0,000013 x^{2}$} & $44,52 * *$ \\
\hline P dentro $D_{100}$ & $\mathrm{~L}$ & $Y=1,4$ & $+0,0049$ & $x$ & & $46,85 * *$ \\
\hline$P$ dentro $D_{150}$ & $\mathrm{~L}$ & $Y=1,5$ & $+0,0041$ & $x$ & & $54,03 *$ \\
\hline Densidades & $Q$ & $Y=1,8$ & $+0,0024$ & $x+0,000$ & $012 x^{2}$ & 86,43 \\
\hline
\end{tabular}


A produção conjunta de proteína bruta na consor ciação braquiaria-siratro variaram entre $1,76 \mathrm{t} / \mathrm{ha} / \mathrm{ano}$ (dens $\underline{i}$ dade $50 \mathrm{plantas} / \mathrm{m}^{2}$ ) a $1,78 \mathrm{t} / \mathrm{ha} / \mathrm{ano}$ (densidade $150 \mathrm{plantas} / \mathrm{m}^{2}$ ), enquanto que para proporções as variações foram entre $1,55 \mathrm{t} /$ ha/ano em $\mathrm{P}_{0}$ a $2,05 \mathrm{t} / \mathrm{ha} / \mathrm{ano}$ em $\mathrm{P}_{100}$. Estas produções foram superiores às encontradas por NG (1976) na consorciação bra quiaria-centrosema, com 0,94 t/ha/ano, e na consorciação bra chiaria-stylosanthes, com 1,11 t/ha/ano; e também supera as produções de proteína bruta citadas por JONES et alii (1967).

4.1.5. Número de Plantas de Leguminosas ao Final do Ex perimento na Consorciação Brachiaria-Siratro

Nas contagens realizadas após cada corte, nem sempre foi possível a determinação do comportamento das espé cies pelo número de plantas, uma vez que o perfilhamento inten so da gramínea tornou impossível a individualização e contagem das plantas, fato mais evidente nas densidades mais altas e que levou à obtenção do número de plantas apenas para a componente leguminosa .

A Tabela 22 apresenta a análise de variância dos dados (transformados) obtidos para o número de plantas de legu minosa ao final do experimento. Os valores de F encontrados mos traram-se significativos para $P$, indicando que a proporção gra mínea-leguminosa estabelecida afetou significativamente o núme ro de plantas da leguminosa ao final do experimento. Da mesma 
TABElA 22 - Anālise de variância, desdobramento da interação P X D, decomposição da SQ dos efeitos, coeficien tes de determinação $\left(R^{2}\right)$ para o número de plantas da componente leguminosa a final do ensaio na con sorciação brachiaria-siratro.

\begin{tabular}{|c|c|c|c|}
\hline Causas de Variação & G.L. & Q.M. & $R^{2}$ \\
\hline Blocos & 3 & 1,559358 & \\
\hline Densidades (D) & 2 & 4,844881 & \\
\hline $\mathrm{L}$ & 1 & 9,2909 & 95,88 \\
\hline Q & 1 & 0,3986 & 4,11 \\
\hline Residuo (a) & 6 & 1,714242 & \\
\hline Proporções (P) & 4 & 62,163352 ** & \\
\hline $\mathrm{L}$ & 1 & $175,8700 * *$ & 70,73 \\
\hline Q & 1 & $59,8338^{* *}$ & 24,06 \\
\hline$P \times D$ & 8 & 3,726624 & \\
\hline$P$ dentro $D_{50}$ & 4 & $14,286745^{* *}$ & \\
\hline $\mathrm{L}$ & 1 & $44,5250 * *$ & 77,91 \\
\hline Q & 1 & $10,7500^{*}$ & 18,81 \\
\hline$P$ dentro $D_{100}$ & 4 & 11,993984 * * & \\
\hline $\mathrm{L}$ & 1 & $36,5680 * *$ & 76,22 \\
\hline Q & 1 & $10,2910^{*}$ & 21,45 \\
\hline$P$ dentro $D_{150}$ & 4 & $43,335871^{* *}$ & \\
\hline $\mathrm{L}$ & 1 & $105,0600 * *$ & 60,61 \\
\hline Q & 1 & 47,7600 ** & 27,55 \\
\hline Resíduo & 36 & 1,979131 & \\
\hline D dentro $P_{20}$ & 2 & 0,205162 & \\
\hline $\mathrm{L}$ & 1 & 0,1498 & 36,52 \\
\hline Q & 1 & 0,2604 & 63,47 \\
\hline
\end{tabular}


Tabela 22 - Continuação.

\begin{tabular}{lccc}
\hline Causas de Variação & G.L. & Q.M. & $\mathrm{R}^{2}$ \\
\hline D dentro $P_{20}$ & 2 & 0,990713 & \\
L & 1 & 1,8590 & 93,82 \\
Q & 1 & 0,1223 & 6,17 \\
D dentro P60 & 2 & 0,109197 & \\
L & 1 & 0,0005 & 0,25 \\
Q & 1 & 0,2178 & 99,74 \\
D dentro P80 & 2 & 0,786338 & \\
L & 1 & 0,0029 & 0,18 \\
Q & 1 & 1,5697 & 99,81 \\
D dentro P 100 & 2 & $17,659899^{* *}$ &. \\
L & 1 & $25,9680^{* *}$ & 73,52 \\
Q & 1 & $9,3517 *$ & 26,47 \\
Residuo & 42 & 1,926153 & \\
& & & \\
\hline
\end{tabular}


forma, no desdobramento da interação $P \times D$ os valores de $F$ fo ram significativos para $\mathrm{P}$ dentro $\mathrm{D}_{50}, \mathrm{P}$ dentro $\mathrm{D}_{100}, \mathrm{P}$ dentro $\mathrm{P}_{150}$, mostrando que nas três densidades o parâmetro em análise foi afetado pela proporção gramínea-leguminosa estabelecida; e ainda que em $D$ dentro $\mathrm{P}_{100}$ o valor de $\mathrm{F}$ significativo é indi cativo de que, nesta proporção, a densidade de plantas estabe lecida teve influência no número final de plantas de legumino sa.

Na decomposição da SQ, também contida na Tabela 22 , observa-se que para $\mathrm{P}$ foram significativas as componentes linear $\left(\dot{R}^{2}\right.$ de $\left.70,73 \%\right)$ e quadrática $\left(R^{2}\right.$ de $\left.24,06 \%\right)$. Para a de composição da SQ da interação, observa-se que para $P$ dentro $\mathrm{D}_{50}$ e P dentro $\mathrm{D}_{100}$ foram significativas as componentes linear e quadrática, com $R^{2}$, respectivamente, de $77,91 \%$ e $18,81 \%$ (P dentro $\mathrm{D}_{50}$ ) e $76,22^{\circ}$ e $21,45_{\circ}^{\circ}$ ( $\mathrm{P}$ dentro $\mathrm{D}_{100}$ ), enquanto que pa ra $P$ dentro $D_{150}$ se mostraram significativas as componentes $1 \underline{i}$. near e quadrática com $\mathrm{R}^{2}$ de $60,61 \%$ e $27,55 \%$, respectivamente.

$\mathrm{Na}$ anālise da Figura 11(a), observa-se, como era esperado, que o número de plantas de leguminosa ao final do ex perimento eleva-se com a densidade de plantas estabelecida, sen do que tal fato é mais acentuado quando analisado dentro de $\mathrm{P}_{100}$ apesar do número de plantas apresentar pequena queda em $\mathrm{D}_{100}$, elevando-se rapidamente em $\mathrm{D}_{150}$. Tal fato também é obser vado na Figura $11(\mathrm{~b})$, que ilustra o efeito da proporção gramí nea-leguminosa no número de plantas $/ \mathrm{m}^{2}$ ao final do ensaio, e que permite afirmar que nas três densidades em estudo a tendên 

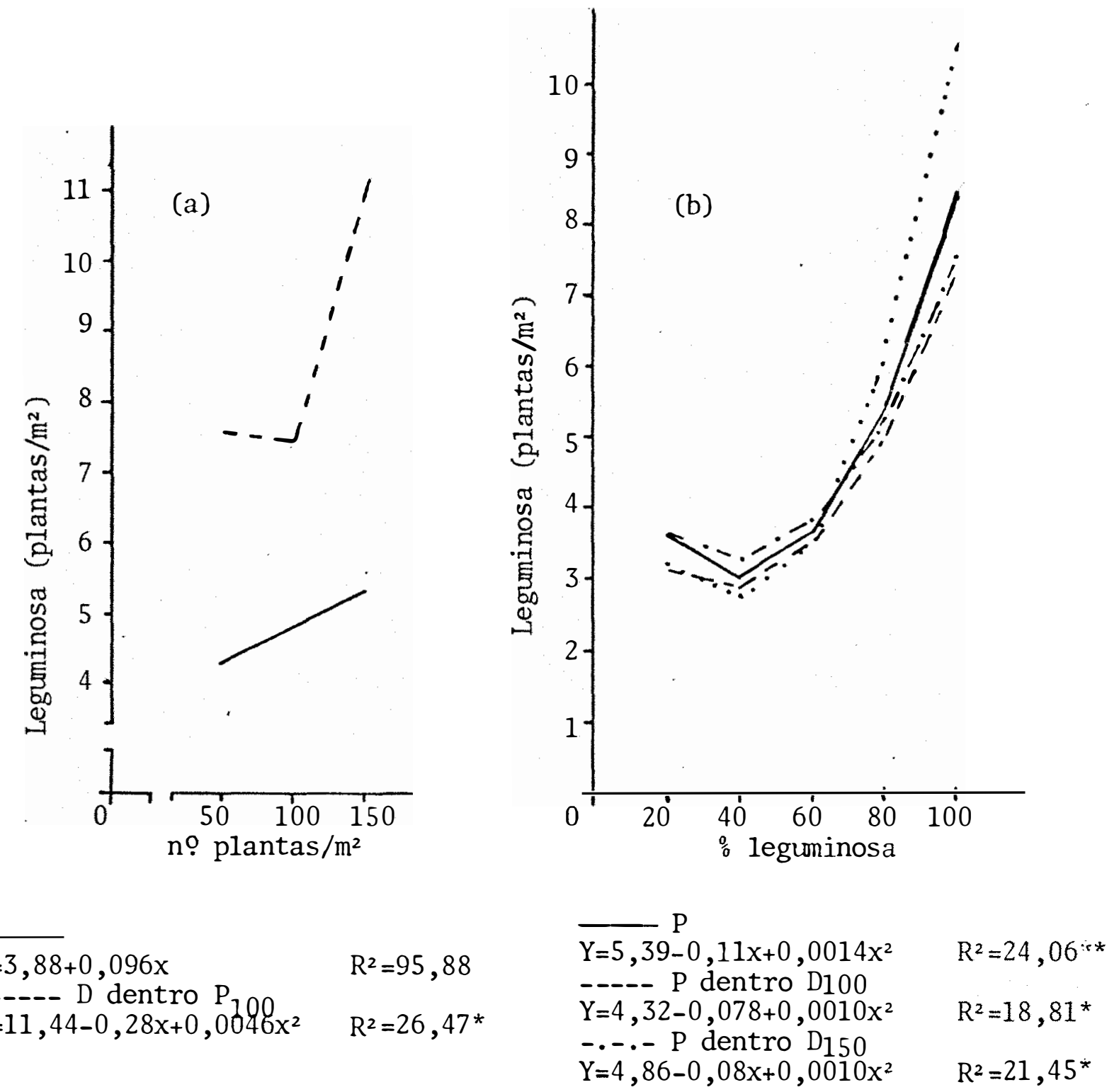

FIGURA 11 - Efeito da densidade de plantas (a) e da proporção gramínea-leguminosa estabelecida (b) no número de plantas de leguminosa ao final do experimento na consorciação brachiaria-siratro. 
TABELA 23 - Diferenças mínimas significativas para a comparação de mêdias, coeficientes de variação e equa ções de regressão usadas na anālise de ..variância para o número de plantas da componente leguminosa na consorciação brachiāria-siratro (mēdia de 4 re petições).

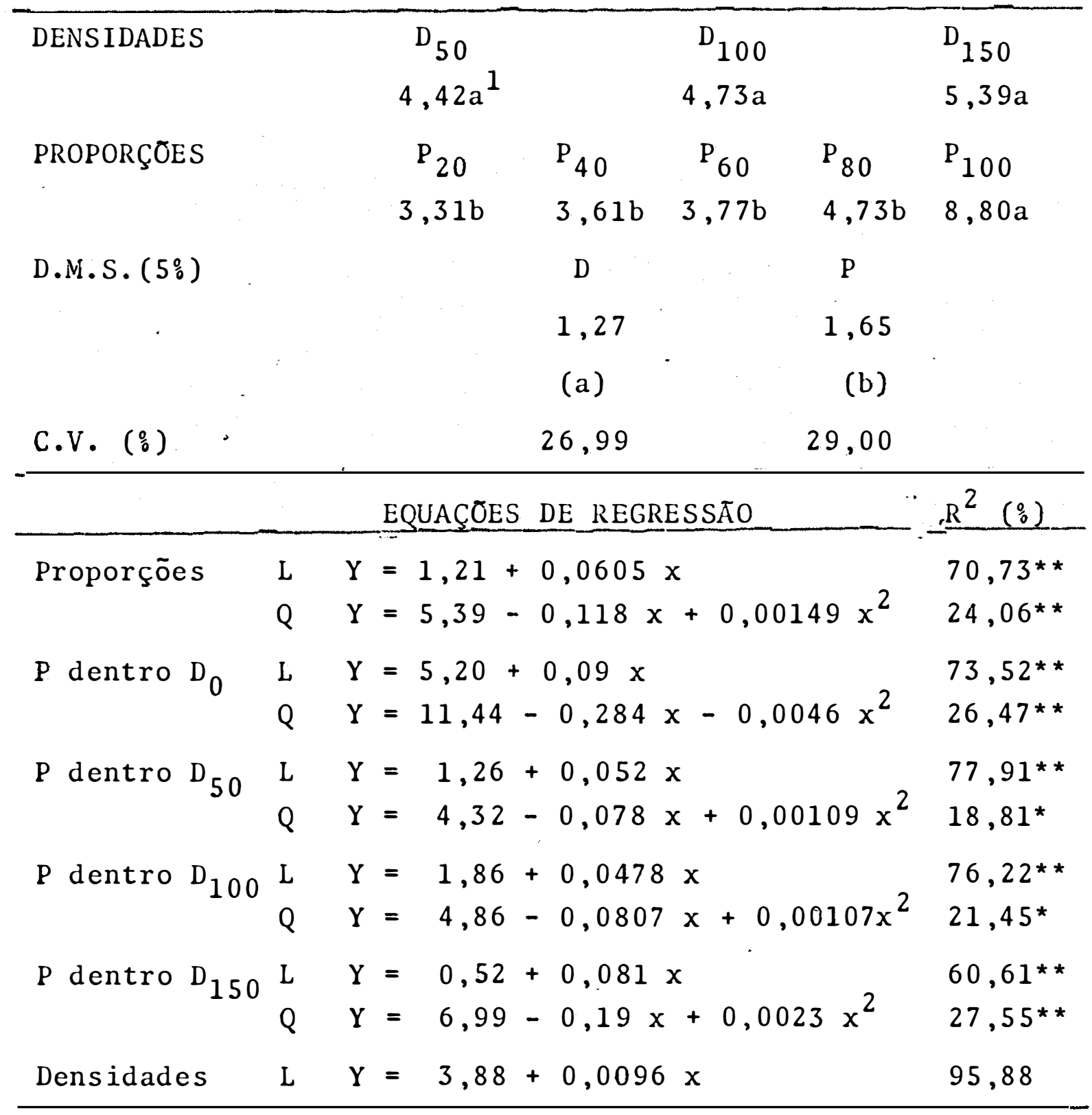

1/ Dados transformados em $\sqrt{x}$. 
cia de comportamento com relação ao parâmetro em anảlise é se melhante; o número de plantas de leguminosa apresenta pequena queda em $\mathrm{P}_{40}$, elevando-se rapidamente a partir desta, sendo que nas densidades mais altas o número de plantas foi maior.

A comparação pelo teste de Tukey, Tabela 23, no entanto, não revelou diferenças significativas para a compara ção das mëdias de densidades, e para as médias de proporções a penas $\mathrm{P}_{100}$ diferiu significativamente $(\mathrm{P}<0,05)$ quando compa rada às demais proporções, enquanto que as demais comparações mostraram-se não significativas.

O. número de plantas de leguminosa ao final do ensaio variou entre 4,42 plantas $/ \mathrm{m}^{2}$ em $\mathrm{D}_{50}$ a $5,39 \mathrm{plantas} / \mathrm{m}^{2} \mathrm{em}$ $D_{150}$, enquanto que para o efeito proporções a variação foi de $3,31 \mathrm{plantas} / \mathrm{m}^{2}$ em $\mathrm{P}_{80} \mathrm{plantas} / \mathrm{m}^{2}$ em $\mathrm{P}_{100}$.

Os resultados encontrados, com exceção da propor ção leguminosa exclusiva, são aproximadamente iguais aos cita. dos por RIBEIRO (1979), com 2,8;5,2 e 2,2 plantas/m ${ }^{2}$ para di ferentes métodos de plantio; e 2,1 e 4,7 plantas $/ \mathrm{m}^{2}$ para dife rentes épocas, sendo que em ambos os casos as dosagens de se mentes foi de 30 sementes viāveis/m² para a mistura centrose ma, galactia e siratro, onde cada espécie participou com uma taxa de semeadura de 10 sementes viāveis $/ \mathrm{m}^{2}$. 
4.2. Consorciação Setária-Siratro

\subsubsection{Porcentagem de Matéria Seca}

As porcentagens de matéria seca por corte estão expressas nas Tabelas, enquanto que as variações no teor médio anual estão representadas nas Figuras.

4.2.1.1. Porcentagem de matéria seca da compo nente gramínea

A Tabela 24 mostra a porcentagem de matéria seca da componente gramínea nos cortes realizados. A variação média anual deste parâmetro está expressa na Figura 12 .

4.2.1.2. Porcentagem de matéria seca da compo nente leguminosa

As porcentagens de matéria seca da componente le guminosa (média de 4 repetições) nos cortes realizados estão expressas na Tabela 25.

A variação média anual de matéria seca desta com ponente está representada na Figura 13 . 


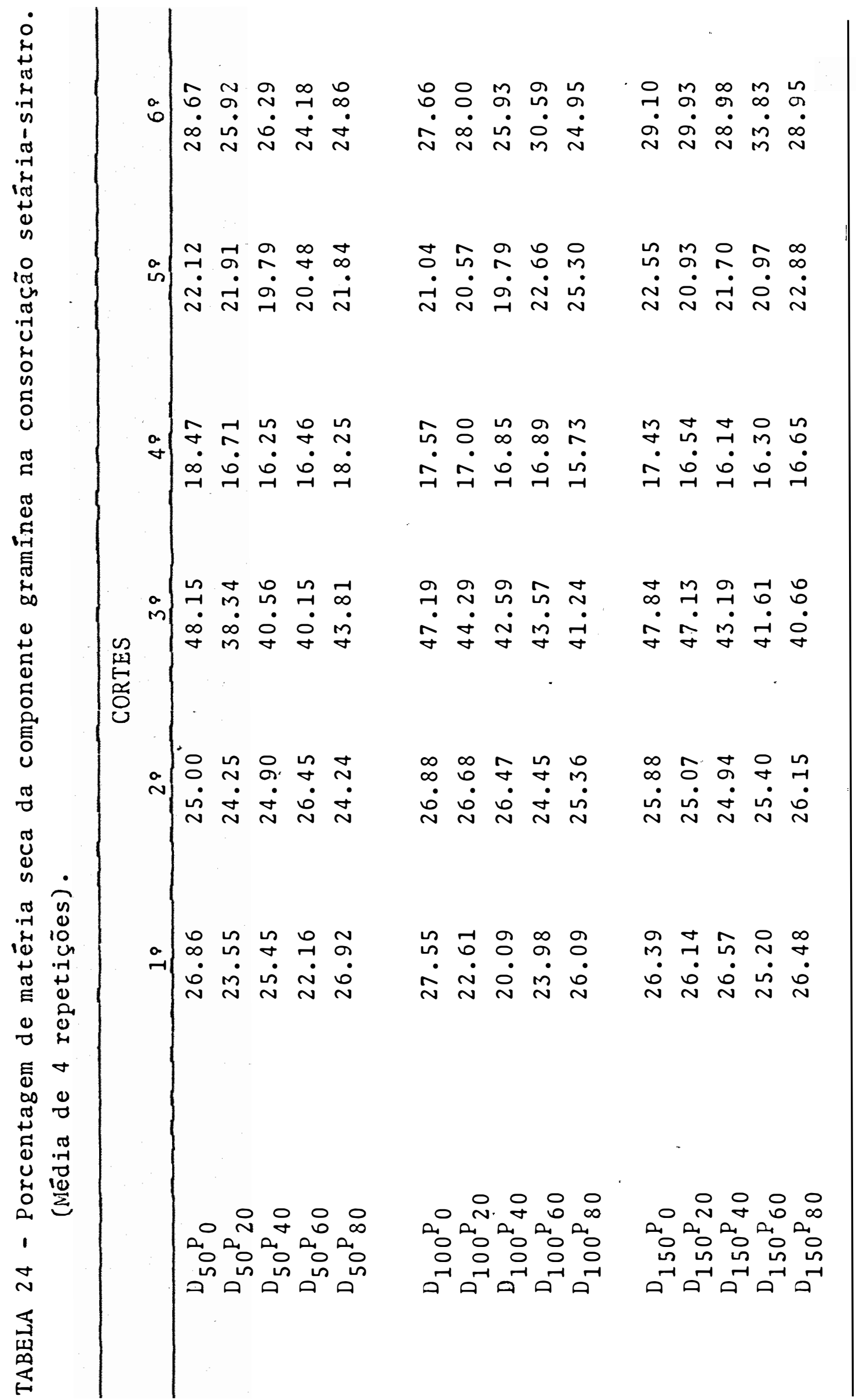




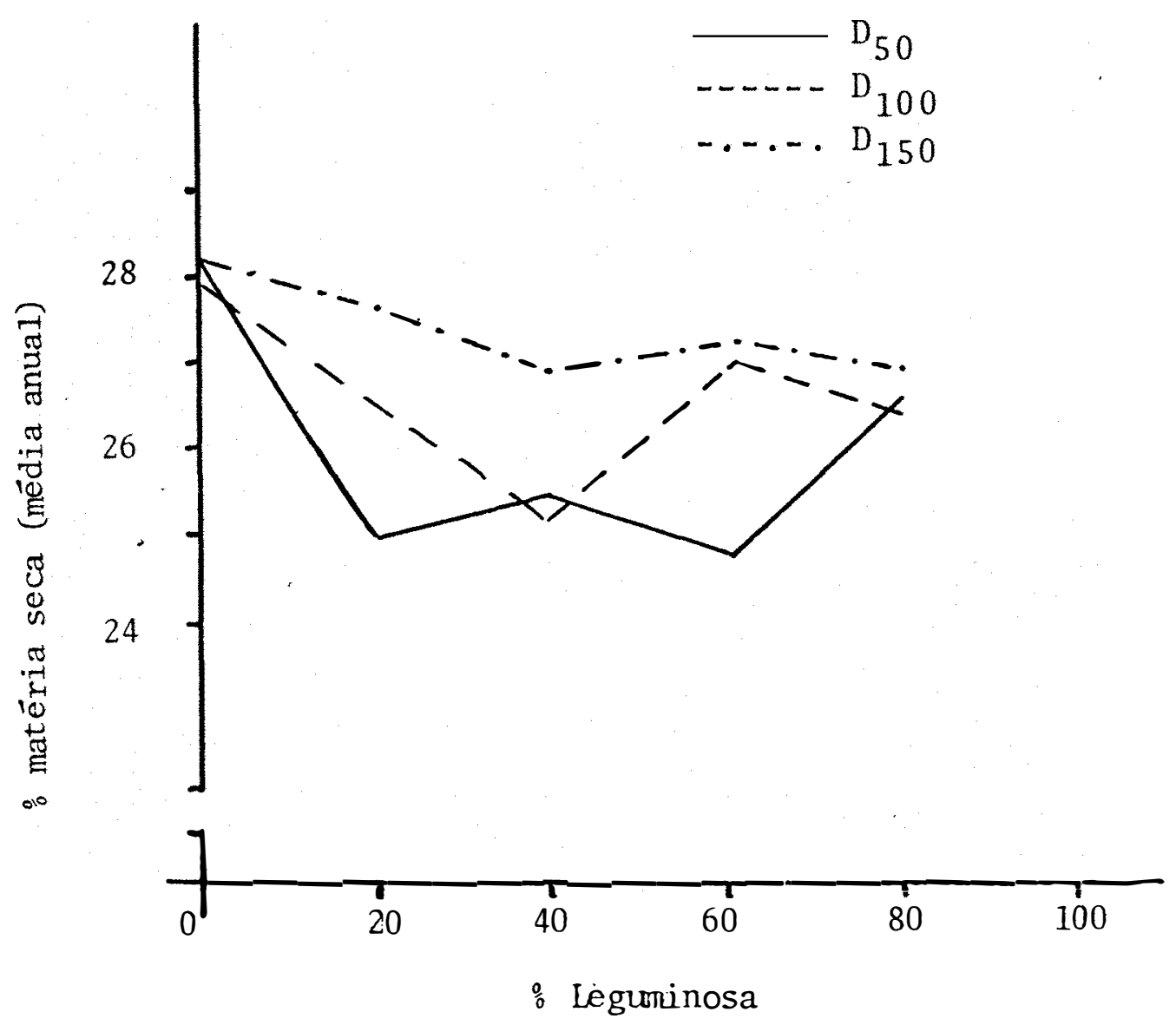

FIGURA 12 - Variação na porcentagem média anual de matéria seca da componente gramínea na consorciação setária-sira tro (média de 7 repetições). 


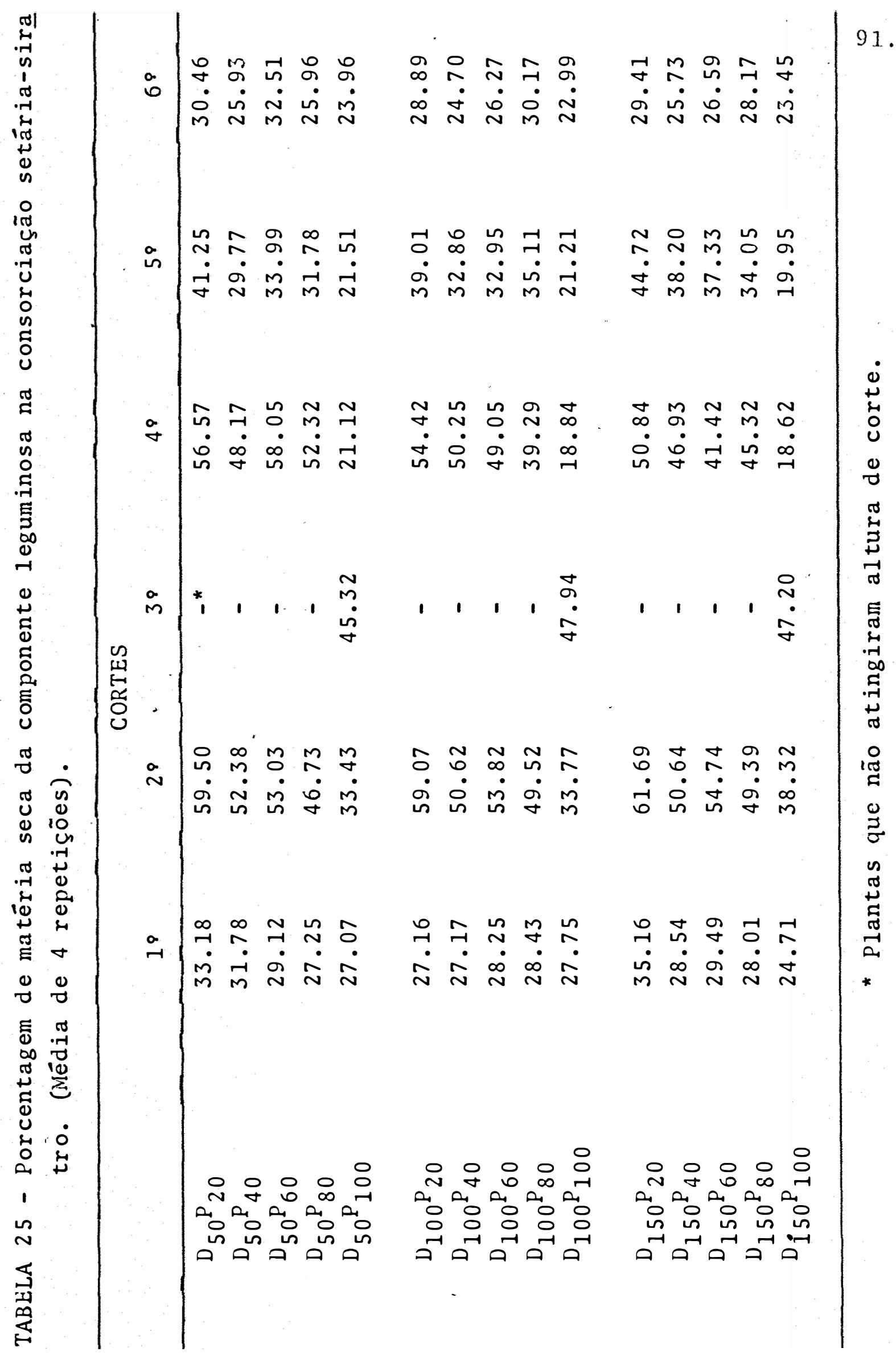




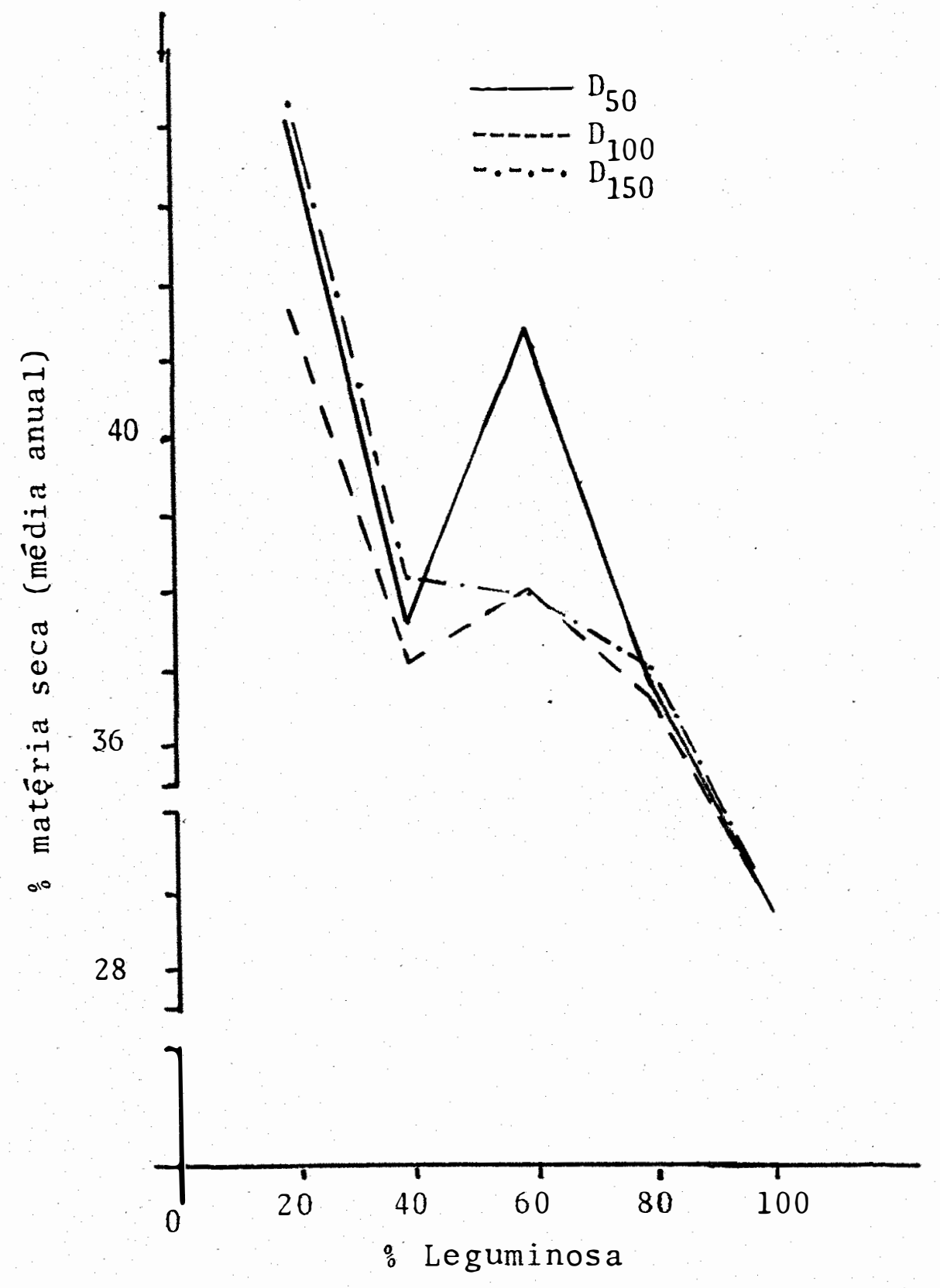

FIGURA 13 - Variação na porcentagem média anual de matéria se ca da componente leguminosa na consorciação setā ria-siratro (média de 6 cortes). 


\subsubsection{Producão Anual de Matéria Saca}

\subsubsection{Produção anual de matêtia seca da coin ponente graminca}

A Tabela 26 contem a anälisc de variancia paxa a produção anuel de materia seca da componente gramínea na con sorciação setäriamsiratro. Os valorcs de F encontrados rcrelam -se significativos em $P$, o que implica em dizer que a produ fão anual desta componente foi afctada pela proporção gramínea - loguminosa estabelecida. No desdobramento da interação P $x$, o valor de F cncontrado foi significativo para $P$ dentro ${ }^{\top 5} 50$, que implica ajzer que na densidade 50 plantas/m² a producão anual da componente graminea tambëm foi afetada pela proporço estabe1ecida.

A Tabela 26 contem também os cstudos de regres são realizados. Para o efeito $P$ nota-se cuc a produção anual da componente gramínca se ajusta a equação linear, com $\mathbb{R}^{2}$ igual a $85,71 \%$; e ainda quc, para o desdobramento da interação P $x$, $\mathrm{P}$ dentro $\mathrm{D}_{50}$ e $\mathrm{P}$ dentro $\mathrm{D}_{100}$ também se ajustam a equacões Ii neares, com $\mathrm{R}^{2}$ de $62,37 \%$ e $81,12 \%$, respectivamente.

A Figura 14(a) mostra o efeito da proporção gra mínea-leguminosa na produção anual de matêria seca da componen te gramínea. Pode-se concluir daí que a produção de matéria se ca da componente gramínea apresenta um comportamento linear ne gativo com o aumento na porcentagem de leguminosa na mistura. 
TABLl 26 - Mnảise de variancia, desdobramonto da interação $P \times D$, decomposição da $\mathrm{SQ}$ dos efeitos e coeficien tes de deteminaça $\left(R^{2}\right)$ paxa a produça de mate ria seca da componente graninea (t/ha/ano) na consorciaģão setäriamsiratro.

\begin{tabular}{|c|c|c|c|}
\hline Causas de Variação & G.I. & Q.M. & $\mathrm{R}^{2}$ \\
\hline Blocos & 3 & 18,790766 & \\
\hline Densidades (D) & 2 & 11,785354 & \\
\hline $\mathrm{L}$ & 1 & 10,1100 & 42,89 \\
\hline Q & 1 & 13,4600 & $57,1.0$ \\
\hline Reäsuo (a) & 6 & 11,099858 & \\
\hline Proporção (P) & 4 & $14,168292^{* *}$ & \\
\hline L & 1 & $48,5770 * *$ & 85,71 \\
\hline Q & 1 & 1,4135 & 2,49 \\
\hline$P \times \quad D$ & 8 & 2,029905 & \\
\hline$P$ dentro $b_{50}$ & 4 & $9,684709^{*}$ & \\
\hline$\dot{L}$ & 1 & $24,1640 * *$ & 62,37 \\
\hline Q & 1 & 0,0936 & 0,24 \\
\hline P dentro D 100 & 4 & 4,567983 & \\
\hline $\mathrm{I}$ & 1 & $14,8230^{*}$ & 81,12 \\
\hline Q & 1 & 3,2016 & 17,52 \\
\hline$P$ dentro $B_{150}$ & 4 & 3,975408 & \\
\hline $\mathrm{L}$ & 1 & 10,9300 & 68,73 \\
\hline Q & 1 & 0,3317 & 2,08 \\
\hline Resíduo & 36 & 3,017675 & \\
\hline D) dentro $\mathrm{P}_{0}$ & 2 & 2,617825 & \\
\hline $\mathrm{L}$ & 1 & 2,6220 & 50,08 \\
\hline Q & 1 & 2,6135 & 49,91 \\
\hline
\end{tabular}


Tabela 26 - continuação.

\begin{tabular}{|c|c|c|c|}
\hline Causas de Vaxjação & G.L. & $Q \cdot M$ & $R^{2}$ \\
\hline$D$ dentro $P_{20}$ & 2 & 7,152300 & \\
\hline $\mathrm{L}$ & 1 & 8,9464 & 62,54 \\
\hline Q & 1 & 5,3581 & 37,45 \\
\hline$D$ dentro $P_{40}$ & 2 & 0,847074 & \\
\hline $\mathrm{L}$ & 1 & 0,0561 & 3,31 \\
\hline$Q$ & 1 & 1,6380 & 96,68 \\
\hline$D$ dentro $P_{60}$ & 2 & 4,068134 & \\
\hline $\mathrm{L}$ & 1 & 8,0801 & 99,31 \\
\hline Q & 1 & 0,0560 & 0,68 \\
\hline i) dentro $p_{80}$ & 2 & 5,239634 & \\
\hline L & 1 & 0,0115 & 0,10 \\
\hline Q & 1 & 10,4280 & 99,89 \\
\hline Resíduo & 22 & 4,634111 & \\
\hline
\end{tabular}



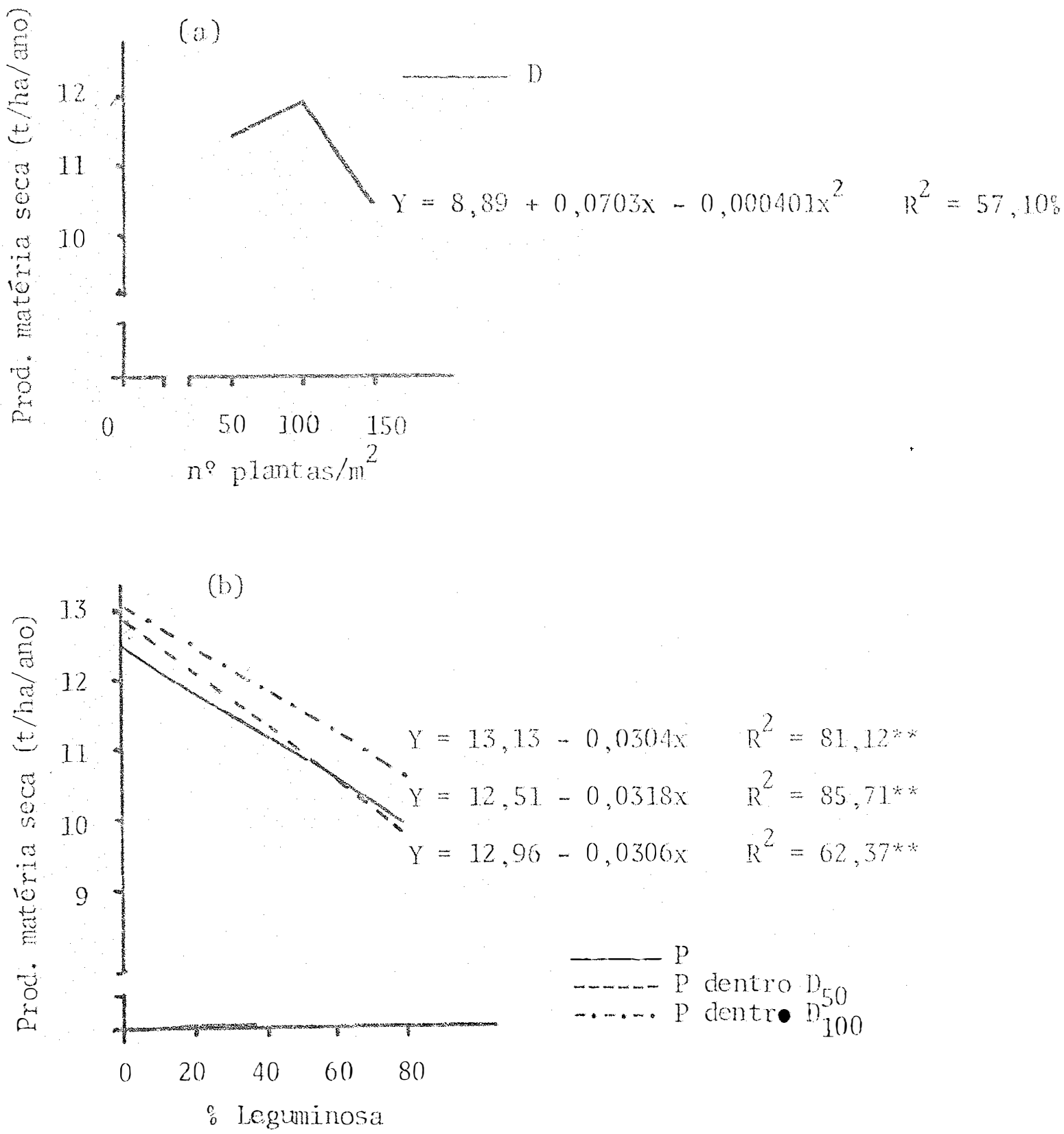

FIGURA 14 - Efeito da densidade de plantas (a) e da proporção graminea-leguminosa estabelecida (b) na produção de matëria seca da componente gramínea (t/ha/ano), na consorciação setẩia-siratro. 
A relagăo graminea. leguminosa roi estabolecia com base no nü mero de plantas/m², o que implica dizer que quando aumentanse a participacão da componente leguminosa na proporgäo, amenta-se o núnero de plantas desta componente com a consequente re dução no nünero de plantas de gramínea.

Segundo AKINOLA (1981), GONCALVES e BARRETO (1979), aumentos na taxa de semeadura (com consequente aumen tos no numero de plantas/m², implican em aumentos na producão de matêra seca, em concordância com os resultados obtidos.

As produções de matêria seca da componente gramí nea encontradas variaram entre 11,41 t/ha/ano (na densidade 50 plantas $/ m^{2}$ ) $11,91 \mathrm{t} / \mathrm{ha} /$ ano (na densidade $100 \mathrm{plantas} / \mathrm{m}^{2}$ ) e $10,40 \mathrm{t} / \mathrm{ha} / \mathrm{ano}$ (na densidade $150 \mathrm{plantas} / \mathrm{m}^{2}$ ), pouco diferindo das producões de matëria seca do capjm setäria citadas por LUCK (1979), que Éi de 10,0 t/ha/ano, e da citada por TIATRU (1972), com 12,7 thatano, quando usaram taxas de semeadura entre 1,5 e $2,0 \mathrm{~kg} / \mathrm{ha}$.

Apesar de não significativa a decomposição da SQ de densidades revela un efeito quadrático com $\mathrm{R}^{2}$ de $57,10 \%$, en tre densidades e produção de matêria seca da componente gramí nea. A Figura $14($ b) mostra que a produção de matéria seca da componente gramīnea aumenta atê a densidade de $100 \mathrm{plantas} / \mathrm{m}^{2}$, entretanto, quando eleva-se a densidade a partir deste ponto, há uma queda na produção, ocasionada pela competição entre plan tas. Resultados idênticos foram encontrados por WEYERSBERG (1972), que aumentou a producão de matéria seca de azevêm quan 
do aumentou a taxa de semeadura ate $1.200,0$ scmentes viaveis/ $\mathrm{m}^{2}$, sendo que a producão permaneceu constante ate a taxa de se meadura de $1.400,0$ sementes viaveis $/ \mathrm{m}^{2}$, sendo que a partir des ta, a produça de materia scca diminuiv quando aumentou-se a taxa de semeadura.

A comparacão das medias pelo teste de Tukey (Ta bola 27) revela que as densidades não diferem quando compara das entre si, enquanto que a comparagão entre médias de propor sões revela $P_{0}$ diferindo significativamente $(P<0,05)$ quando comparado com $P_{40}$ e $P_{80}$, e que as demais comparacoes entre mé dias mostraramuse não significativas.

4.2.2.2. Produção anval de materia seca da com ponente leguminosa

A Tabela 28 contem a anälise de variancia dos da dos obtidos para a produção anual de matéxia seca da componen te leguminosa na consorciação setäria-siratro. Os valores de F encontrados se mostram altamente significativos para $P$ e nodes dobramento da interasão $\mathrm{P} x \mathrm{D}$ para $\mathrm{P}$ dentro $\mathrm{D}_{50}$, $\mathrm{P}$ dentro $\mathrm{D}_{100}$ " P dentro $\mathrm{D}_{150}$, o que implica dizer que o parâmetro analisado foi afetado pela proporfão gramínea-leguminosa estabelecida em todas as densidades em estudo; e também foi significativo para D dentro $\mathrm{P}_{100}$, o que indica que a proporsão $0 \%$ gramínea - $100 \%$ leguminosa a densidade afetou a producão anual de matéria seca da componente leguminosa. 
Tabela 27 - Diferencas minimas significativas para a conparaça de médias, coeficientes de variação e equacõos de regressĩo usadas na análise de variância para a producão de matexia seca da componente graminea (t/ha/ino) na consorciacão setária-siratro (media de 4 repetiçoes).

\begin{tabular}{|c|c|c|c|c|c|c|}
\hline \multirow[t]{2}{*}{ DENSIDADES } & & $D_{50}$ & & $\mathrm{D}_{100}$ & & $\mathrm{D}_{250}$ \\
\hline & & $11,41 \mathrm{a}$ & & $11,91 \mathrm{a}$ & & $10,40 a$ \\
\hline \multirow[t]{2}{*}{ PIOPORGOES } & & $\mathrm{P}_{0}$ & $P_{20}$ & $\mathrm{P}_{40}$ & $P_{60}$ & $\mathrm{P}_{80}$ \\
\hline & & $12,86 a$ & $11,53 \mathrm{ab}$ & $10,81 \mathrm{~b}$ & $11,09,11$ & $9,90 b$ \\
\hline \multirow[t]{3}{*}{ D.M.S. $(5 \%)$} & & & $\mathrm{D}$ & & $p$ & \\
\hline & & & 3,23 & & 2,03 & \\
\hline & & & (a) & & (b) & \\
\hline \multirow[t]{2}{*}{$C . V \cdot\left(\begin{array}{l}0 \\
0\end{array}\right)$} & & & 29,63 & & 15,44 & \\
\hline & & \multicolumn{3}{|c|}{ EQUACOES DE REGRESSÃO } & & $\mathrm{R}^{2} \quad\left(\begin{array}{l}0 \\
1\end{array}\right)$ \\
\hline Proporşōes & L & $Y=12,51$ & $-0,0318$ & $x$ & & $85,71 * *$ \\
\hline$P$ dentro $D_{50}$ & $L$ & $Y=12,96$ & $-0,0306$ & $x$ & & $62,37 * *$ \\
\hline P dentro $D_{100}$ & $L$ & $Y=13,13$ & $-0,0304$ & $x$ & & $81,12^{*}$ \\
\hline
\end{tabular}


TABELA 28 - Anảise de variancia, desdobranento da interação $P \times D$, decompesiça da $S Q$ dos efeitos e coeficien tes de deterninação $\left(\mathrm{R}^{2}\right)$ para a produção de mate ria seca da componente leguminosa (t/ha/ano) na consorciaço setäria-siratro.

\begin{tabular}{|c|c|c|c|}
\hline Causas de Variação & G.L. & $\mathrm{Q} \cdot \mathrm{M}$ & $\mathrm{R}^{2}$ \\
\hline B1ocos & 3 & 1,014788 & \\
\hline Densidades (D) & 2 & 0,762668 & \\
\hline$L$ & 1 & 1,4478 & 94,91 \\
\hline Q & 1 & 0,0775 & 5,08 \\
\hline Resíduo (a) & 6 & 0,512550 & \\
\hline Proporção (P) & 4. & $261,348389^{* *}$ & \\
\hline $\mathrm{L}$ & 1 & $595,5400 *$ & 56,96 \\
\hline Q & 1 & $318,690 * *$ & 30,48 \\
\hline$P \times 1$ & 8 & $0,5 \$ 5720$ & \\
\hline$P$ dentro $D_{50}$ & 4 & $86,437219^{* * *}$ & \\
\hline $\mathrm{L}$ & 1 & $201,4200 * *$ & 58,25 \\
\hline Q & 1 & $101,5700 * \%$ & 29,37 \\
\hline$P$ dentro $v_{100}$ & 4 & $74,843217 * *$ & \\
\hline $\mathrm{L}$ & 1 & $174,9300 * *$ & 58,43 \\
\hline Q & 1 & $91,9800 * *$ & 30,72 \\
\hline P dentro ${ }^{1150}$ & 4 & $101,239392 * *$ & \\
\hline $\mathrm{L}$ & 1 & $220,5200 * *$ & 54,45 \\
\hline$Q$ & 1 & $126,6000 * *$ & 31,26 \\
\hline Residuo & 36 & 0,479201 & \\
\hline v dentr $\bullet \mathrm{P}_{20}$ & 2 & 0,215358 & \\
\hline $\mathrm{L}$ & 1 & 0,2850 & 66,17 \\
\hline Q & 1 & 0,1457 & 33,82 \\
\hline $\mathrm{D}$ dentro $\mathrm{P}_{40}$ & 2 & 0,072400 & \\
\hline $\mathrm{L}$ & 1 & 0,1352 & 93,37 \\
\hline Q & 1 & 0,0096 & 6,62 \\
\hline
\end{tabular}


Tabela 28 - continuação.

\begin{tabular}{|c|c|c|c|}
\hline Causas de Variaça & G.L. & $Q \cdot M$ & $R^{2}$ \\
\hline i) dentro PGo & 2 & 0,097308 & \\
\hline L & 1 & 0,1770 & 90,95 \\
\hline$Q$ & 1 & 0,0176 & 9,04 \\
\hline$D$ dentro P 80 & 2 & 0,194475 & \\
\hline L & 1 & 0,0288 & 7,40 \\
\hline$Q$ & 1 & 0,3601 & 92,59 \\
\hline D dentro P 100 & 2 & $2,520000 * *$ & \\
\hline $\mathrm{L}$ & 3 & $2,3653^{*}$ & 46,81 \\
\hline$Q$ & 1 & $2,6867^{*}$ & 53,18 \\
\hline Residiuo & 40 & 0,435871 & \\
\hline
\end{tabular}


A decomposicão da $S Q$ de $P$ (Tabola 28 ) mostra que houve efeitos linear e quadrätica e que a producão anual de ma têria seca da componente leguminosa se ajusta a essas equacões, com $x^{2}$ de $56,96 \%$ (lincar) e $30,48 \%$ (quadratica).

No desdobramento da interacão $P x \mathrm{~J}$, observa-se que para a decomposigäo da SQ, p dentro D, as componentes 1 i near e quadrätica se mostraram signjficativas para as três densidades, sendo que os $R^{2}$ foram de 58,25 e 29,37 , para a den sidade 50 plantas $/ \mathrm{m}^{2} ; 58,43$ e 30,72 para a densidade 100 plan tas $/ \mathrm{m}^{2} ; e 54,45$ e 31,26 para a densidade $150 \mathrm{plantas} / \mathrm{m}^{2}$. A de composicáa de $S Q$ de D dentro P mostra que para D dentro P 100 os efeitos significativos foram linear e quadrätico, com $R^{2}$ de 46,81 e $53,18 \%$, respectivamente.

Os fatores agronomicos que possam ter interferi do nos resultados não puderam ser explicados através de equa cões cübicas e de graus superiores. No presente parâmetro a curva de produção anual de matêria seca da componente legumino

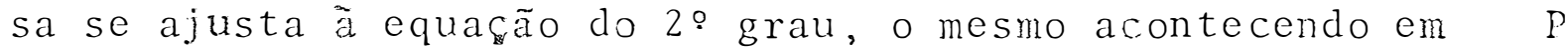
dentro $\mathrm{D}_{50}$, P dentro $\mathrm{D}_{100}$ e P dentro $\mathrm{D}_{150}$, e as curvas foram traçadas com os valores estimados por esta equação.

A Figura $15(\mathrm{a})$ mostra o efeito da densidade de plantas na produção anual de matêria seca da componente legumi nosa, onde nota-se que esta tem uma ligeira queda quando ele va-se a densidade de 50 para $100 \mathrm{p} I$ antas $/ \mathrm{m}^{2}$, entretanto, torna a se elevar quando a densidade de plantas passa para 150 plan tas $/ \mathrm{m}^{2}$, o que contraria as afirmacões de MIJ)LETON (1973), que 

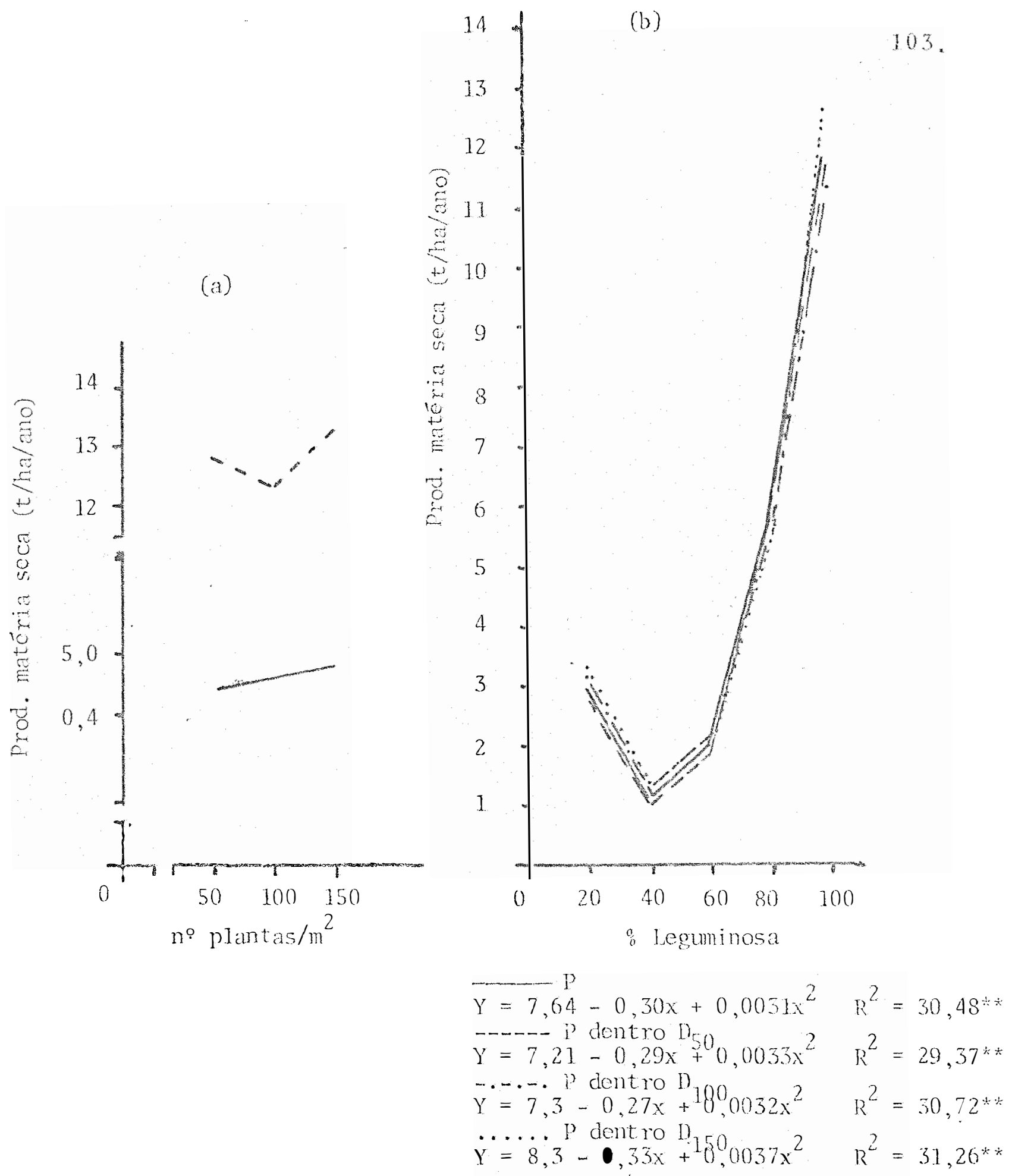

FIGURA 15 - Efeito da densidade de plantas (a) e da proporçao gramínea-leguminosa estabelecjda (b) na produção de matéria seca da componente leguminosa. (t/ha/ ano) na consorciação setária-siratro. 
aumentou a produgäo de materia scca da componente loguminosa com aumentos na taxa de scmeadura, c RICKERT e HUMPIREYS (1970), que aumentaram ate detcrminado limitc a producia do ma têria scca com aumentos no numero de plantas/m².

A Figura 15(b) mostra um comportamento pratica mentc scmelhante para as densidades com pequenos aumentos c de crêscimos na producão anual do matéria scca da componcnte Icgu minosa quando clcva-sc a participacão desta compononte na pro porção cstabclecida, com consequente aumento no numcro de plan tas desta componente. Entretanto, quando clevou-sc a proporção de P80 para P'100 houve um acentuado aumento na produção do ma téria scca da componcntc. A produção do matéria scca, no cntan to, em linhas gerais, aumenta com a proporgão graminca-1egumi nosa (aumenta com numero de plantas, uma vez que as proporcões são cstabelecidas com base nas densidades), concordando, desta forma, com JONES (1971).

As produções de matéria scca anual da componente leguminosa foi supcrior, exceção à P100 (lcouminosa cxclusiva) às citadas por NG (1976), que obteve produçõcs de 2,35 c 4,61 t/ha/ano; por THAIRU (1972), com 2,32 t/ha/ano; por AKINOLA (1981) com 1,74 e 2,32 t/ha/ano; por TOSI et alii (1979), com 4,4 e 1,9 t/ha/ano; por RAYMENT et alii (1977) com 3,5 t/ha/ ano e por MONTEIRO et alii (1980) com 1,8 t/ha/ano, scndo, en tretanto, inferior à citada por MATTOS et alii (1977) com 5 a $6 \mathrm{t} / \mathrm{ha} / \mathrm{ano}$.

No efeito proporf̧öcs as producõcs variaram entre 


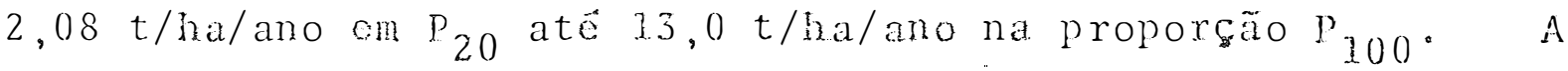
comparação das mêdias pelo teste de T'ukey mostra que as dersi dades não difexem significativamente quardo comparadas entre si, e que as compaxac̃es entre as mêdias de proporgões mostrou $\mathrm{P}_{100}(13,0 \mathrm{t} / \mathrm{ha} / \mathrm{ano})$ diferindo significativamente $(\mathrm{P}<0,05)$ das outras médias de proporcões; enquanto que nas demais compa raçoes realizadas apenas $\mathrm{P}_{80}(3,10 \mathrm{t} / \mathrm{ha} / \mathrm{ano})$ diferiu significa tivamente $(P<0,05)$ de $P_{20}(2,08$ iha/ano $)$, enquanto que as demais mostraram-se não significativas (Tabela 29).

4.2.2.3. Producão anual conjunta de matêria se $\mathrm{ca}$

A análise de variância dos dados obtidos para a produçáo anuaj conjunta de matéria seca na consorciagáo setâa ria-siratro está contida na Tabela 30 . Os valores de F encon trados não se revelaram signićicativos para nenhum dos fatores em estudo, o que significa que a produção anual conjuntia de ma têria seca da consorciação setäria-siratro não teve efeito de densidades de plantas, da proporcão gramínea-leguminosa estabe lecida, nem da interação destes fatores.

Apesar dos valores de F não significativos, fo ram realizados estudos de regressão para os efeitos D e P, vi sando identificar una relação funcional entre os fatores testa dos e os parâmetros analjsados. Na anảlise da Tabela 48 nota-se que apesar dos efeitos não significativos, as curvas de 
TABLuA 29 - Diforengas minimas significativas para a comparação de mêdias, coeficientes de variaço e equa çös de regrossão usadas na anälise de variancia paxa a produção de nateria seca da componente $10-$ guninosa (t/ha/ano) na consorciação setária - siratro (Media de 4 repetiçöes).

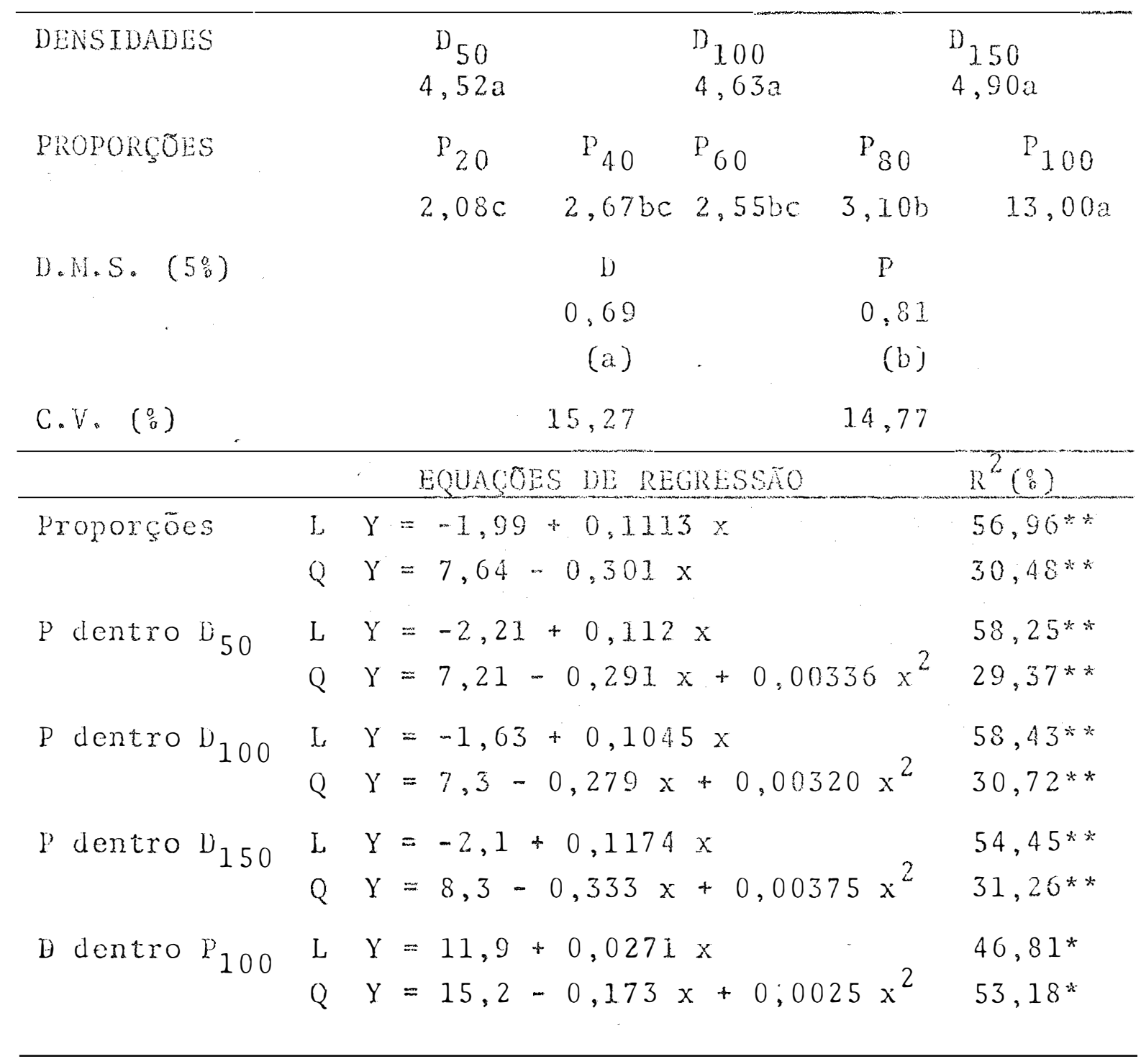


TABELA 30 - Anālise de variância descobramento da interação $P \times D$, decomposiçäo da $S Q$ dos efcitos e cocficien tes de determinação $\left(R^{2}\right)$ para a produção conjunta de matéria seca (t/ha/ano) na consoxciação setá ria-siratro.

\begin{tabular}{|c|c|c|c|}
\hline Causas de Variação & G. L. & Q.M. & $R^{2}$ \\
\hline B3ocos & 3 & 13,348787 & \\
\hline Densidades $(U)$ & 2 & 6,196231 & \\
\hline $\mathrm{L}$ & 1 & 3,8025 & 30,68 \\
\hline Q & 1 & 8,5898 & 69,31 \\
\hline Resíduo (a) & 6 & 12,049605 & \\
\hline Proporçōes (P) & 5 & 1,376016 & \\
\hline $\mathrm{L}$ & 1 & 0,0761 & 1,10 \\
\hline Q & 1 & 4,8540 & 70,55 \\
\hline $\mathrm{P} \times \mathrm{X}$ & 10 & 3,177551 & \\
\hline $\mathrm{P}$ dentro $\mathrm{D}_{150}$ & 5 & 2,358248 & \\
\hline $\mathrm{L}$ & 1 & 1,0812 & $9, .17$ \\
\hline Q & 1 & 2,5029 & 21,22 \\
\hline$P$ dentro $b_{100}$ & 5 & 2,950086 & \\
\hline $\mathrm{L}$ & 1 & 2,5175 & 17,06 \\
\hline Q & 1 & 4,6647 & 31,62 \\
\hline$P$ dentro $D_{150}$ & 5 & 2,422775 & \\
\hline $\mathrm{L}$ & 1 & 4,6157 & 38,10 \\
\hline Q & 1 & 0,0055 & 0,04 \\
\hline Resíduo (b) & 45 & 2,921829 & \\
\hline b dentro $\mathrm{P}_{0}$ & 2 & 2,617825 & \\
\hline $\mathrm{L}$ & 1 & 2,6220 & 50,08 \\
\hline Q & 1 & 2,6135 & 49,91 \\
\hline
\end{tabular}


Tabela 30 - continuação.

\begin{tabular}{|c|c|c|c|}
\hline Causas de varią̧̃o & G.L. & $Q \cdot M$. & $R^{2}$ \\
\hline 1) dentro $\mathrm{P}_{20}$ & 2 & $6,6512.34$ & \\
\hline $\mathrm{L}$ & 1 & 6,0204 & 45,25 \\
\hline Q & 1 & 7,2820 & 54,74 \\
\hline D) dentro P 40 & 2 & 0,681034 & \\
\hline $\mathrm{L}$ & 1 & 0,3698 & 27,14 \\
\hline Q & 1 & 0,9922 & 72,84 \\
\hline$D$ dentro $P_{60}$ & 2 & 2,973309 & \\
\hline L & 1 & 5,9340 & 99.78 \\
\hline$Q$ & 1 & 0,0126 & 0,21 \\
\hline$D$ dentro P 80 & 2 & 6,634576 & \\
\hline $\mathrm{L}$ & 1 & 0,1711 & 1,28 \\
\hline Q & 1 & 13,0980 & 98,71 \\
\hline$D$ dentro $P_{100}$ & 2 & 2,526009 & \\
\hline $\mathrm{L}$ & 1 & 2,3653 & 46,31 \\
\hline Q & 1 & 2,6867 & 53,18 \\
\hline Residuo & 25 & 4,443041 & \\
\hline
\end{tabular}


produção conjunta de matêria seca anual para densidades e pa ra proporgões se ajustam às equacões quadräticas, com $R^{2}$ de 69,31 e $70,55^{\circ}$, respectivamente.

Na Figura $16(\mathrm{a})$ nota-se que a produção anual con junta de matêria seca quando a densidade passou de 50 para 100 plantas $/ \mathrm{m}^{2}$; entretanto, quando esta aumentoupara 150 plantas/ $m^{2}$ a produção anual conjunta de matéria secia declinou, uma vez que as plantas passam a competir entre si pelos fatores de crescimento. Este resultado concorda com MIDDLETON (1973), que afirma ser maior a resposta a aumentos na clensidade de legumi nosa em presença de densidades de gramíneas mais baixas.

A Figura 16(b) mostra o efeito da proporsão gra minea-leguminosa na produčão anua] conjunta de matêria seca. Observa-se que à modida que introduz-se a leguminosa na propor ção, há un pequeno aumento na producão conjunta de matéria se ca, que pode ser atribuído a uma maior quantidade de nitrogẹ nio introduzida no sistema. A produção anual conjunta de matê ria seca se estabiliza entre $\mathrm{P}_{40}$ e $\mathrm{P}_{60}(13,5$ t/ha/ano) e a par tir daí tende a declinar, uma vez que a leguminosa apresenta um menor potencial para a produção de matéria seca quando com parado com a gramínea, e sua substituicão gradativa pela legü minosa não compensa a redução na produção de matéria seca, de acordo com VIEIRA (1974), que afirmou que a produção de matẻ ria seca em altas densidades tende ao equilíbrio, com o decor rer do tempo.

As produçoes anuais de matêria seca para a con 
110.

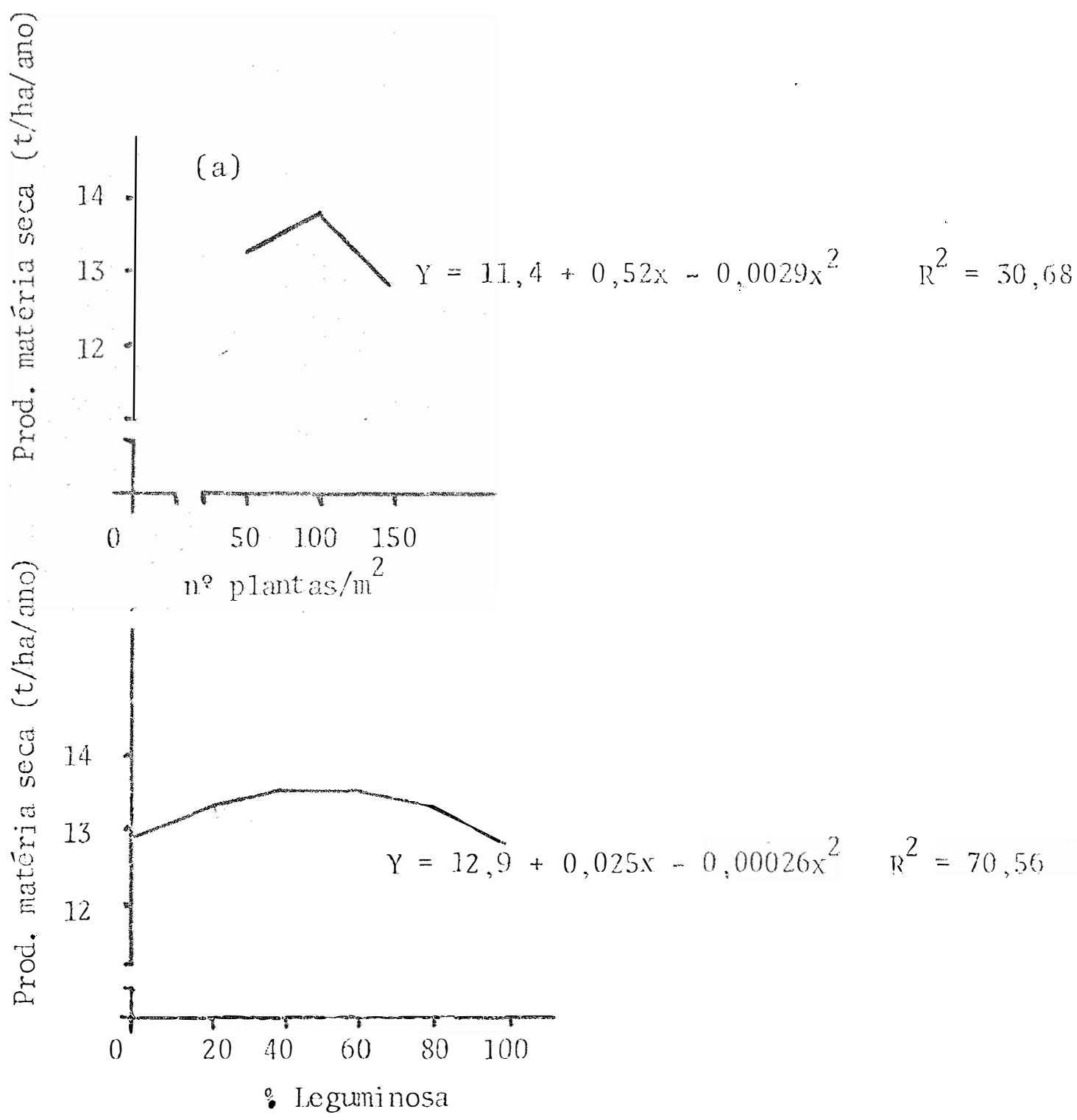

FIGURA 16 - Efeito da densidade de plantas (a) e da proporsão gramínea-leguminosa estabelecida (b) na produsão conjunta de matêria seca (t/ha/ano) na consorcia ção setâria-siratro. 
- Tabela 31 ... Difercnças mínimas significativas para a comparaçón de médias, cocficientes de variação e cquaçöes de regressão usadas na anailise de variancia para a produço conjunta cle matêria scca (t/ha/ano) da consorciaça setäria-sira tro (nédia de 4 repetições).

\begin{tabular}{|c|c|c|c|c|c|c|}
\hline \multirow[t]{2}{*}{ IDENSIDADES } & & $\mathbf{D}_{50}$ & \multicolumn{3}{|c|}{$\mathrm{D}_{100}$} & $\mathrm{D}_{150}$ \\
\hline & & $13,32 \mathrm{a}$ & \multicolumn{3}{|c|}{$13,77 a$} & $12,76 a$ \\
\hline \multirow[t]{2}{*}{ PROPORCOES } & $\mathrm{P}_{0}$ & $\mathrm{P}_{20}$ & $\mathrm{P}_{40}$ & $P_{60}$ & $P_{80}$ & $P_{100}$ \\
\hline & $12,86 a$ & $13,62 \mathrm{a}$ & $1.3,46 a$ & $13,66 a$ & $13,09 a$ & $13,00 \mathrm{a}$ \\
\hline \multirow[t]{2}{*}{ D.M.S. } & & - & $\begin{array}{c}D \\
3,07\end{array}$ & & $\begin{array}{c}P \\
2,07\end{array}$ & \\
\hline & & & (a) & & (b) & \\
\hline \multirow[t]{2}{*}{$C . V .\left(\begin{array}{l}0 \\
0\end{array}\right)$} & & & 26,12 & & 12,86 & \\
\hline & & \multicolumn{4}{|c|}{ EQUACOOES DE RECRESSÃO } & $\mathrm{R}^{2}\left(\frac{0}{6}\right)$ \\
\hline Dcinsidades & $\mathrm{Q}$ & $Y=11,4$ & $+0,0529$ & $x-0,00$ & $93 x^{2}$ & 30,68 \\
\hline Proporções & $Q$ & $Y=12,9$ & $+0,025 x$ & $r-0,000$ & $26 x^{2}$ & 70,55 \\
\hline
\end{tabular}


sorciação setäria-siratro $(12,76$ a 13,12 t/ha/ano $)$ foram supe riores às citadas por JONES et alii (1976) na consorciação Pae palum plicatulum-siratro (10,4 t/ha/ano); ligeiranente inferio res à citada por THAIRU (1972) na consorciação setâria - desmô dio ( 14,7 t/ha/ano), e mostraram-se superiores aos citados por GONSALVEZ e BARRETO (1979), na consorciação Rhodes-siratro (3,0 -5,5 t/ha/ano); e as citadas por RIBEIRO (1979) na consorciacão Napier-leguminosa (centrosema + galactia + siratro) (9,5 $-11,6$ t/ha/ano) .

A comparação das médias pelo teste de Tukey nãa mostrou significância entre as médias de densidades, nem entre as mêdias de proporções (Tabela 31).

4.2.3. Teor de Proteina Bruta

Os teores de proteína bruta por corte estão ex pressos nas Tabelas, enquanto que os teores mêdios anuais e tão representados nas Figuras.

4.2.3.1. Teor de proteína bruta da componente gramínea

Os teores mẹdios de proteína bruta por corte es tão expressos na Tabela 32; enquanto que a Figura 17 represen ta a variação média anual deste teor na componente gramínea da consorciação setäria-siratro. 
113.

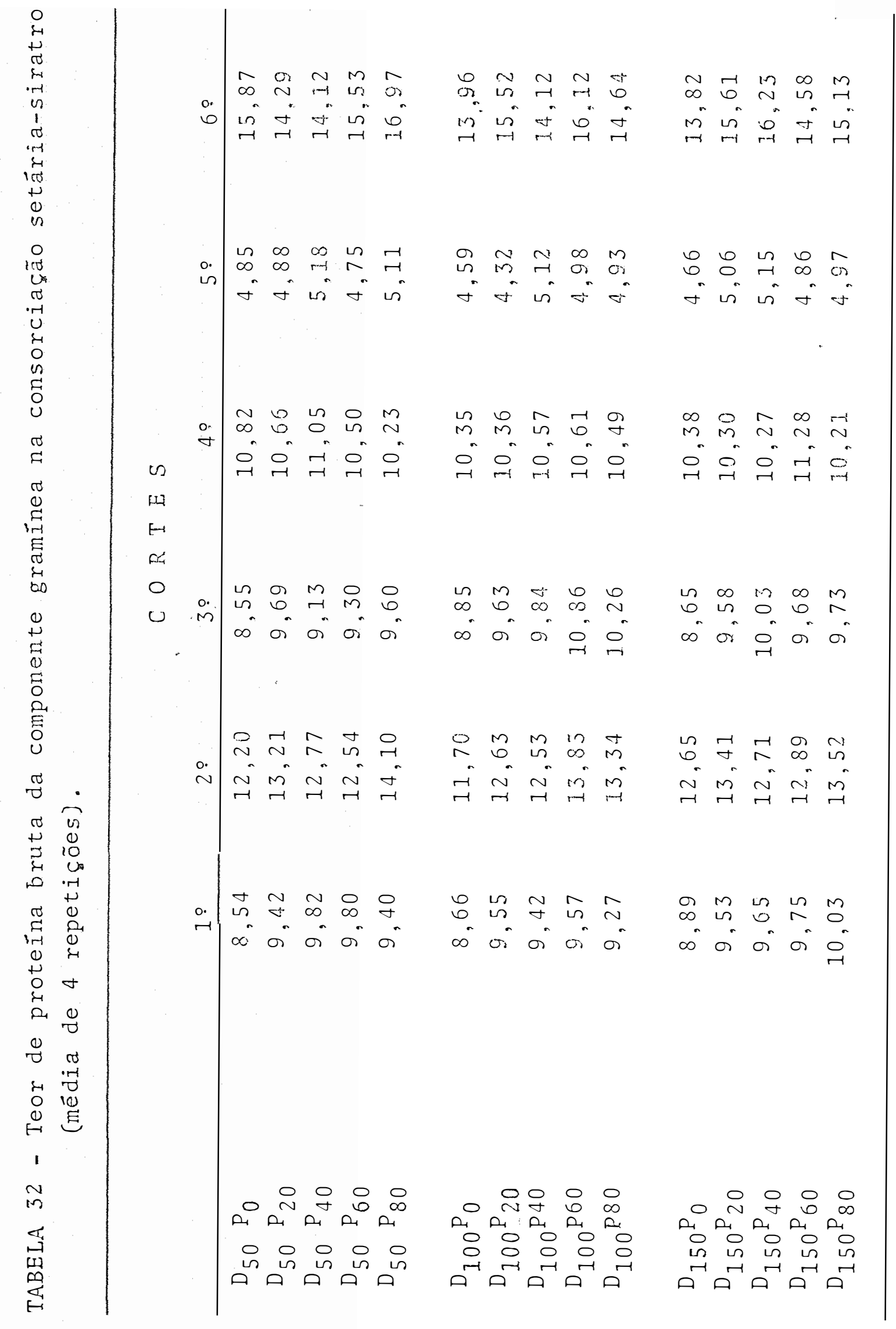


114.

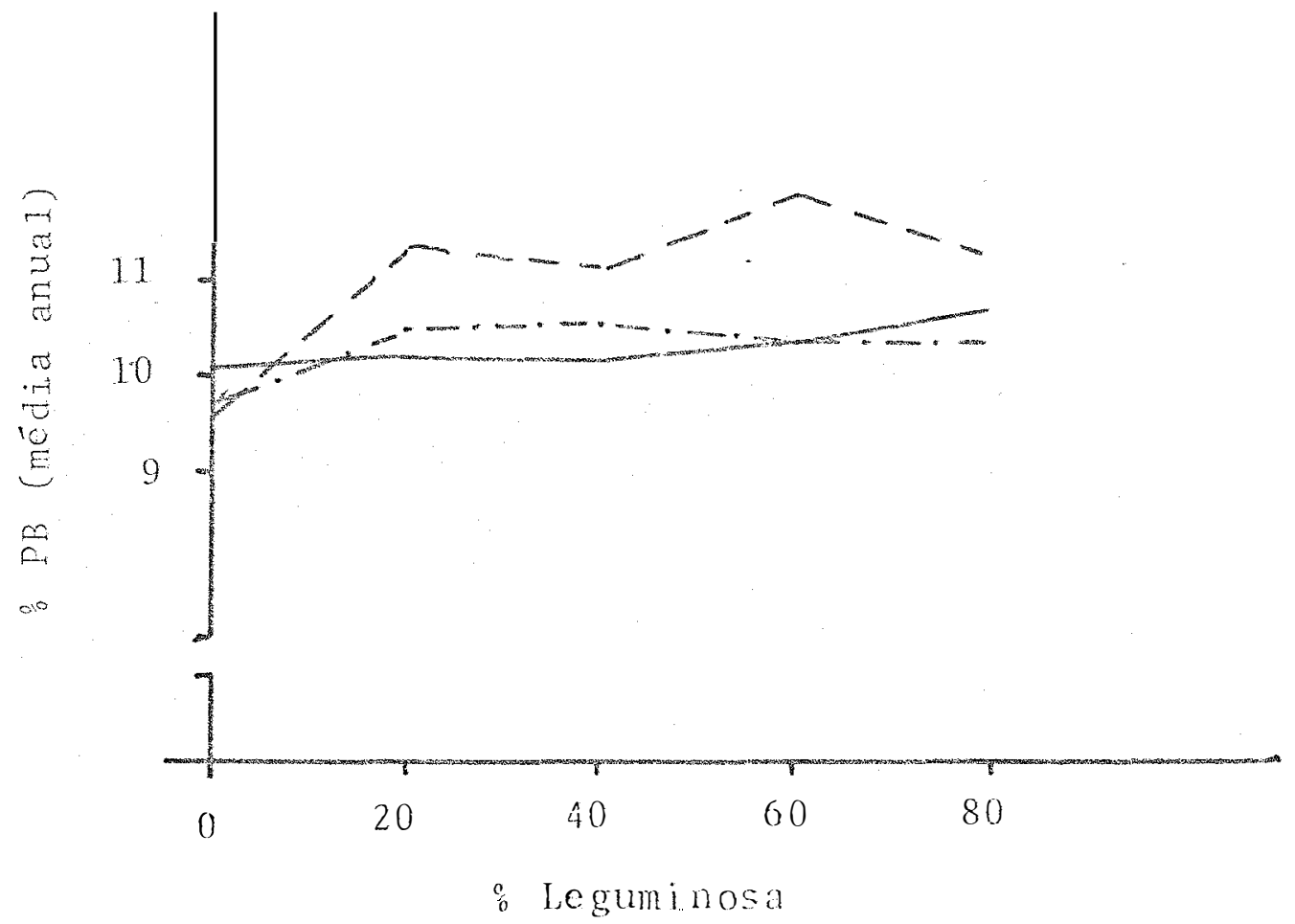

FIGURA 17 - Variação no teor médio anual de proteína bruta da componente gramínea na consorciação setāria - sira tro (média de 6 cortes). 
4.2.3.2. Teor de proteina bruta da componente leguminos a

A Tabela 33 contem os teores mëdios de proteína bruta da componente leguminosa nos diversos cortes realizados. Já a Figura 18 mostra a variação média anual deste teor na con sorciação setäria...siratro.

\subsubsection{Produção Anual de Protejna Bruta}

4.2.4.1. Produção de proteina bruta da componen te gramínea

A anâlise de variância dos dados obtidos nos mos tra através da Tabela 34, que os valores de F obtidos mostra ram-se signjficativos para $\mathrm{P}$ e no desdobramento $\mathrm{P} x \mathrm{D}$, para $\mathrm{O}$ efeito $\mathrm{P}$ dentro $\mathrm{D}_{50}$, o que nos indica que a porcentagem gramí nea-leguminosa influiu na produçäo anual de proteína bruta da componente gramínea, tanto nas proporçoes quanto na proporsão dentro da densidade 50 plantas $/ \mathrm{m}^{2}$.

A decomposição da SQ de P mostra (Tabela 34) que a produção anual de proteína bruta da componente graminea se alusta a equação linear com $R^{2}$ jgual a $92,98^{\circ}$.

No desdobramento da interação $\mathrm{P} \times \mathrm{D}$ a decomposi cão da SQ de $P$ dentro $D$ revela que apenas para $P$ dentro $D_{50}$ a componente linear se mostrou significativa, com $R^{2}$ de $74,07 \%$. 
116.

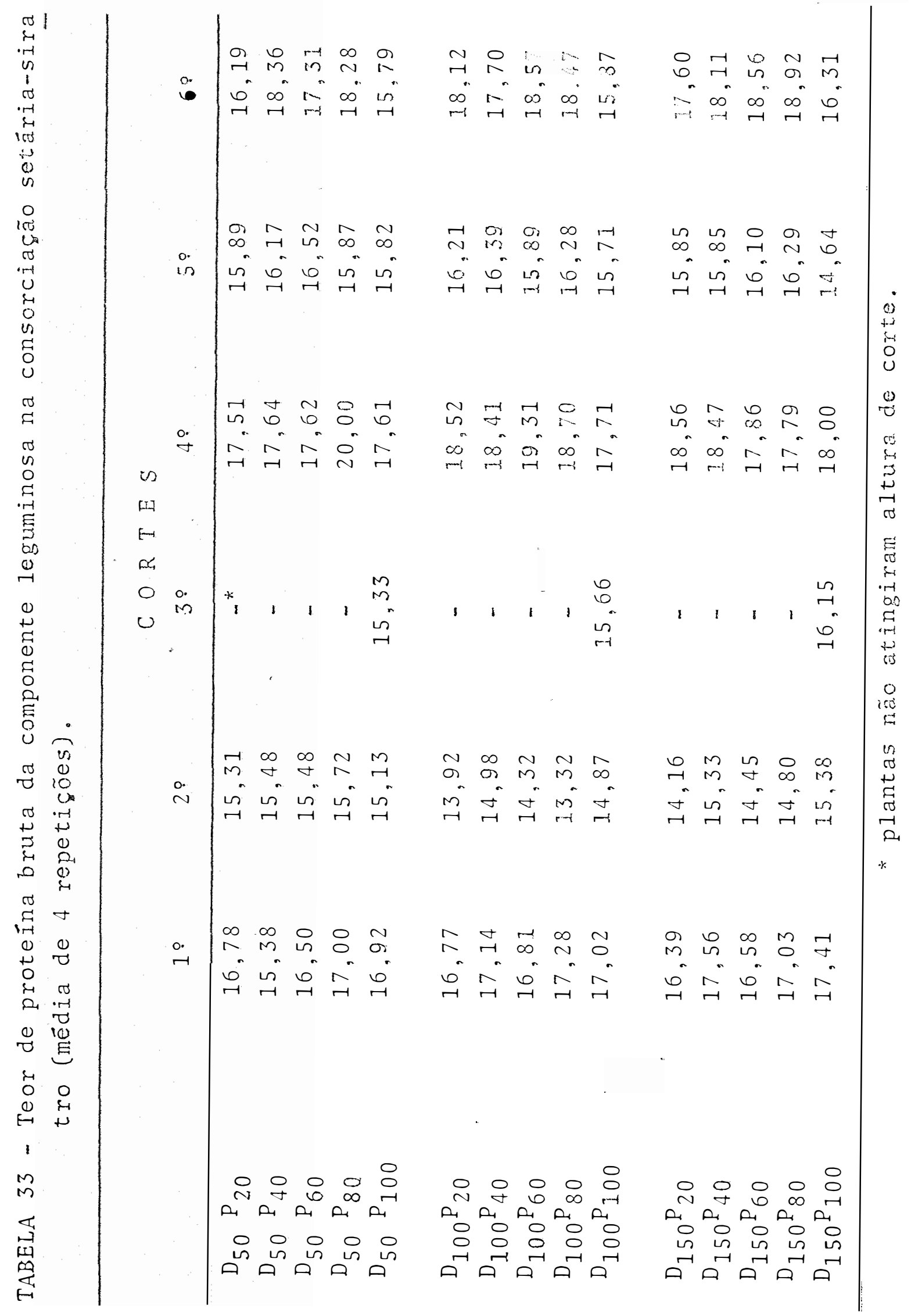




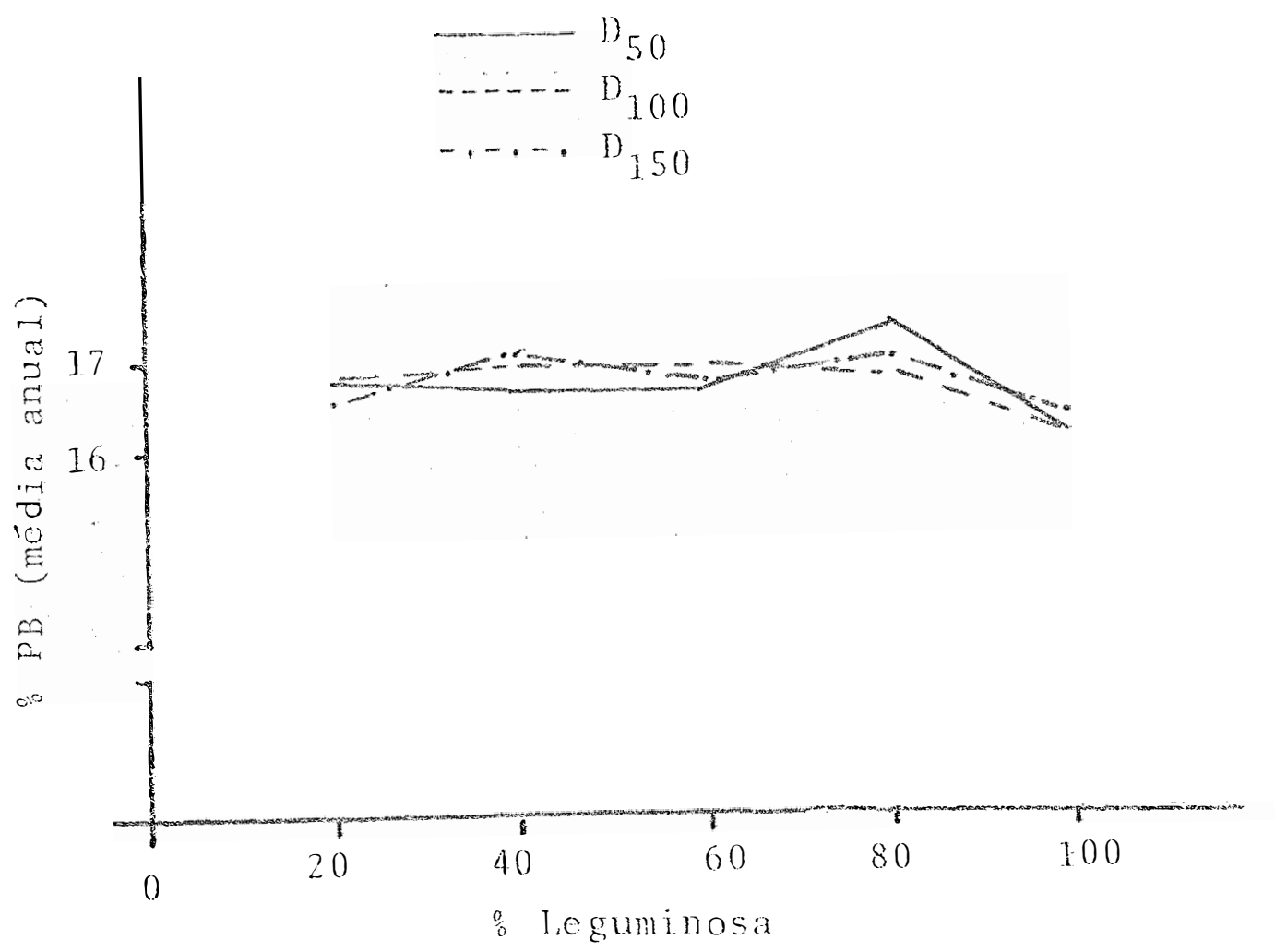

FIGURA 18 - Variação no teor mẻdio anual de proteína bruta da componente leguminosa na consorciação setäria--sira tro (mêdia de 6 cortes). 
TARELA 34 - Anâlise de variância, desdobramento da interação P $x$ D, decompesicão da SQ dos efeitos e coeficientes de determinação $\left(R^{2}\right)$ para a produçāo de proteína bruta da componcnte graminea (t/ha/ano) na consor ciação setäria-siratro.

\begin{tabular}{|c|c|c|c|}
\hline Causas de Variação & G.L. & Q.M. & $\mathrm{R}^{2}$ \\
\hline Blocos & 3 & 0,182513 & \\
\hline $\begin{array}{l}\text { Densidades (D) } \\
\text { I. } \\
\text { Q }\end{array}$ & $\begin{array}{l}2 \\
1 \\
1\end{array}$ & $\begin{array}{l}0,091932 \\
0,1288 \\
0,0550\end{array}$ & $\begin{array}{l}70,06 \\
29,93\end{array}$ \\
\hline Resĩduo (a) & 6 & 0,082264 & \\
\hline $\begin{array}{c}\text { Proporsöes (P) } \\
\text { L } \\
\text { Q }\end{array}$ & $\begin{array}{l}4 \\
1 \\
1\end{array}$ & $\begin{array}{l}0,130093^{* *} \\
0,4838^{* *} \\
0,0077\end{array}$ & $\begin{array}{r}92,98 \\
1,48\end{array}$ \\
\hline$P \times I)$ & 8 & 0,016029 & \\
\hline $\begin{array}{c}\text { P dentro } D_{50} \\
L \\
Q\end{array}$ & $\begin{array}{l}4 \\
1 \\
1\end{array}$ & $\begin{array}{l}0,096395^{*} \\
0,2856^{* *} \\
0,0023\end{array}$ & $\begin{array}{r}74,07 \\
0,60\end{array}$ \\
\hline $\begin{array}{l}\text { P dentro } D_{100} \\
\mathrm{~L} \\
\mathrm{Q}\end{array}$ & $\begin{array}{l}4 \\
1 \\
1\end{array}$ & $\begin{array}{l}0,037570 \\
0,1276^{*} \\
0,0157\end{array}$ & $\begin{array}{l}84,96 \\
10,49\end{array}$ \\
\hline $\begin{array}{l}\text { P dentro } D_{150} \\
\mathrm{~L} \\
\mathrm{Q}\end{array}$ & $\begin{array}{l}4 \\
1 \\
1\end{array}$ & $\begin{array}{l}0,028187 \\
0,0980 \\
0,0004\end{array}$ & $\begin{array}{r}86,92 \\
0,40\end{array}$ \\
\hline Resícluo & 36 & 0,030029 & \\
\hline $\begin{array}{c}\text { D dentro } \mathrm{P}_{0} \\
\mathrm{~L} \\
\mathrm{Q}\end{array}$ & $\begin{array}{l}2 \\
1 \\
1\end{array}$ & $\begin{array}{l}0,048824 \\
0,0946 \\
0,0030\end{array}$ & $\begin{array}{r}96,88 \\
3,11\end{array}$ \\
\hline $\begin{array}{c}\text { D dentro } P_{20} \\
\text { L } \\
Q\end{array}$ & $\begin{array}{l}2 \\
] \\
1\end{array}$ & $\begin{array}{l}0,0351.00 \\
0,0364 \\
0,0337\end{array}$ & $\begin{array}{l}51,92 \\
48,07\end{array}$ \\
\hline $\begin{array}{c}\text { D dentro } \mathrm{P}_{40} \\
\mathrm{~L} \\
\mathrm{Q}\end{array}$ & $\begin{array}{l}2 \\
1 \\
1\end{array}$ & $\begin{array}{l}0,003558 \\
0,0004 \\
0,0066\end{array}$ & $\begin{array}{r}6,32 \\
93,67\end{array}$ \\
\hline
\end{tabular}


TABEIA 34 - continuadão.

\begin{tabular}{cccc}
\hline Causas de Variaçio & G.I. & Q.M. & $R^{2}$ \\
\hline & & & \\
D) dentro $P_{60}$ & 2 & 0,034033 & \\
L & 1 & 0,0648 & 95.20 \\
Q & 1 & 0,0032 & 4.79 \\
D) dentro $P_{80}$ & 2 & 0,034533 & \\
L & 1 & 0,0008 & 1,15 \\
Q & 1 & 0,0682 & 98,84 \\
Resíduo & 27 & 0,040476 & \\
& & & \\
\hline
\end{tabular}


Apesar de não significativo $p$ dentro $D_{100}$, quancio decomposta mostra que a componente linear foi significativa, con $R^{2}$ de $84,96 \%$

Para o efeito densidades, obscrva-se (Figura 19. a), una queda linear (embora nä́o significativo) no teor médio anual de proteína bruta da componente leguminosa, à medida que aumentou-se à densidade de plantas.

Na Figura 19 (b) nota-se que a produçăo anual de proteina bruta da componente graminea diminui linearmente com o aumento da proporção gramineamleguminosa, o que não era espe rado, pois com o aumento da participação da leguminosa na mis tura, há consequentemente uma recução no numero de plantas de gramîneas com a redução na produção, entretanto, um maior núme ro de plantas de leguminosa leva a una maior quantidade de ni trogênio no sistema.

Entretanto, na densidade $100 \mathrm{plantas} / \mathrm{m}^{2}$ a dimi. nuição na produção anual de protcína bruta foi menor, o que im plica dizer que comparativamente às outras densidades, D100 foi a que melhor se comportou com relação ao parâmetro em discus são.

Os resultados obtidos, no entanto, foram lige ramente inferiores aos encontrados por THAIRU (1972) na consor ciação setäria-desmodium, com $250 \mathrm{~kg} / \mathrm{ha}$ de $\mathrm{N}$ (aproximadamente $1.562,5 \mathrm{~kg} / \mathrm{ha} /$ ano de proteína bruta).

A comparação das médias pelo teste de Tukey mos tra que para as médias de densidades as comparações se mostra 

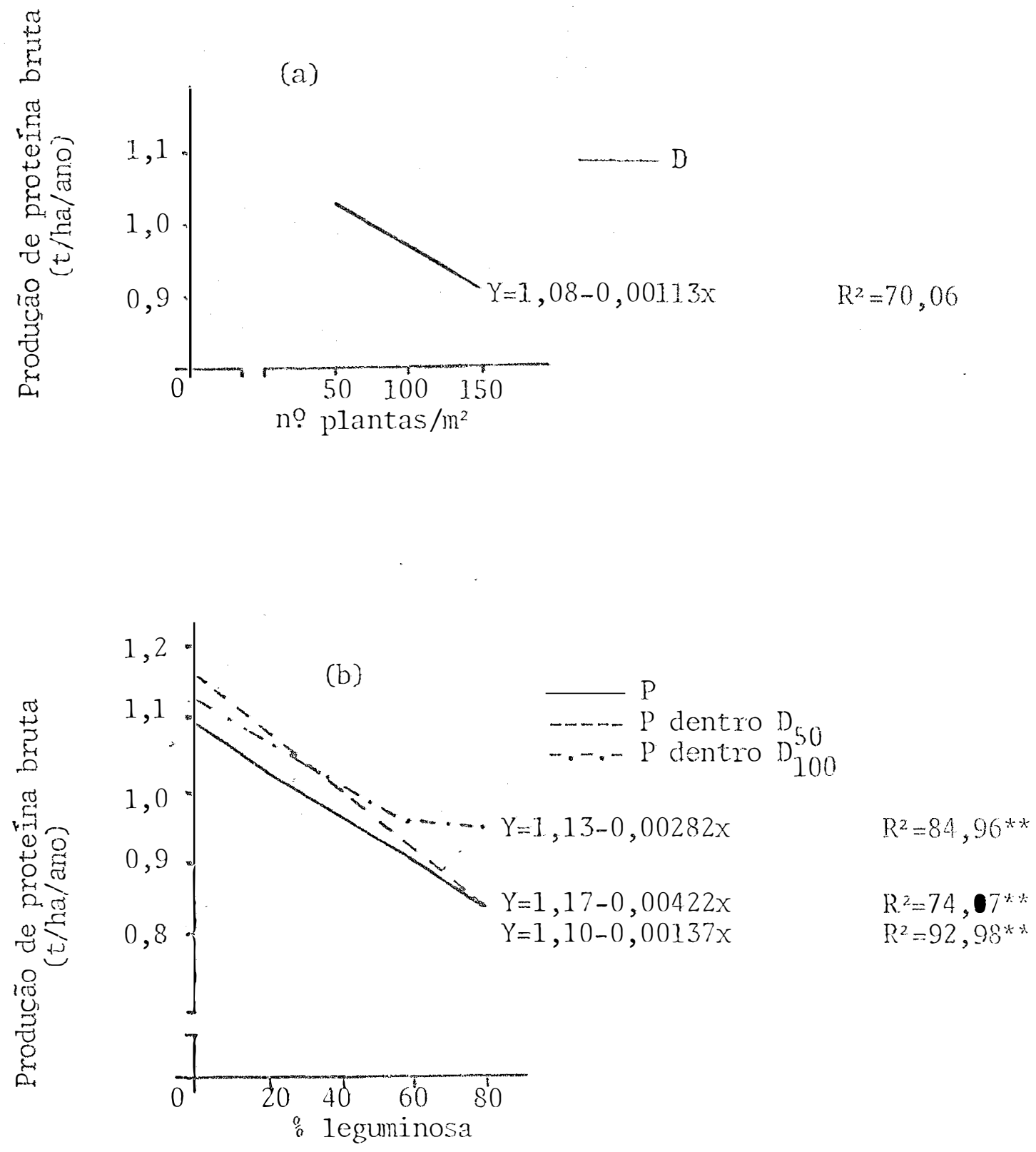

Figura 19 - Efeito da densidade de plantas (a) e da proporsão graminea-1eguminosa estabelecida (b) na produção de proteína bruta da componente gramínea (t/ha/ano) na consorciação setäria-siratro. 
- Tabela 35. - Diferencas mínimas signiricativas para a comparação de médias, coeficientes de variação e equaçôs de regressão usadas na análisc de variância para a produção de protcina bruta da componente graminea ( $t / h a / a n o)$ na con sorciação setária-siratro (média de 4 repetições).

\begin{tabular}{|c|c|c|c|c|c|c|}
\hline \multirow[t]{2}{*}{ DENSIDADES } & & $\mathrm{D}_{50}$ & \multicolumn{3}{|c|}{$\mathrm{D}_{100}$} & $\mathrm{D}_{150}$ \\
\hline & & 1,09 & \multicolumn{3}{|c|}{ l,0la } & $0,89 a$ \\
\hline \multirow[t]{2}{*}{ PROPORCOES } & & $\mathrm{P}_{0}$ & $\mathrm{P}_{20}$ & $\mathrm{P}_{40}$ & $P_{60}$ & $\mathrm{P}_{80}$ \\
\hline & & $1,12 \mathrm{a}$ & $1,00 a b$ & $0,95 \mathrm{ab}$ & $0,94 \mathrm{ab}$ & $0,84 b$ \\
\hline \multirow[t]{3}{*}{ D.M.S. $(5 \%)$} & & & $\mathrm{D}$ & & $\mathrm{P}$ & \\
\hline & & & $0,2.7$ & & 0,20 & \\
\hline & & & (a) & & (b) & \\
\hline \multirow[t]{2}{*}{$C . V .\left(\frac{\rho}{\partial}\right)}$. & & & 29,39 & & 17,76 & \\
\hline & \multicolumn{4}{|c|}{ EQUIACOES DE REGRESSÃO } & & $\mathrm{R}^{2}\left(\frac{10}{\theta_{i}}\right)$ \\
\hline Propors.ões & $\mathrm{L}$ & $Y=1,10$ & $-0,0031$ & $x$ & & $92,98 * *$ \\
\hline$P$ dentro $D_{50}$ & $\mathrm{~L}$ & $Y=1,17$ & $-0,0042$ & $\mathrm{x}$ & & $74,07 * *$ \\
\hline P dentro $\mathrm{D}_{100}$ & $\mathrm{~L}$ & $Y=1,13$ & $-0,0028$ & $x$ & & $84,96 * *$ \\
\hline Densidades & $\mathrm{L}$ & $Y=1,08$ & $-0,0011$ & $x$ & & 70,06 \\
\hline
\end{tabular}


ram não significativas, enquanto que para as mëdias de propor ções as comparaçoos mostram Po djferindo significativanente (P $<0,05)$ apenas de $\mathrm{P}_{100}$, enquanto que as demais comparacöes se mostraram não significativas (Tabela 35).

A melhor producão de proteina bruta $(1,09$ t/hal ano) foi obtida na densidade $50 \mathrm{plantas} / \mathrm{m}^{2}$, enquanto que para o efeito $\mathrm{P}$ a melhor produção $\left(1,12\right.$ t/ha/ano) foi obtida em $\mathrm{P}_{0}$.

4.2.4.2. Produção anual de proteina bruta da componente leguminosa

A Tabela 36 contem a anälise de variância dos da dos obtidos para a produção anual de proteína bruta na compo nente leguminosa, onde observa-se que os valores de F encontra dos mostraxam-se significativos para o efeito P, e no desdobra mento $\mathrm{P} \times \mathrm{D}$ foi significativo para $\mathrm{P}$ dentro $\mathrm{D}_{50}$, $\mathrm{P}$ dentro $\mathrm{P}_{100}$, P dentro $\mathrm{D}_{150}$ e para $\mathrm{D}$ dentro $\mathrm{P}_{100}$, o que indica que a produ ção de proteina bruta da componente leguminosa foi afetada pe 1a proporção gramínea-leguminosa estabelecida nas três densida des em estudo, e ainda que em $\mathrm{P}_{100}$ as densidades também afeta ram o parâmetro em questão.

$\mathrm{Na}$ decomposição da SQ de $\mathrm{P}$ as componentes linear e quadrätica se mostraram significativas, com $R^{2}$ respectivamen te de 58,61\% (1inear) e 29,74\% (quadrätica).

Para o desdobramento da interação P $x$ D, embora não significativa, a decomposição da SQ de p dentro D (Tabela 56) mostra que nas três densidades os efeitos linear e quadrá 
TABzel 36 - nnádise de variância, desdobramento da interação $P \times D$, decomposição da SQ dos efeitos o coeficien tes de detcrminação $\left(R^{2}\right)$ para a produção de prote na bruta da componente leguminosa (t/ha/ano) na consorciação setâriamsiratro.

\begin{tabular}{|c|c|c|c|}
\hline Causas de Variação & G.L. & Q.M. & $R^{2}$ \\
\hline Bjocos & 3 & 0,013969 & \\
\hline $\begin{array}{c}\text { Densidades (D) } \\
\text { L } \\
\text { Q }\end{array}$ & $\begin{array}{l}2 \\
1 \\
1\end{array}$ & $\begin{array}{l}0,039151 \\
0,0731 \\
0,0052\end{array}$ & $\begin{array}{r}93,35 \\
6,64\end{array}$ \\
\hline Resíduo (a) & 6 & 0,031287 & \\
\hline $\begin{array}{l}\text { Proporçōes pl } \\
\text { L } \\
\text { Q }\end{array}$ & $\begin{array}{l}4 \\
1 \\
1\end{array}$ & $\begin{array}{c}6,459277^{* *} \\
15,1440^{* *} \\
7,6853^{* *}\end{array}$ & $\begin{array}{l}58,63 \\
29,74\end{array}$ \\
\hline$P \times D$ & 8 & 0,020428 & \\
\hline $\begin{array}{l}\text { P dentro } D_{50} \\
\mathrm{~L} \\
\mathrm{Q}\end{array}$ & $\begin{array}{l}4 \\
1 \\
1\end{array}$ & $\begin{array}{l}2,003982^{* *} \\
4,7955^{* *} \\
2,3085^{* *}\end{array}$ & $\begin{array}{l}59,82 \\
28,79\end{array}$ \\
\hline $\begin{array}{l}\text { P dentro Is } 100 \\
\text { L } \\
Q\end{array}$ & $\begin{array}{l}4 \\
1 \\
1\end{array}$ & $\begin{array}{l}1,898782^{* *} \\
4,6854 * * \\
2,2120^{* * *}\end{array}$ & $\begin{array}{l}61,68 \\
29,12\end{array}$ \\
\hline $\begin{array}{l}\text { P dentro } D_{150} \\
\text { L } \\
Q\end{array}$ & $\begin{array}{l}4 \\
1 \\
1\end{array}$ & $\begin{array}{l}2,597370^{* * *} \\
5,6927^{* * *} \\
3,2208^{* * *}\end{array}$ & $\begin{array}{l}54,79 \\
31,00\end{array}$ \\
\hline Resíduo & 36 & 0,012822 & \\
\hline $\begin{array}{c}\text { D dentro P } \\
\text { L } \\
Q\end{array}$ & $\begin{array}{l}2 \\
1 \\
1\end{array}$ & $\begin{array}{l}0,006458 \\
0,0078 \\
0,0051\end{array}$ & $\begin{array}{l}60,48 \\
39,51\end{array}$ \\
\hline $\begin{array}{c}\text { D dentro } P_{40} \\
\mathrm{~L} \\
\mathrm{Q}\end{array}$ & $\begin{array}{l}2 \\
1 \\
1\end{array}$ & $\begin{array}{l}0,006258 \\
0,0120 \\
0,0005\end{array}$ & $\begin{array}{r}95,97 \\
4,02\end{array}$ \\
\hline $\begin{array}{c}\text { D dentro } P_{60} \\
\text { L } \\
Q\end{array}$ & $\begin{array}{l}2 \\
1 \\
1\end{array}$ & $\begin{array}{l}0,002608 \\
0,0032 \\
0,0020\end{array}$ & $\begin{array}{l}61,34 \\
38,65\end{array}$ \\
\hline
\end{tabular}


TABEIA 36 - continuação.

\begin{tabular}{|c|c|c|c|}
\hline Causas de Variaşão & G. I. & Q.M. & $R^{2}$ \\
\hline $\begin{array}{c}\text { D dentro } \mathrm{P}_{80} \\
\mathrm{~L} \\
\mathrm{Q}\end{array}$ & $\begin{array}{l}2 \\
1 \\
1\end{array}$ & $\begin{array}{l}0,019908 \\
0,0006 \\
0,0392\end{array}$ & $\begin{array}{r}1,53 \\
98,46\end{array}$ \\
\hline $\begin{array}{cc}\text { D dentro } & P_{100} \\
\mathrm{~L} & \\
\mathrm{Q} & \end{array}$ & $\begin{array}{l}2 . \\
1 \\
1\end{array}$ & $\begin{array}{l}0,085633^{*} \\
0,1404^{* *} \\
0,0308\end{array}$ & $\begin{array}{l}82,00 \\
1.7,99\end{array}$ \\
\hline Resíduo & 29 & 0,036515 & \\
\hline
\end{tabular}


tico se mostraram significativos, sendo que $R^{2}$ Coi, respecti vamente, para $\mathrm{P}$ dentro $\mathrm{D}_{50}, 59,82 \%$ (Iinear), 28,27\% (quadrátí ca); para P dentro $D_{100}$ foram de 61,68\% (1inear), 29,12\% (qua drática), enqauanto que para P dentro D 150 foram de $54,79 \%$ (1i near), 31,00\% (quadrätica).

Para D dentro P a decomposição da SQ mostrou que apenas em $\mathrm{P}_{100}$ a componente linear foi significativa, com o $\mathrm{R}^{2}$ igual a $82,00 \%$.

$\mathrm{Na}$ Figura 20 (a) nota-se que com o aumento do nú mero de plantas (densidade) aumentou-se o parâmetro em anâlise; e que em $\mathrm{P}_{100}$ este aumento foi mais acentuado pois a legumino sa livre da competiçăo da graminea apresentou um me thor desen volvimento.

Pela Figura $20(b)$ nota-se um aumento em $\mathrm{P}_{20}$ se guido de pequena queda em $\mathrm{P}_{40}$ e $\mathrm{P}_{60}$ e novamente a produção a nual de proteína bruta da componente leguminosa eleva-se com o aumento da porcentagem desta na mistura, nas três densidades en estudo, de certa forma esperado, pois embora a produção de ma têria seca total tenha diminuido com o aumento da participação da leguminosa na mistura, o teor de proteína bruta mais alto desta componente levou a produções cada vez maiores quando se aumentou sua participação na proporção gramínea-leguminosa es tabelecida. Tambẻm com o aumento no número de plantas de legu minosa (proporção), aumentou-se a quantidade de nitrogênio no sistema, o que permitiu que as porcentagens de proteína bruta e, consequentemente, as produções anuais de proteína bruta na 
(a)
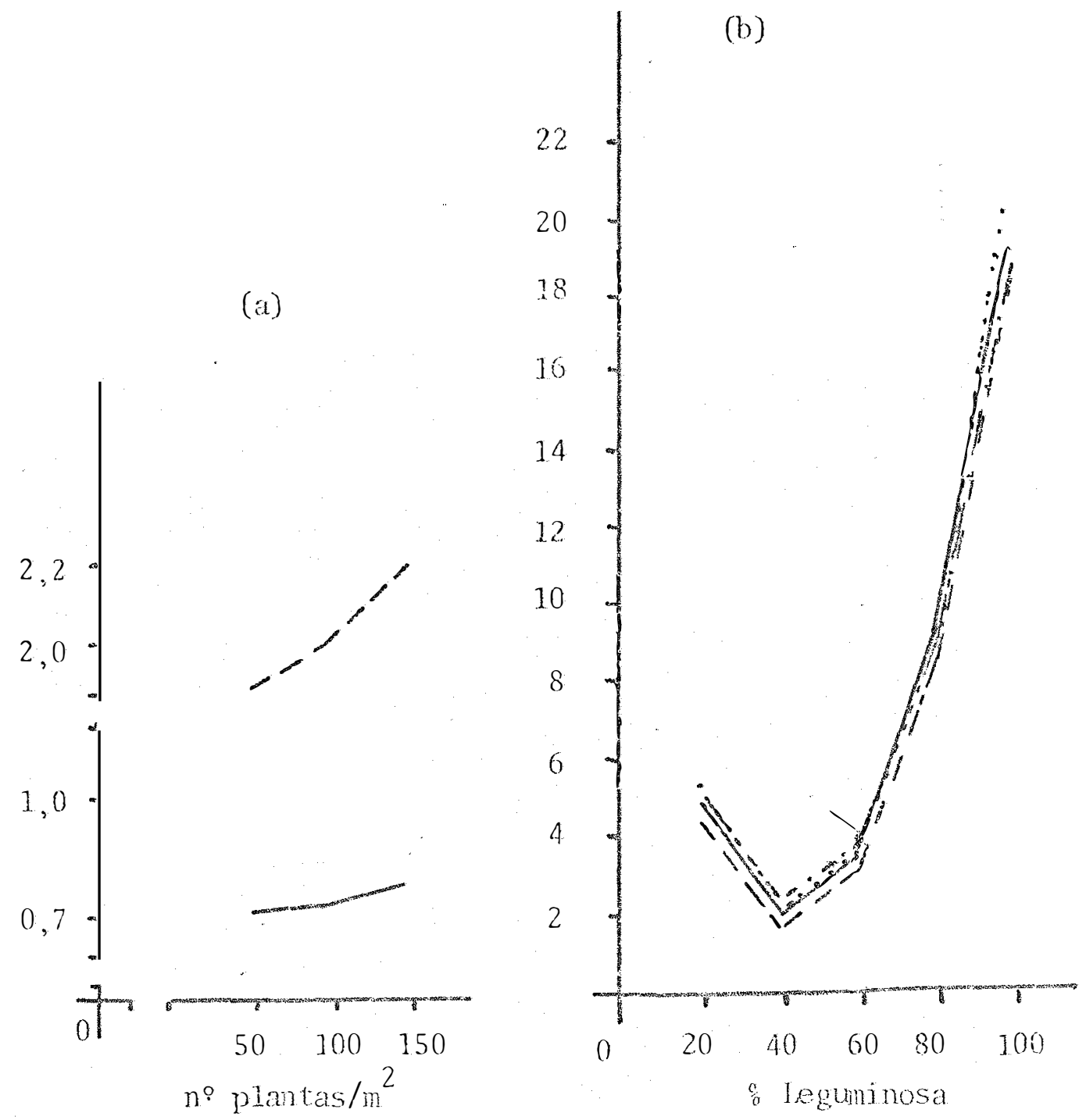

127.

$$
\begin{aligned}
& \text { - } \mathrm{D} \text { - } \\
& \mathrm{Y}=0,67+0,00085 \mathrm{x} \quad \mathrm{R}^{2}=93,35 \quad \mathrm{Y}=0,3+0,017 \mathrm{x} \quad \mathrm{R}^{2}=58,61 \\
& Y=1,8+0,00066 x \quad R^{2}=82,00^{* *} \quad Y=1,09-0,043 x+0,0005 x^{2} \quad R^{2}=28,79^{* *} \\
& Y=1,14-0,042 x+0,00049 x^{2} \quad R^{2}=29,12^{* * *} \\
& \text {..... P dentro } 15150 \\
& Y=1,34-0,053 x+0,00059 x^{2} \quad R^{2}=31,00^{* *}
\end{aligned}
$$

FIGURA 20 - Efeito da densidade de plantas (a) e da produção gra mínea-leguminosa estabelecida (b) na produção de pro teîna bruta da componente leguminosa ( $t / h a / a n o$ ) na consorciação setária-siratro. 
componente leguminosa aumentassem com o numero de plantas (pro poxcões estabelecidas).

As producões encontradas variaram de 0,71 t/ha/ ano (densidade 50 piantas $/ \mathrm{m}^{2}$ ), 0,77 t/halano (densidade 100 plantas $/ \mathrm{m}^{2}$ ) e $0,80 \mathrm{t} / \mathrm{ha} /$ ano (densidade $150 \mathrm{plantas} / \mathrm{m}^{2}$ ), que pe lo teste de Tukey não mostraram diferença significativa quan do comparadas entre si (Tabela 37), mas as médias de proporções, tambëm comparadas pelo teste de Tkey, mostram que $P_{100}$ $(2,07 \mathrm{t} / \mathrm{ha} / \mathrm{ano})$, quando comparadas ãs demaís proporcões, se mostraram significativamente diferentes $(P<0,05)$ quanto ao parâmetro em anảise; e que $\mathrm{P}_{80}(0,54$ t/ha/ano $)$ se mostrou sig nificativamente diferente $(P<0,05)$ apenas quando comparada com $P_{20}(0,34 \mathrm{t} / \mathrm{ha} / \mathrm{ano})$, enquanto que as demais comparafões mostraram-se não significativas.

De modo geral, as producões anuais de proteína bruta da componente leguminosa, quando consorciadas, concordam com os resultados de THAIRU (1972), que na consorciação setä ria-siratro obteve, para a componente leguminosa, produções de nitrogênio de $67 \mathrm{~kg} / \mathrm{ha} / \mathrm{ano}$, ou o equivalente a $0,418 \mathrm{t} / \mathrm{ha} / \mathrm{ano}$ de proteina Eruta; com os resultados de JONES et a zii (1967), que obtiveram produções de proteína bruta de 0,534 t/ha/ano. Para a leguminosa exclusiva $\left(\mathrm{P}_{100}\right)$, as producões de proteína bruta encontradas $(2,07$ t/ha/ano) foram superiores às citadas por MONTEIRO et alii (1980), que variaram entre 0,201 e 0,389 t/ha/ano. 
TABELA 37 - Diferenças minimas significativas para a compara ção de médias, coeficientes de variação e equaçôs de regressão usadas na anâlise de variância para a produção de proteina bruta da componente legumino sa (t/ha/ano) na consorciação setäria-siratro (më dia de 4 repetições).

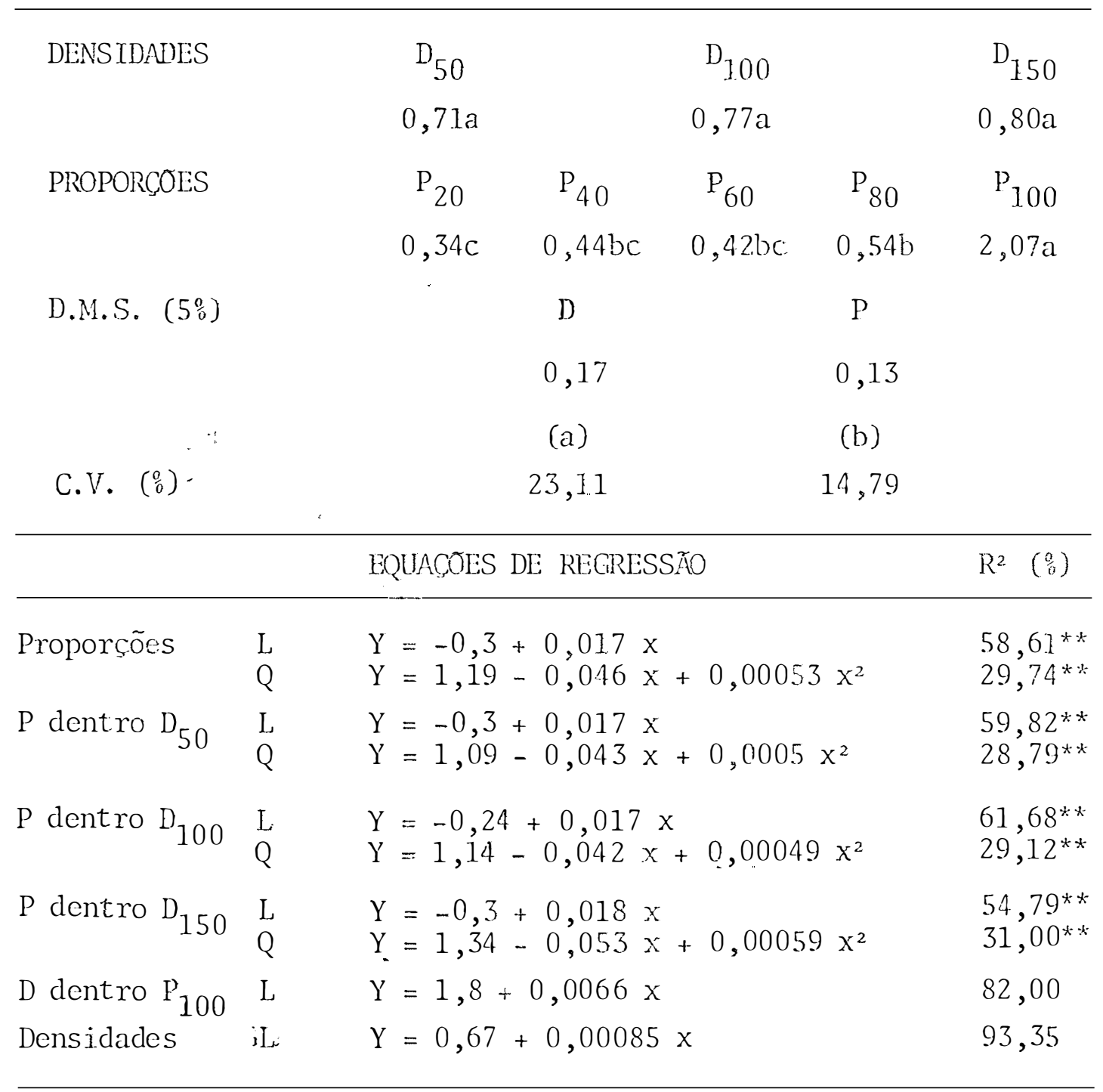


4.2.4.3. Produção anual conjunta de proteína bru ta

A análise de variância dos dados obtidos para a produção anual conjunta de proteína bruta está contida na Tabe la 38. Os valores de F encontrados se mostraram altamente sig nificativos para $P$, e no desdobramento $P \times D$ significativos pa ra $\mathrm{P}$ dentro $\mathrm{D}_{50}$, P dentro $\mathrm{D}_{100}$ e $\mathrm{P}$ dentro ${ }_{15}{ }_{150}$, o que permite dizer que nas três densidades em estudo a proporção gramínealeguminosa estabelecida afetou a produção anual conjunta de proteína bruta. A decomposição da SQ de P mostra que hã um efeito linear ( $R^{2}$ igual a $\left.64,31 \%\right)$ e quadrático $\left(R^{2}\right.$ igual a 10,92\%), significativos entre a proporçäo graminea--1eguminosa, e a produção anual conjunta de proteína bruta.

Embora a interação $P$ x $D$ tenha se mostrado não significativa, o desdobramento de P dentro D (Tabela 38) mos tra que para $P$ dentro $D_{50}$ a componente linear e quadrática fo ram significativas, sendo que os $\mathrm{R}^{2}$ foram de 53,725 e $10,92 \%$, respectivamente.

Para $\mathrm{P}$ dentro $\mathrm{D}_{100}$ foi significativa a componen te linear com $\mathrm{R}^{2}$ correspondente de $74,93 \%$, enquanto que para $\mathrm{P}$ dentro $D_{150}$ foram significativas a componente linear $\left(R^{2}\right.$ igual - a $58,90 \%)$ e quadrática $\left(R^{2}\right.$ igual a $\left.10,78 \%\right)$.

Para densidades, a Figura 21 (a) mostra que a pro dução de proteína bruta conjunta eleva-se com o aumento da den sidade de plantas; entretanto, este aumento, a partir de $\mathrm{D}_{100}$ 
TABLila 38 - Anälise de variância, desdobramento da intaração $P \times D$, decomposiçäo da $S()$ dos efeitos e coeficien tes de determinacão $\left(R^{2}\right)$ para a produção conjunta de proteina bruta ( $t / h a / a n o)$ na consorciação setá ria-siratro.

\begin{tabular}{|c|c|c|c|}
\hline Causas de Variaşão & G.L. & Q.M. & $\mathrm{R}^{2}$ \\
\hline Blocos & 3 & 0,136613 & \\
\hline $\begin{array}{c}\text { Densidades (D) } \\
\text { L } \\
\text { Q }\end{array}$ & $\begin{array}{l}2 \\
1 \\
1\end{array}$ & $\begin{array}{l}0,048330 \\
0,0096 \\
0,0870\end{array}$ & $\begin{array}{r}9,96 \\
90,03\end{array}$ \\
\hline Resíduo (a) & 6 & 0,141973 & \\
\hline $\begin{array}{l}\text { Proporções (P) } \\
\text { L } \\
\text { Q }\end{array}$ & $\begin{array}{l}5 \\
1 \\
1\end{array}$ & $\begin{array}{l}1,209196^{* *} \\
3,8882^{* *} \\
0,6603^{* *}\end{array}$ & $\begin{array}{l}64,31 \\
10,92\end{array}$ \\
\hline$P \times D$ & 10 & 0,054392 & \\
\hline $\begin{array}{l}\mathrm{P} \text { dentro } \mathrm{D}_{50} \\
\mathrm{~L} \\
\mathrm{Q}\end{array}$ & $\begin{array}{l}5 \\
1 \\
1\end{array}$ & $\begin{array}{l}0,284196^{* * *} \\
0,7633^{* *} \\
0,2405^{* *}\end{array}$ & $\begin{array}{l}53,72 \\
16,92\end{array}$ \\
\hline $\begin{array}{l}\text { P dentro } D_{100} \\
\text { L } \\
Q\end{array}$ & $\begin{array}{l}5 \\
1 \\
1\end{array}$ & $\begin{array}{l}0,315407^{* *} \\
1,1817^{* *} \\
0,0877\end{array}$ & $\begin{array}{r}74,93 \\
5,56\end{array}$ \\
\hline $\begin{array}{l}\text { P dentro } \mathrm{D}_{150} \\
\mathrm{~L} \\
\mathrm{Q}\end{array}$ & $\begin{array}{l}5 \\
1 \\
1\end{array}$ & $\begin{array}{l}0,718376^{* *} \\
2,1158^{* *} \\
0,3854^{* *}\end{array}$ & $\begin{array}{l}58,90 \\
10,73\end{array}$ \\
\hline Resíduo (b) & 45 & 0,030747 & \\
\hline $\begin{array}{c}\text { D dentro } P_{0} \\
L \\
Q\end{array}$ & $\begin{array}{l}2 \\
1 \\
1\end{array}$ & $\begin{array}{l}0,056058 \\
0,1104 \\
0,0016\end{array}$ & $\begin{array}{r}98,51 \\
1,48\end{array}$ \\
\hline $\begin{array}{c}\text { D dentro } \mathrm{P}_{20} \\
\mathrm{~L} \\
\mathrm{Q}\end{array}$ & $\begin{array}{l}2 \\
1 \\
1\end{array}$ & $\begin{array}{l}0,038433 \\
0,0128 \\
0,0640\end{array}$ & $\begin{array}{l}16,65 \\
83,34\end{array}$ \\
\hline
\end{tabular}


TABELA 38 - continuação.

\begin{tabular}{|c|c|c|c|}
\hline Causas de Variaşäo & G. L. & Q.M. & $\mathrm{R}^{2}$ \\
\hline $\begin{array}{c}\mathrm{D} \text { dentro } \mathrm{P}_{40} \\
\mathrm{~L} \\
\mathrm{Q}\end{array}$ & $\begin{array}{l}2 \\
1 \\
1\end{array}$ & $\begin{array}{l}0,009608 \\
0,0066 \\
0,0126\end{array}$ & $\begin{array}{l}34,41 \\
65,58\end{array}$ \\
\hline $\begin{array}{c}\text { D dentro } P_{60} \\
L \\
Q\end{array}$ & $\begin{array}{l}2 \\
1 \\
1\end{array}$ & $\begin{array}{l}0,019900 \\
0,0392 \\
0,0006\end{array}$ & $\begin{array}{r}98,49 \\
1,50\end{array}$ \\
\hline $\begin{array}{c}\text { D dentro } P_{80} \\
L \\
Q\end{array}$ & $\begin{array}{l}2 \\
1 \\
1\end{array}$ & $\begin{array}{l}0,110658 \\
0,0028 \\
0,2185^{*}\end{array}$ & $\begin{array}{r}1,27 \\
98,72\end{array}$ \\
\hline $\begin{array}{c}\text { D dentro P } \\
\text { L } \\
\text { Q }\end{array}$ & $\begin{array}{l}2 \\
1 \\
1\end{array}$ & $\begin{array}{l}0,085633 \\
0,7.404 \\
0,0308\end{array}$ & $\begin{array}{l}82,00 \\
17,99\end{array}$ \\
\hline Resïcuo & 23 & 0,049285 & \\
\hline
\end{tabular}


tende a decrescer, decréscimo este que ê atribuído à compet $\underline{i}$ são originada entre as plantas, uma vez que a densidade pode ser considerada alta, conforme afirmesão de VIEIRA (1974), on de, nas densidades mais altas, as producões tendem ao equili brio, com o decorrer do tempo.

Graficamente, vê-se pela Figura $21(\mathrm{~b})$, que hâten dência de comportamento semelhante nas três densidades em estu do. Entretanto, valores mais baixos foram obtidos em $\mathrm{D}_{150}$, em virtude do maior número de plantas (maior competicão); entre tanto, à medida que a leguminosa aumentou sua participação na proporção estabelecida, o parâmetro em análise teve ligeira que da entre $\mathrm{P}_{20}$ e $\mathrm{P}_{80}$, aumentando novamente em $\mathrm{P}_{100}$.

Os resultados obtidos concordàm com os encontra dos por JONES et alii (1967) com $190 \mathrm{~kg}$ de $\mathrm{N}$ (ou 1, 187 t/ha/ ano de proteína bruta) e com os obtidos por THAIRU (1972), on de a produção anual de nitrogênio na consorciasão foi de 0,311 t/ha/ano (1,943 t/ha/ano).

Na comparação das mëdias pelo teste de Tukey (Ta be la 39), temos que as comparacões para as médias de densida des mostraram-se não significativas, enquanto que para as mê dias de proporcões temos que $\mathrm{P}_{100}(2,07 \mathrm{t} / \mathrm{ha} / \mathrm{ano})$ diferiu sig nificativamente $(P<0,05)$ de todas as demais proporções. As demais comparações mostraram ainda $\mathrm{P}_{20}(1,35 \mathrm{t} / \mathrm{ha} / \mathrm{ano}), \quad \mathrm{P}_{40}$ $(1,40 \mathrm{t} / \mathrm{ha} / \mathrm{ano}), \mathrm{P}_{60}(1,37 \mathrm{t} / \mathrm{ha} / \mathrm{ano})$ e $\mathrm{P}_{80}(1,39 \mathrm{t} / \mathrm{ha} / \mathrm{ano})$, to das diferindo significativamente de $\mathrm{P}_{0}(1,13 \mathrm{t} / \mathrm{ha} / \mathrm{ano})$. A maior produção anual conjunta de proteína bru 


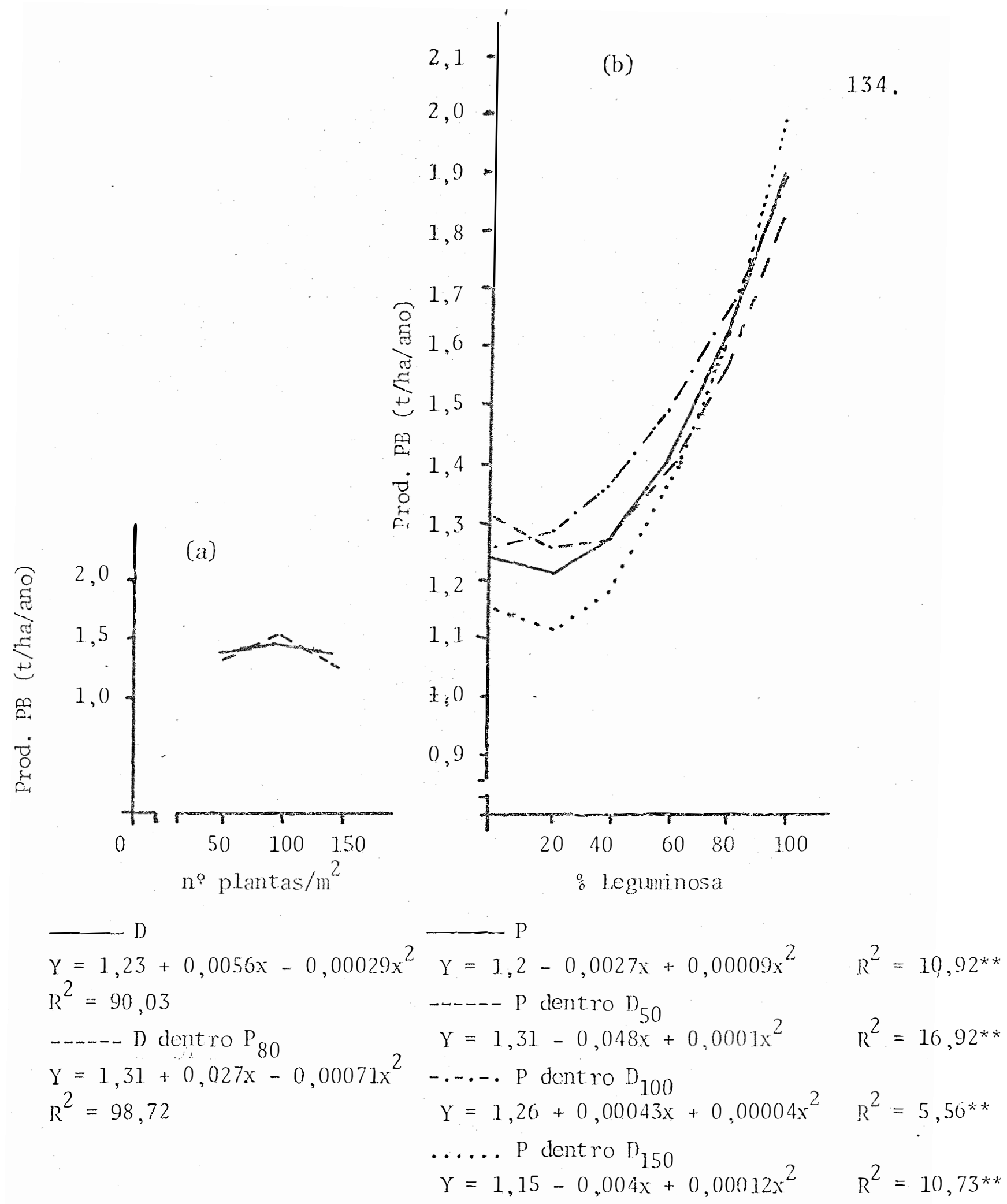

FIGURA 21 - Efeito da densidade de plantas (a) e da produção gra minea-leguminosa estabelecida (b) na produção conjun ta de proteína bruta ( $t / h a / a n o)$ na consorciação setá ria-siratro. 
TABELA 39 - Difcrenças minimas significativas para a compara fãa de médias, coeficientes de variaçăo e equações de regressão usadas na anälise de variância para a produção conjunta de proteina bruta ( $t / \mathrm{ha} / \mathrm{ano}$ ) na consorciação setária-siratro (mëdia de 4 repeti (̧ões].

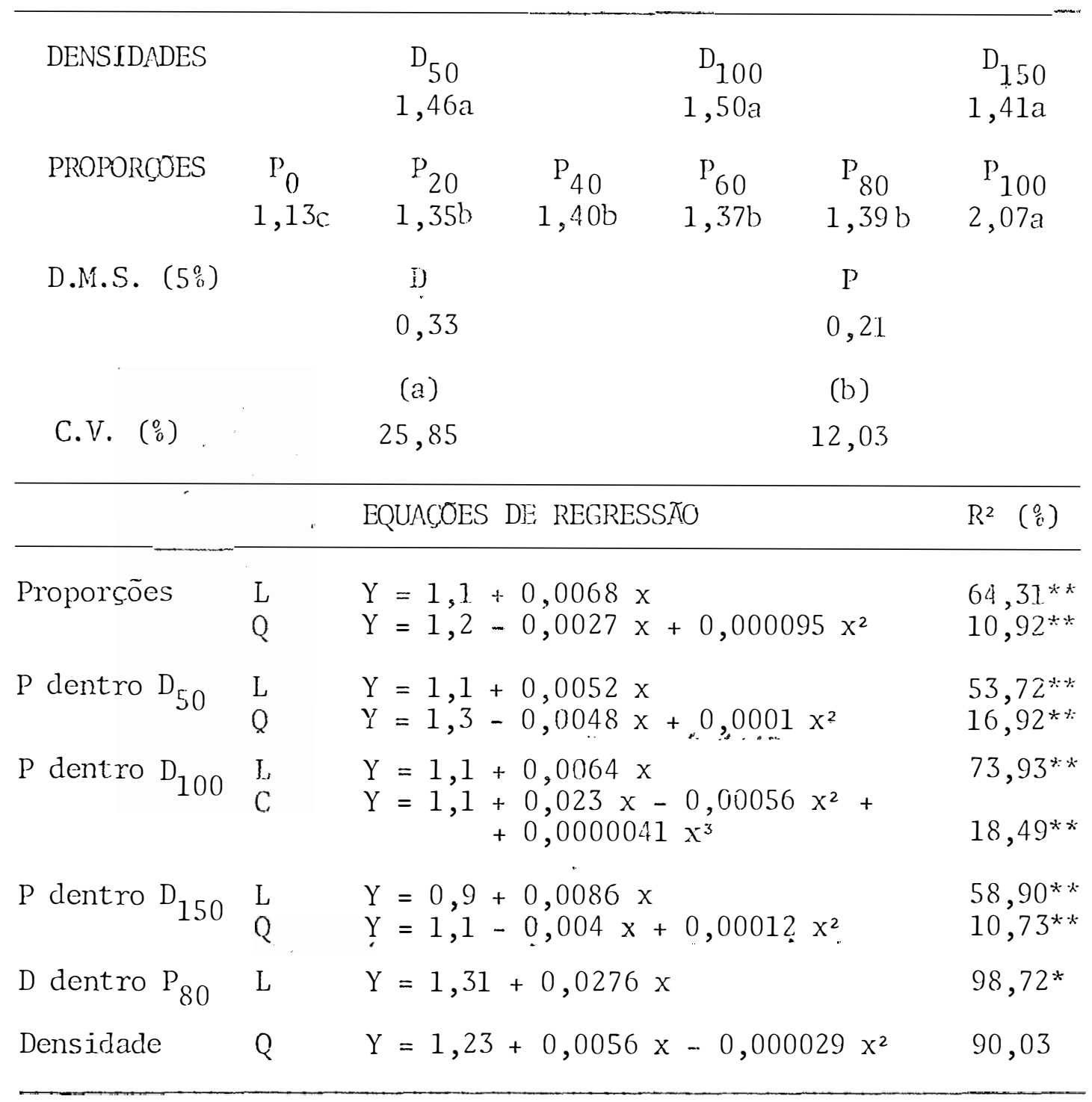


ta foi obtida na proporção lcguminosa exclusiva ( 10 ), enquan to que a menor foi obtida na proporção gramínea exclusiva $\mathrm{P}_{0}$.

\subsubsection{Nümero de Plantas no Final do Expeximento}

o comportamento das espëcies atravês do nümero de plantas foi determinado sómente para a componente legumino sa, uma vez que o perfilhamento intenso da gramínea não permi tiu a contagem das plantas de graminea.

A Tabela 40 apresenta a anảlise de variância dos dados obtidos para o nümero de plantas da componente legumino sa ao final do ensaio. Os valores de F encontrados se mostram significativos para os efeitos D, P c a interação destes dois, o que mostra que o número de plantas usado, a proporção gramí nea-leguminosa estabelecida e a interação destes dois fatores afetaram o nümero final de plantas na componente leguminosa. No desdobramento da interação $P x D$ os valores de $F$ se mostraram significativos para $\mathrm{P}$ dentro $\mathrm{D}_{50}$, P dentro $\mathrm{D}_{100}, \mathrm{P}$ dentro $\mathrm{D}_{150}$ e para D dentro $\mathrm{P}_{100}$, evidenciando que nas três densidades o parâmetro em discussão foi afetado pela proporção gramínea-le guminosa estabelecida; e em $\mathrm{P}_{100}$ o parâmetro analisado foi afe tado pela densidade de plantas usada.

A decomposição da $\mathrm{SQ}$ dos efeitos também está con tida na Tabela 40 onde observa-se que, para o efeito D, a com ponente linear se mostrou significativa, com $R^{2}$ igual a 99,81\%; enquanto que para $P$ foram significativas as componentes linear 
TABELA 40 - Anälise de variância, desdobramento da interação $P \times D$, decomposição da $S Q$ dos efeitos, coeficien tes de determinação $\left(R^{2}\right)$ para o numero de plantas de leguminosa a final do experimento na consorcia ção setâriamsiratro.

\begin{tabular}{|c|c|c|c|}
\hline Causas de Variação & G.L. & Q.M. & $\mathrm{R}^{2}$ \\
\hline Blocos & 3 & 1,516324 & \\
\hline $\begin{array}{c}\text { Densidades (D) } \\
\text { L } \\
\text { Q }\end{array}$ & $\begin{array}{l}2 \\
1 \\
1\end{array}$ & $\begin{array}{l}12,865891^{* *} \\
25,6830^{* *} \\
0,0486\end{array}$ & $\begin{array}{r}99,81 \\
0,18\end{array}$ \\
\hline Resíduo & 6 & 1,094833 & \\
\hline $\begin{array}{c}\text { Proporções (P) } \\
\text { L } \\
\text { Q }\end{array}$ & $\begin{array}{r}4 \\
1 \\
1\end{array}$ & $\begin{array}{c}60,187679^{* * *} \\
188,1300^{* *} \\
30,4470^{* *}\end{array}$ & $\begin{array}{l}78,14 \\
12,64\end{array}$ \\
\hline$P \times D$ & 8 & $2,107120^{*}$ & \\
\hline $\begin{array}{l}\text { P dentro } D_{50} \\
\mathrm{~L} \\
\mathrm{Q}\end{array}$ & $\begin{array}{l}4 \\
1 \\
1\end{array}$ & $\begin{array}{l}11,700033^{* *} \\
44,1740^{* * *} \\
1,2711\end{array}$ & $\begin{array}{r}94,39 \\
2,71\end{array}$ \\
\hline $\begin{array}{l}\text { P dentro } D_{100} \\
\mathrm{~L} \\
\mathrm{Q}\end{array}$ & $\begin{array}{l}4 \\
1 \\
1\end{array}$ & $\begin{array}{l}20,55491.5 * * \\
53,7180^{* *} \\
19,9240^{* *}\end{array}$ & $\begin{array}{l}65,33 \\
24,23\end{array}$ \\
\hline $\begin{array}{l}\text { P dentro } D_{150} 15 \\
\mathrm{Q}\end{array}$ & $\begin{array}{l}4 \\
1 \\
1\end{array}$ & $\begin{array}{l}32,146969^{* *} \\
95,6730^{* *} \\
15,7300^{* *}\end{array}$ & $\begin{array}{l}74,40 \\
12,23\end{array}$ \\
\hline Resíduo & 36 & 0,691650 & \\
\hline $\begin{array}{c}\text { D dentro } P_{20} \\
\text { L } \\
Q\end{array}$ & $\begin{array}{l}2 \\
1 \\
1\end{array}$ & $\begin{array}{l}2,698241 \\
2,2803 \\
1,8872\end{array}$ & $\begin{array}{l}54,71 \\
45,28\end{array}$ \\
\hline $\begin{array}{c}\text { D dentro } \mathrm{P}_{40} \\
\mathrm{~L} \\
\mathrm{Q}\end{array}$ & $\begin{array}{l}2 \\
1 \\
1\end{array}$ & $\begin{array}{l}1,641142 \\
2,5204 \\
0,0143\end{array}$ & $\begin{array}{r}99,43 \\
0,56\end{array}$ \\
\hline
\end{tabular}


TABELA 40 - continuação.

\begin{tabular}{lccc}
\hline Causas de Variação & G.L. & Q.M. & \multicolumn{1}{c}{$\mathrm{R}^{2}$} \\
\hline $\begin{array}{c}\text { D dentro P } \\
\text { L }\end{array}$ & 2 & 2,995256 & \\
Q & 1 & $4,3321^{*}$ & 93,64 \\
D dentro P & 1 & 0,2942 & 6,35 \\
L & 2 & 0,700586 & \\
Q & 1 & 0,4738 & 43,78 \\
D dentro P & 1 & 0,6082 & 56,21 \\
$\quad$ L & 2 & $19,537888^{* *}$ & \\
Q & 1 & $29,8620^{* *}$ & 98,95 \\
Residuo & 1 & $0,31.56$ & 1,04 \\
\hline
\end{tabular}


e quadrática com $\mathrm{R}^{2}$ igual a $78,14 \%$ (linear) e 30,44\% (quadráti ca). No desdobramento da intaração $P \times D$ a decomposição da $S Q$ mostra que para $\mathrm{P}$ dentro $\mathrm{D}_{50}$ foi significativa a componente $1 \underline{i}$ near, com $R^{2}$ igual a $94,39 \%$; para $P$ dentro $D_{100}$ foram signifí cativas a componente linear e quadrática com $\mathrm{R}^{2}$, respectivamen te, de 65,33\% (linear) e 24,23\% (quadrätica); e para $P$ dentro $\mathrm{D}_{150}$ tambêm foram significativas as componentes linear e qua drätica com os $\mathrm{R}^{2}$ de $74,40 \%$ e $12,23 \%$, respectivamente. Para $\mathrm{D}$ dentro $\mathrm{P}_{60}$, embora não significativo, o nümero de plantas se ajusta à equaçāo linear significativa, com $\mathrm{R}^{2}$ de $93,64^{\circ}$ e para P dentro $\mathrm{D}_{100}$ a componente linear se mostra significativo, com $\mathrm{R}^{2}$ igual a $98,95 \%$.

- Na anālise da Figura 22(a) observa-se que o nüme ro final de plantas de leguminosas, como era esperado, aumen tou com a densidade de plantas usada. Na proporção leguminosa exclusiva ( $\left.\mathrm{P}_{100}\right)$ sem a presença competitiva da gramínea, os nú meros de plantas de leguminosa foram mais altos nesta propor são. Pela Figura 22(b) nota-se que quanto ao efeito de $P$ e $P$ dentro $\mathrm{D}_{50}$, como era esperado, observa-se um comportamento se melhante, isto é, à medida que elevou-se a participação da le guminosa na inistura aumentou-se o nümero final em plantas des ta componente, exceto em $\mathrm{P}$ dentro $\mathrm{D}_{100}$ onde houve pequena que da no nümero de plantas em $\mathrm{P}_{20}$ para $\mathrm{P}_{40}$. Este resultado era es perado, uma vez que as proporcōes foram estabelecidas em ter mos de porcentagem dentro de cada densidade, e cada aument.o na porcentagem de leguminosa implicou em aumentos no nümero de 

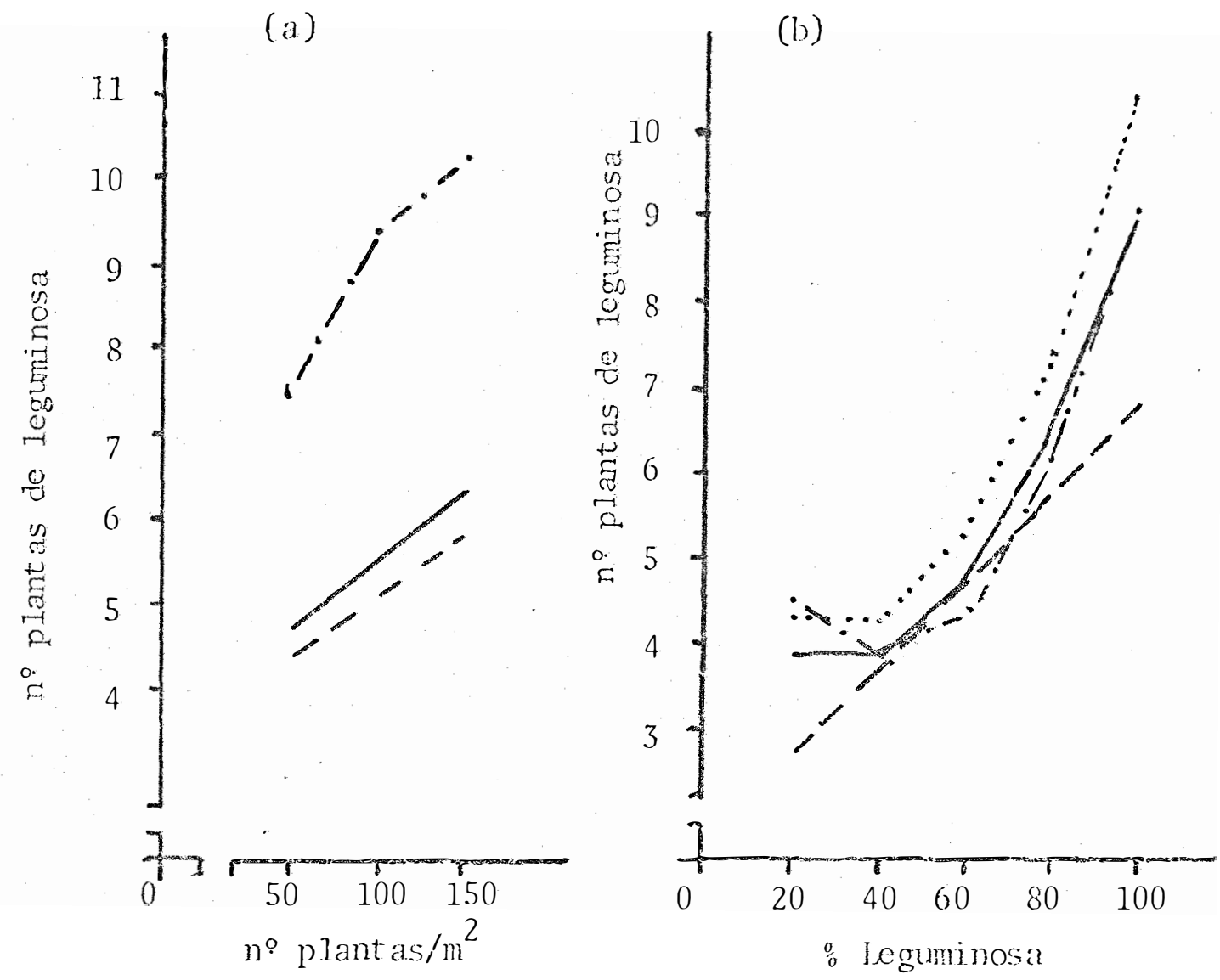

$$
\begin{aligned}
& Y=4,04+0,016 x \quad R^{2}=99,88^{* * *} \quad Y=4,87-0,065 x+0,0010 x^{2} \quad R^{2}=12,64^{* *} \\
& Y=3,69-0,029 x \quad R^{2}=93,64^{* *} \quad Y=1,67+0,0515 x \quad P_{50}^{2}=94,39^{* *} \\
& \begin{array}{ll}
Y=5,59+0,096 x & \cdots \cdots
\end{array} R^{2}=98,85^{* *} \quad Y=6,3-0,121 x+0,0014 x^{2} \quad R^{2}=24,23 * * \\
& \begin{array}{l}
\cdots \ldots \text { P dentro } \mathrm{I}_{150} \\
\mathrm{Y}=5,4-0,081 \mathrm{x}+0,0013 \mathrm{x}^{2} \quad \mathrm{R}^{2}=12,23 * *
\end{array}
\end{aligned}
$$

FIGURA 22 - Efeito da densidade de plantas (a) e da proporcão graminea-leguminosa estabelecida (b) no nümero de plantas de leguminosa a final do experimento na consorciação setäria-siratro. 
plantas desta componente e consequente redução no nümero de plantas de graminea. A partir de $\mathrm{P}_{80}$ o parâmetro em discussão voltou a elevarmse sendo maiox mas densidades mais elevadas.

A comparação das médias pelo teste de Tukey reve la que nas médias de àensidades $D_{150}(6,42$ plantas/m²) diferiu significativamente $(P<0,05)$ quando comparadas com $D_{50}$ e I) 100 $\left(4,82\right.$ e 5,68 plantas $\left./ \mathrm{m}^{2}\right)$ e que estas duas não diferiram quan do comparadas entre si (Tabela 41). Para as médias de propox çōes, a comparação entre elas revela que $\mathrm{P}_{100}$ diferiu signifi cativamente $(\mathrm{P}<0,05)$ das demais proporcõos, e que $\mathrm{P}_{80} \mathrm{e} \mathrm{P}_{60}$ diferiram significativamente quando comparadas com $\mathrm{P}_{20}$, e que as demais comparações não foram significativas. Para a compara ção em D dentro $\mathrm{P}_{50}$ observa-se que $\mathrm{P}_{100}$ diferiu significativâ mente $(P<0,05)$ das demais proporcões e que $\mathrm{P}_{80}$ e $\mathrm{P}_{60}$ também diferiram significativamente $(P<0,05)$, quando comparadas com $\mathrm{P}_{20}$; as demais comparações não foram significativas.

Em $\mathrm{D}_{100}$, apenas $\mathrm{P}_{100}$ diferiu significativamente $(\mathrm{P}<0,05)$ quando comparada com as demais médias, enquanto que as demais comparações entre as proporções se mostraram não sig nificativas. Na $\mathrm{D}_{150}, \mathrm{P}_{100}$ tambëm diferiu significativamente (P $\langle 0,05\}$ quando comparada às demais proporcões, e ainda que $\mathrm{P}_{80}$ e $\mathrm{P}_{60}$ tambëm diferem significativamente $(\mathrm{P}<0,05)$ quando com parado com $\mathrm{P}_{20}$. As demais comparações entre as médias de pro porções na densidade 150 plantas $/ \mathrm{m}^{2}$ se mostraram não signifi cativas.

Para P dentro D as comparacões mostraram-se sig 
TABELA 41. - Diferenças minimas significativas para a compara ção de médias, coeficiente de variação e equações de regressão usadas na anälise de variância para o número de plantas de leguminosa para a consorcia ção setäriamsiratro (mẻdia de 4 repetições).

\begin{tabular}{|c|c|c|c|c|c|c|}
\hline \multicolumn{7}{|c|}{ PROPOROOES } \\
\hline & & $\mathrm{P}_{40}$ & $P_{60}$ & $P_{80}$ & $\mathrm{P}_{100}$ & Média \\
\hline $\mathrm{D}_{50}$ & $2,84 \mathrm{C} \cdot \mathrm{A}$ & $3,98 \mathrm{CA}$ & $4,54 \mathrm{bA}$ & $5,34 \mathrm{bA}$ & $7,41 \mathrm{aC}$ & $4,82 B$ \\
\hline $\mathrm{D}_{100}$ & $4,21 \mathrm{bA}$ & $4,46 \mathrm{bA}$ & $4,94 \mathrm{bA}$ & $5,11 \mathrm{bA}$ & $9,69 \mathrm{aBA}$ & $5,68 B A$ \\
\hline$D_{150}$ & $3,91 \mathrm{bcA}$ & $5,10 \hat{c A A}$ & $6,01 \mathrm{bA}$ & $5,83 \mathrm{bA}$ & $11 ., 27 \mathrm{aAA}$ & $6,42 \mathrm{~A}$ \\
\hline Média & $3,65 C$ & $4,51 b$ & $5,16 b$ & $5,43 b$ & $9,46 \mathrm{a}$ & \\
\hline D.M.S. $(5 \%)$ & & $\mathrm{D}$ & $\mathrm{P}$ & $\operatorname{PxD}$ & $\mathrm{PdD}$ & DdP \\
\hline \multirow{4}{*}{ C.V. $\left(\begin{array}{l}0 \\
0\end{array}\right)$} & & 1,01 & 0,97 & 2,14 & 1,68 & 1,51 \\
\hline & & & (a) & & (b) & \\
\hline & & & 18,52 & & 14,72 & \\
\hline & \multicolumn{5}{|c|}{ EQUACOES DE: REGRESSAO } & $\mathbf{R}^{2}\left(\begin{array}{l}0 \\
0\end{array}\right)$ \\
\hline Densidades & $\mathrm{L}$ & \multicolumn{4}{|c|}{$Y=4,04+0,016 x$} & $99,81^{* *}$ \\
\hline Proporções & $\begin{array}{l}\mathrm{L} \\
\mathrm{Q}\end{array}$ & \multicolumn{4}{|c|}{$\begin{array}{l}Y=1,89+0,062 x \\
Y=4,87-0,065 x+0,0010 x^{2}\end{array}$} & $\begin{array}{l}78,14 * * \\
12,64 * *\end{array}$ \\
\hline $\mathrm{D}$ dentro $\mathrm{P}_{60}$ & $\mathrm{~L}$ & \multicolumn{4}{|c|}{$Y=3,69+0,036 x$} & $93,64^{*}$ \\
\hline D dentro $\mathrm{P}_{100}$ & $L_{-}$ & \multicolumn{4}{|c|}{$Y=5,59+0,096 x$} & $98,95 * *$ \\
\hline P dentro $D_{50}$ & $\mathrm{~L}$ & \multicolumn{4}{|c|}{$Y=1,67+0,052 x$} & $94,39 * *$ \\
\hline$P$ dentro $\mathrm{D}_{100}$ & $\begin{array}{l}\mathrm{L} \\
\mathrm{Q}\end{array}$ & \multicolumn{4}{|c|}{$\begin{array}{l}Y=2,21+0,0579 x \\
Y=6,38-0,121 x-0,0014 x^{2}\end{array}$} & $\begin{array}{l}65,33^{* *} \\
24,23^{* *}\end{array}$ \\
\hline$P$ dentro $D_{150}$ & $\begin{array}{l}\mathrm{L} \\
\mathrm{Q}\end{array}$ & \multicolumn{4}{|c|}{$\begin{array}{l}Y=1,79+0,077 x \\
Y=5,49-0,081 x+0,001 x^{2}\end{array}$} & $\begin{array}{l}74,40 * * \\
12,23 * *\end{array}$ \\
\hline
\end{tabular}


nificativas apenas em $\mathrm{P}_{100}$, onde $\mathrm{D}_{50}$ diferiu significativamen te $(P<0,05)$ quando comparado com $D_{100}$ e $\operatorname{com} D_{150}$ e que estas duas também diferem quando comparadas entre si.

Os nümeros médios de plantas encontrados ao fi nal do experimento, para a componente leguminosa na consorcia ção setária-siratro, variaram de $4,8 \mathrm{plantas} / \mathrm{m}^{2}$ em $D_{50}$ a 6,42 plantas $/ \mathrm{m}^{2}$ em $\mathrm{D}_{150}$ e entre $3,65 \mathrm{plantas} / \mathrm{m}^{2}$ em $\mathrm{P}_{20}$ a 9,46 plan $\mathrm{tas} / \mathrm{m}^{2}$ em $\mathrm{P}_{100}$.

Estes resultados encontram correspondência nos citados por RIBEIRO (1979), que 11 meses após a semeadura en controu, para a componente leguminosa, de 2,8 a $5,2 \mathrm{plantas} / \mathrm{m}^{2}$ quando testou diferentes métodos de introdução de leguminosa (centrosema + galactia + siratro) em pastagens de capim Napier; e aos citados pela EMBRAPA (1981c) que 380 dias após a semeadu ra encontrou $5,0 \mathrm{plantas} / \mathrm{m}^{2}$ para o siratro. 
5. CONCLUSOES

A anälise dos dados obtidos permite que se che gue às seguintes conclusões, para a consorciação braquiāriasiratro:

1. A melhor densidade da referida mistura foi a de $150 \mathrm{plantas} / \mathrm{m}^{2}$, embora as diferenças entre densidades te nham sido não significativas. A proporção onde se obteve me lhor produção de matéria seca e proteína bruta situou..se entre 40 e $60 \%$ de leguminosa no número de plantas.

2. A medida que aumentou-se a densidade de plan tas aumentou-se, embora não significativamente, o nümero final de plantas de leguminosa na mistura.

3. o nümero de plantas na mistura não influiu so bre os teores de proteína bruta das componentes gramínea e le guminosa.

4. Os teores de proteína bruta da componente gra mínea aumentaram com o aumento da participação da leguminosa na mistura, enquanto que os teores da componente leguminosa 
manteve-se sem alterações.

Na consorciação setäria-siratro, a anảlise dos dados permite concluir-se que:

1. A melhor densidade da referida mistura $\vec{e}$ a de 100 plantas $/ \mathrm{m}^{2}$, onde se obtem a melhor produção anual de maté ria seca e proteína bruta, sendo o nümero de plantas de legumi nosa na formação na mistura situa-se entre 40 e $60 \%$.

2. o nümero de plantas de leguminosa ao final do experimento aumentou com a densidade de planta usada, onde a densidade $150 \mathrm{plantas} / \mathrm{m}^{2}$ apresentou maior valor, diferindo sig nificativamente de $50 \mathrm{plantas} / \mathrm{m}^{2}$.

3. O teor de proteína bruta das componentes gra mínea e leguminosa não foram influenciados pelo número de plan tas estabelecido inicialmente.

4. Na componente gramínea, a proporção estabele cida não afetou o teor de proteína bruta desta componente, en quanto que na componente leguminosa o teor de proteína bruta sofreu alterações não significativas. 
146.

6. BIBLIOGRAFIA CITADA

AGROCERES, 1977. Pastagens melhoradas: alternativas para um rebanho mais produtivo. São Paulo, 47p. (Boletim de Divul gação) .

ASGOCIATION OF OFFICIAL AGRICULTURAL CHEMISTS, 1965. OfficiaI methods of analysis. Washington, D.C., 957p.

AKINOLA, J.0., 1981. Growth of signal grass (Brachiaria decum bens) alone and with legumes in Northern Nigeria. Tropical Grassland. Brisbane, 15(3):130-134.

BLASCZYCK, G. e O.A.M., REHFELD, 1973. Influência de três ní veis de adubação fosfatada sobre o rendimento de duas gramí neas consorciadas, sob pastoreio rotativo em solos de cerra do. Apud LEMOS, A.A.B. e A.A. PinTo, Comp. Cerrado: bi bliografia analítica. Empresa Brasileira de Pesquisa Agro pecuária. Brasília, p.52. 
BUljER, R.E.; H.P. STEENMEYER, L.R. WUIN; S. ARNOVICH, 1972. Comportamento de gramineas perenes introduzidas no Brasil Central. Pesquisa Agropecuäria Brasileira. Sêrie Zootec nia. Brasilia, $\underline{7}: 17-21$.

CARVAlHo, S.R. de; S. ARONOVICH; P.F.L. FARIA, 1975. Estabele cimento de leguminosas forrageiras tropicais em consorcia ção com gramineas na zona leiteira do Vale do Paraíba Flu minense. Revista da Sociedade Brasileira de Zootecnia. Vi çosa, $\underline{4}(1):: 12-8$.

COOK, S.J. e.K.F. LOWE, 1977. Establishment of siratro pastü res. Trópical Grassland. Brisbane, $11(1): 41-48$.

CORBEA, Z.A. e H.L. MARTINES, 1980. Sowing method and density in the establishment of Buffel grass cv. Biloela. Pastos y Forrages, 3(3):405-413. Apud Herbage Abstracts, Aberystu lyth, $\underline{52}(6): 267,1982$.

DEMATTE, J.L.I., 1980. Levantamento detalhado dos solos do "Campus" experimental de Ilha Solteira. Piracicaba, ESALQ/ /USP, $114 \mathrm{p}$.

EMPRESA BRASILEIRA DE PESQUUISA AGROPECUARIA. Centro Nacional de Pesquisa em Gado de Corte, 1981a. Relatório Técnico A nual 1979. Campo Grande, p. 33-66. 
EMPRESA BRASILEIRA DE PESQUISA AGROPECUARTA. $1981 \mathrm{~b}$. Programa Nacional de Pesquisa de Gado de Corte. Brasilia, 291p.

EMPRESA BRASILEIRA DE PESQUisa agropeCuÁRIA. Centro de Pesqui sa Agropecuâria do Cerrado, 1981c. Relatório Técnico Anua1 1979-1980. Brasília, p.143-160.

EMPRESA BRASILEIRA DE PESQUISA AGROPECUARIA. Centro de Pesqui sa Agropecuâria do Cerrado, 1982. Relatório Técnico Anual 1980-1981. Brasilia, p.138-145.

EMPRESA GOIANA DE PESQUISA AGROPECUARIA, 1977. Encontro sobre forrageiras do gênero Brachiaria. Goiania, Secretaria da Agricultura, $225 \mathrm{p}$.

EMPRESA GOIANA DE PESQUISA AGROPECUARIA, 1979. Relatório Téc nico 1979. Goiânìa, 239p .

FRANCO FILHO, E., 1963. Aproveitamento dos cerrados como pas tagens. In: Anais da 1. Reunião Brasileira dos Cerrados. Sete Lagoas, p.61-69.

FURTADO, X.C.; A.R. CONDE; J.M. SOBRINHO; A. MENDONÇA, 1977. Efeito da consorciação de leguminosas com o capim brachia ria (Brachiaria decumbens). In: Anais da XIV Reunião Anual da Sociedade Brasileira de Zootecnia, Recife, p.267. 
GONSALVES, J.O.N. e I.L. BARRETO, 19.79. Densidade de semeadu ra e produção de matêria seca do capim de Rhodes e do sira tro. Pesquisa Agropecuária Brasileira, Brasília, 14(3):273 -278 .

GOODLAND, R.J.A., 1979. Histöria dos trabalhos no Cerrado atê 1968. In: GOODLAND, R.J.A.; M.G. FERRI, Coord. Ecologia do Cerrado; Trad. Eugenio Amada. Belo Horizonte, Ed. Ita tiaia; São Paulo, Ed. USP, p.13-21 (Reconquista do Brasil, v.52).

GOODLAND, R.J.A.; M.G. FERRI, 1979. Ecologia do Cerrado. Trad. Eugenio Ámada. Belo Horizonte, Ed. Itatiaia, São Paulo, Ed. UsP. (Reconquista do Brasil, v. 52).

HODGE, A., 1979. Sow pastures in the South Burnett. Quensland Agricultural Journal. Brisbane, 105(5):386-95.

JONES, R.J.; J.G. DAVIES; R.B. WAITE, 1967. The contribution of some tropical legumes to pasture yields of dry matter and nitrogen at Samford, south-eastern Queensland. Australian Journal Experimental Agriculture and Animal Husbandry. Me 1 bourne, $\underline{7}(24): 57-65$.

JONES, R.J., 1971. The effects of staching rate, rate of phos phorus application and legume seld rate on the yield and bo 
tanical composition of a Setaria anceps. cv. Nandi/Phaseolus. atropurpureuns cv. Siratro pastures. In: JONES, R.J. Tro pical legumes - their growth and response to manageinent va riables in a sub tropical environment. Armidale. Universi ty of New England, p. 89-108. (Thesis of PhD).

JONES, R.J., 1972. The place of legumes in a tropical pastu res. Farnhan Royal Bucks, Cunnighan Laboratory. Ascap Tec nical Bulletin, Queensland, $\mathrm{n} \odot 9,69 \mathrm{p}$.

JONES, R.M., 1975. Effects of soil fertility, weed competion and legume seedling rate on a establishment of a tropical pasture species, in south-east Queensland. Australian Jour nal of Experimental Agriculture and Animal Husbandry. Me 1 bourne, $15(72): 54-63$.

JONES, R.M., 1979. Effects of stocking and grazing frequency on a siratro (Macroptilium atropurpureum)/Setaria anceps. cv. Nandi pasture. Australian Journal of Experimental Agricul ture and Animal Husbandry. Melbourne, 19 (98):318-324.

LUCK, P.E., 1979. Setaria - an important pasture grass. Queens 1and Agricultural Journal. Brisbane, 105(2) :136-44.

LOCH, D.S., 1977. Brachiaria decumbens. (Signal grass). A Re view with particular reference to Australia. Tropical 
Grassland, Bristane, 1I(2):141-57.

LOURENÇO, A.J.; H.J. SARTINI; M. SANTAMARIA, 1979 . Efeito do pastejo na composição da pastagem de capim Napier (Pennise. tum purpureum Schum) consorciado com leguminosas. Boletim da Indústria Animal. Nova Odessa, 36(1):157-169.

MARCELINO SOBRINHO, J.; A. DRUDI; C. FURTADO, 1977. Forrage ras nativas do Estado de Goiās. In: XIV Reunião Anual da Sociedade Brasileira de Zootecnia, Recife, p.280.

MATTOS, H.B. de, 1977. Leguminosas forrageiras. IN: DIAS JR., V.L.; A. BOOK; E.G. BORGES, Coord. In: 1: Encontro de Atua lização de Pastagens. Nova Odessa, Nestlé/Instituto de Zoo tecria, p.67-85.

MIDDLETON, G.H., 1973. Effects of sowing rate on yield and com position of a siratro - Nandi pasture. Queensland Journal. of Agriculture and Animal Science. Brisbane, 30(1):45-52.

MONTEIRO, F.A.; S.A.A. LIMA; J.C. WERNER; H.B. de MATTOS, 1980. Adubação potảssica em leguminosas e em capim colonião (Pani cum maximum Jacq.) adubado com níveis de nitrogênio ou con sorciados com leguminosas. Boletim da Indústria Animal. No va Odessa, $\underline{37}(1): 127-148$. 
NG, T.T., 1976. Performance of some tropical grass legume mix ture in Sarawak. The Malysion Agriculture Journal. Kuala, 50(3): $100-10$.

PEDREIRA, J.V.S., 1977. Produção de forragens. In: DIAS JR., V.L.; A. BOOK; E.G. BORGES, Coord. 19 Encontro de Atualiza ção de Pastagens, Nova Odessa, Netlë/Instituto de Zootec nia, p. 13-40.

RAI, P.; K.C. VELAYUDHAN; K.C. KANODIA, 1981. Effects of plants densities on the growth attributes of Cenchrus cilia ris Lenn. Indian Journal of Ecology, 8(2): 198-203. Apud Herbage Abstracts, Aberystwyth, $\underline{52}(10): 453,1982$.

RAYMENT, G.E.; R.C.BRUCE; G.B. ROBBINS, 1977. Response of es tablishment siratro (Macroptilium atropurpureum cv.Siratro) pastures in south east Queensland to phosphorus fertilizer. Tropical Grassland, Brisbane, 11(1):67-77.

RIBEIRO, H., 1979. Estabelecimento de leguminosas forrageiras em gramíneas cespitosas. Piracicaba, ESALQ/USP, 44p. (Dis sertação de Mestrado).

RICKERT, K.G.; L.R. HUMPHREYS, 1970. Effects of a variation in density and phosphate application on growth and composition of Townsville stylo (Stylosanthes humilis). Australian Jour 
nal of Experimental Agriculture and Animal Husbandry, Mel bourne, $\underline{10}(45): 442-449$.

ROLON, J.D.; N.A. COSTA, 1979. Pastagens consorciadas estabele cidas em solos de cerrado. Rendimentos e produtividade (3웅 ano). In: Anais da XVI Reunião Anual da Sociedade Brasile ra de Zootecnia. Curitiba, p.333-4.

SERRAO, E.A.S.; M. SIMAOO NETO, 1971. Informações sobre duas e $\underline{s}$ pécies de gramineas forrageiras do gênero Brachiaria na Ama zônia: Brachiaria decumbens stapf e Brachiaria ruziziensis et Everard. Boletim Técnico do Ipean, Belém, 2(1):1-31.

THAIRU, D.M., 1972. The contribution of Desmodium uncinatum to the yield of Setaria Sphacelata. East African Agricultural. and Forestry Journal. Nairobi, 37(3):215-9.

TOSI, H.; J. NAKAGAWA; A.C. SILVEIRA; S.N. KRONKA, 1979 . Compe tição de leguminosas forrageiras em quatro níveis de aduba ção fosfatada. Revista da Sociedade Brasileira de Zootec nia. Viçosa, $\underline{8}(3): 376-386$.

VIEIRA, J.M., 1974. Espaçamento e densidade de semeadura de Brachiaria decumbens Stapf para formação de pastagens. Pira cicaba, ESALQ/USP, 106p. (Dissertação de Mestrado). 
VILELA, H., 1977. Formação de Pastagens. Belo Horizonte, EMATER, p. 17-8. (Circular tếcnica, 1).

ZIMMER, A.H., 1981. Fatores 1imitantes associados à formação de pastagens no Brasil Tropical. Revista Brasileira de Se mentes. Brasilia, $\underline{3}(1): 73-84$.

WEYERSBERG, C., 1981. Influence of sowing rate on annual and Italian ryegrass on stand development and yield. Wirtschaft. sugene Futter, 25( 1 : :12-20. Apud Herbage Abstracts, Aberyst wyth; $\underline{52}(1): 2,1982$.

WINTER, W.H.; L.A. EDYE; R.G. MEGARRITY; W.T. WILHIANS, 1977. Effects of fertilizer and stocking rate on pasture and beef production from sown pastures in Northern Cape York Pennin sula. I - Botanical and Chemical composition of the pasture. Australian Journal od Experimental Agriculture and Animal Husbandry, Melbourne, 17(84): 66-74. 